\title{
City-Friendly Smart Network Technologies and Infrastructures: The Spanish Experience
}

By Antonio Gómez-Expósito ${ }^{(1)}$, Fellow IEEE, Angel Arcos-Vargas, José M. Maza-Ortega, José A. Rosendo-Macías, Senior Member IEEe, Gabriel Alvarez-Cordero, Susana CarilloAparicio, Juan González-Lara, Daniel Morales-Wagner, and Tomás González-García

ABSTRACT | Efficient, resilient, and sustainable electricity delivery is a key cornerstone in increasingly large and complex urban environments, where citizens expect to keep or rise their living standards. In this context, cost-effective and ubiquitous digital technologies are driving the transformation of existing electrical infrastructures into truly smart systems capable of better providing the services a low-carbon society is demanding. The goal of this paper is twofold: 1) to review the dramatically evolving landscape of power systems, from the old framework based on centralized generation and control, aimed at serving inelastic customers through alternating current (ac) transmission networks and one-way distribution feeders, to a new paradigm centered mainly around two main axes: renewable generation, both centralized and distributed, and active customers (prosumers), interacting with each other through hybrid ac/dc smart grids; 2) to illustrate, through featured success stories, how several smart grid concepts and technologies have been put into practice in Spain over the last few years to optimize the performance of urban electrical assets.

KEYWORDS I Asset optimization; demand management; distribution automation; distributed generation; resilience; smart grids

Manuscript received July 3, 2017; revised November 20, 2017; accepted January 7, 2018. This work was supported by the European Union under Grants 3DMicrogrid (ENERG-11-286) and EASY-RES (ID-764090); by the Spanish Ministry of Economy and Competitiveness under Grants ENE2011-24137, ENE2015-69597-R, and ENE2017-84813-R; by the Spanish Ministry of Industry under CDTI Grants Smartcity (FEDER Technology Fund), Zem2All (Japan Spain Innovation Program, JSIP), and Monica (Innterconecta program); and by the Andalusian Government under Grant CATEST (P11-TEP-7411). (Corresponding author: Antonio Gómez-Expósito.)

A. Gómez-Expósito, A. Arcos-Vargas, J. M. Maza-Ortega, and J. A. RosendoMacias are with the University of Sevilla, 41004 Sevilla, Spain (e-mail: age@us.es).

G. Alvarez-Cordero is with REE, Alcobendas, 28109 Madrid, Spain.

S. Carillo-Aparicio and J. González-Lara are with Endesa, 28042 Madrid, Spain.

D. Morales-Wagner is with Ingelectus, 41092 Sevilla, Spain.

T. González-García is an Independent Consultant, Spain.

Digital Object Identifier: 10.1109/JPROC.2018.2793461

\section{INTRODUCTION}

It is expected that today's 7.5 billion people will increase to nearly 10 billions by 2050 , of which about $65 \%$ will live in urban areas [1]. This will pose major challenges at the global level, related with resource availability and economic sustainability, while a number of existing problems at the local- or city-area level (governance, traffic jams, air pollution, infrastructure resiliency, etc.) will be exacerbated. In this context, all links of the electric system chain (generation, transmission, distribution, and consumption) will play a more crucial role in assuring that urban citizens enjoy a safe, resilient, cost-competitive, clean, and sustainable energy delivery.

Indeed, the abuse of fossil fuels for the last two-anda-half centuries has driven our modern society toward a crossroads which has the potential to undermine the very pillars of our civilization. This simply means that we cannot continue doing "business as usual" in energy consumption, but an aggressive, carbon-free roadmap is seen as unavoidable. Fortunately, scientific and technological progress, from increasingly efficient PV arrays, LED lighting, miniaturized sensors, or power electronics to ubiquitous, low-cost microcomputers, wireless communications, signal processing algorithms, or data analytics software, to name just a few of the hottest undergoing developments, has come to our rescue under the umbrella of so-called "smart technology."

In addition to a very fashionable adjective, today "smart" has become a powerful meme with clear commercial connotations (smartphone, smart TV, smart car, smart watch, smart box, smart notebook, etc.; after all, who wants a nonsmart gadget?). Interestingly enough, though, the first definition for "smart" in the Oxford 
dictionary has nothing to do with "intelligent" but refers to "tidy and elegantly dressed people" or "stylish and exclusive objects." Only in its second entry is smart (informally) associated with "having a quick-witted intelligence." Anyway, at least for people well into their fifties, both uses of "smart" are not new, but will surely bring back memories of childhood, when the Get Smart TV series, created by Mel Brooks and featuring Don Adams as Maxwell Smart spy (Agent 86), became so popular in many countries for five seasons (1965-1970). A brief sequel on TV in 1995 and a film remake in 2008 unsuccessfully tried to further exploit the same plot and characters. It remains for sociologists to determine whether Maxwell Smart somehow influenced the technical leaders who pioneered the use of "smart" to denote the complex electrical grids of the 21st century. We must admit, however, that the somewhat superficial popularity of the term does not make justice with the largest and most complex cyber-physical system ever built by the human being.

To the best of our knowledge, the first reference to "smart" in power systems can be traced back to the work by Vu, Begovic, and Novosel, published in 1997 in IEEE Computer Applications in Power [2]. This seminal paper, dealing with advanced protection devices and hierarchical control schemes to prevent voltage collapse in open transmission access environments, introduced the term "self-managing and reliable transmission grid" (hence the acronym SMART grid). In fact, both "smart devices" and "smart algorithms" were used in profusion. Almost in parallel, at the International Conference on Distributed Computing Systems in Amsterdam, Brazier et al. published a paper dealing with load management in deregulated contexts, whose abstract began as follows [3]: "Emerging technologies allowing two-way communication between utility companies and their customers, as well as with smart equipment, are changing the rules of the energy market." Therefore, the smart grid notion originated, in the late 1990s, to satisfy the needs created by the new regulatory wave, when markets and grid open access were further stressing the transmission systems. Luckily enough, the technology was almost ready.

According to the records available in the IEEE Xplore database (see Table 1), the smart grid concept started to flourish in 2004 and fully blossomed in 2008, when the CIRED organized a seminar on Smart Grids for Distribution in Frankfurt. A pioneering vision of the future U.S. electricity system was provided by Pratt in [4],

Table 1 Number of Cumulated Items in IEEE Xplore Metadata Containing "Smart Grid(s)" and/or "Smart City(ies)"

\begin{tabular}{|l||c|c|c|c|c|c|c|}
\hline & 2004 & 2005 & 2006 & 2007 & 2008 & 2012 & 2016 \\
\hline \hline Smart grid(s) & 4 & 7 & 13 & 22 & 94 & 6,630 & 20,150 \\
\hline Smart city(-ies) & 1 & 1 & 1 & 1 & 1 & 160 & 3,320 \\
\hline Both keywords & 0 & 0 & 0 & 0 & 0 & 100 & 2,378 \\
\hline
\end{tabular}

where the recently created GridWise initiative was introduced. From those early years, one of the most widely cited papers was the one by Amin and Wollenberg, in 2005, titled "Toward a smart grid: Power delivery for the 21st century" [5].

Then, the biggest progress was made in 2010, when the Power \& Energy Society, in cooperation with other IEEE societies, released the IEEE TRANSActions on SMART Grids, along with four regional International Conferences on Innovative Smart Grid Technologies.

It was soon recognized that, in addition to technological developments and pilot programs, standardization efforts [6], [7], ad hoc regulation [8], and cost-benefit analyses would be needed to ensure interoperability and plug-and-play interfacing capability, while at the same time allowing new business models to be deployed. The European Commission (EC) legislation on smart meters [9] constitutes a good example of how the right policy can speed up the development and early introduction of new technologies. The Electricity Directive of the Third Energy Package (issued in 2009) requires Member States to ensure implementation of intelligent metering systems by 2020, while the Energy Efficiency Directive (2012) supports the development of energy services based on data from smart meters, demand response, and dynamic prices. This explains that the rollout of smart meters is already done or is expected to finish before 2020 in 16 Member States.

The reader is referred to Section III for a more detailed account of smart grid goals, challenges, and tools, particularly concerning urban systems.

We have lately become so exposed to "smart city" in the media that it now sounds like a very old concept. However, it is also a relative newcomer that catalyzed in the late 1990s from earlier and less elaborated notions, such as intelligent, digital, or eco cities. In North America, the first smart city initiatives crystalized in or around 2000 (see, for instance, [10], where one of the first visions of the city of the future was presented). In the European Union, constant efforts have been also devoted in the last decade to devising a strategy for achieving "smart" growth for its metropolitan areas [11], which is considered crucial for its 2020 strategy [12]. The well-cited paper by Hollands [13] emphasized in 2008 the fact that "smart city" was a fuzzy concept. Still today, smart cities are ill-defined as some interested parties put the emphasis on business-friendly, high-tech urban growth while others stress the citizen-friendly social and environmental sustainability as a major strategic component of smart cities [11], [12].

According to Table 1, the "smart city" concept gained momentum, in terms of scientific production, some four years behind smart grids did, when the number of documents in IEEE Xplore containing that keyword increased from just 65 in 2011 to 160 in 2012. So far, nearly 3500 documents 
associated to smart cities can be found in Xplore, which is only one sixth of the production on smart grids. The last row of Table 1 suggests that roughly two thirds of the publications on smart cities also address smart grid issues, but a more careful analysis reveals that this is not actually the case, as many times smart grids are referred to only tangentially or in passing. In fact, most smart city documents in Xplore deal with ICT issues (Internet of Things, big data, sensor networks, cybersecurity, etc.).

Among the documents gathered in Xplore, the oldest papers addressing electric utility issues within the context of smart cities were presented in 2009 at two European conferences. In [14], a GIS-based framework was proposed to follow up the operational status of the maintenance and construction activities routinely undertaken by utilities on their urban networks. A simulator based on software agents, aimed at recreating the dynamic behavior of a smart city, including discrete heterogeneous devices that consume and/or produce energy (e.g., smart homes), was presented in [15].

Since then, a long list of "smart city" papers dealing with several key aspects of electric energy systems in urban areas have been published [17], [18]. These include, but are not restricted to, public lighting [19], electric vehicle charging [20], load management and prosumer interactions via smart meters [21], cogeneration, energy efficiency and smart buildings [22], [23], asset optimization [16], etc.

Furthermore, the literature abounds in surveys and overviews of smart-city-related technologies, architectures, and frameworks [24]-[26], as well as ongoing projects and experiences [27], [28].

This paper first presents a brief overview of how electric energy systems evolved over the 20th century, providing some clues about why they gradually became giant interconnected grids aimed at serving the needs of centralized, mostly fossil-fuel-based, large-scale generating units. The main purpose of this section is to help the reader better understand why changing the current paradigm is proving so difficult.

Then, the new smart grid wave (what many people call revolution), brought about by ubiquitous and increasingly cheaper digital systems and the need to decarbonize the energy sector, is analyzed in more detail, paying special attention to those technologies and infrastructures which may have a potentially deeper impact on urban electrical networks. Generation, transmission, and distribution subsectors, along with new actors such as distributed generation (DG), prosumers, and storage, are discussed separately.

In the second part of the paper, an account is provided of representative and pioneering projects undertaken in Spain, all of them illustrating how electricity delivery to urban areas can benefit to a large extent from some of the technologies introduced previously.

\section{THE GRIDS OF THE 20TH CENTURY: AN OVERVIEW}

\section{A. Centralized Synchronous Generation}

Late in the 19th century, after the big success of Edison's Pearl St. system, quite a few isolated and relatively small power systems started to thrive almost simultaneously in the United States and Europe. Those early power generators [direct current (dc) or alternating current (ac)] were driven either by hydraulic turbines (typically located outside the suburbs) or reciprocating engines moved by steam from coal-fired boilers (usually integrated in the cities and further contributing to air pollution). Very soon, sustained efficiency improvements and cost reduction of increasingly larger steam turbines, involving higher pressures and temperatures, fostered the interconnection and fast expansion of primitive ac power systems, for which the unification of existing frequencies was a requirement. At the same time, dc systems virtually disappeared, except for a few niche applications in which the dc motor could not be conveniently replaced by the robust yet inflexible ac motor. Since its invention by Parsons in 1884, the steam turbine had grown in size from $50 \mathrm{MW}$ in the 1920s up to several hundreds of MW in the 1940s, reaching today's typical 1000-MW size in the 1960s [29]. In parallel, energy efficiencies raised from less than $10 \%$ to nearly $40 \%$ in the top-class facilities. As a direct consequence, huge generation stations were steadily expelled from urban areas to strategically and usually distant places where refrigeration water was available.

Then, the arrival of nuclear stations in the 1970s and more efficient, combined-cycle gas turbines in the 1980s reinforced the centralized nature of electricity production. For several decades, economies of scale encouraged the vertical integration of all activities into a single monopolistic utility, which had the obligation to serve, for a regulated price, within its region of influence [30].

The rollout and consolidation of such a paradigm significantly reduced the cost of electricity and fostered universal access to reliable electric service [31]. On the negative side, roughly two thirds of the (mostly fossil) primary energy used for power production was wasted, as the efficiency of thermal stations hardly reached $35 \%$ on average. A notable exception to the fully centralized electricity production model took place in several Northern European countries, where nonutility cogeneration [or combined heat and power (CHP)] systems, with overall efficiencies sometimes exceeding $80 \%$, were widely used for district heating (in Denmark, for instance, cogeneration currently provides nearly $50 \%$ of electricity).

The new regulatory wave of the 1990s, aimed at removing the barriers and inefficiencies of monopolistic utilities by unbundling vertically integrated businesses, significantly changed the way energy was traded and priced, yet the basic centralized structure and energy flow patterns of the past decades essentially remained unchanged. 


\section{B. Interconnected AC Transmission Systems}

Power transformers and the ingenuity of Tesla played a crucial role in the settlement of disputes between dc and ac systems. As discussed above, it was soon realized that only high-voltage (HV) and ultrahigh-voltage (UHV), three-phase ac systems would be capable of transmitting to energy-greedy conurbations the huge amounts of electricity produced by large-scale, distant generators. Over the period of 1907-1912, overhead lines with rated voltages as high as $100 \mathrm{kV}$ had been built in the United States and Germany, while today's maximum rated voltage in Western Europe ( $380 \mathrm{kV}$, currently designated as $400 \mathrm{kV}$ ) became commercially available in Sweden during the 1950s. In 1965, Hydro-Québec erected the first 735-kV transmission line [33] that pioneered the $765-\mathrm{kV}$ top rated voltage currently existing in a limited number of countries. Even though the Soviet Union built in 1982, and operated for a few years, the first $1200-\mathrm{kV}$ transmission corridors, it was not until 2009 when China started to operate the first $1000-\mathrm{kV}$ line based on gas insulated switchgear (GIS). This 640-km line connects two substations equipped with three 1000-MVA, single-phase transformers and three 320-Mvar, single-phase shunt reactors, which represent the state of the art in ac transmission [34].

While the maximum distance that an overhead ac line can serve for a given rated voltage (around $1500 \mathrm{~km}$ for $765 \mathrm{kV}$ ) is limited by the series reactance, the transmission capability of underground or submarine ac cables, being characterized by an order of magnitude lower surge impedance, is severely undermined by the thermal stress of the associated capacitive currents, which are proportional to the total length. Mainly for this reason, ac cables longer than roughly $130 \mathrm{~km}$ are hardly found, the length record being $162 \mathrm{~km}$ for a $145-\mathrm{kV}$ submarine cable [35].

As stated above, dc motors never disappeared owing to their speed control versatility. Once ac systems entered the scene, those motors had to be driven by controlled rectifiers made of mercury-arc valves, invented in 1902 by Hewitt and significantly improved over the next decades. This culminated in 1954 in the development by Uno Lamm of the first high voltage dc (HVDC) commercial link in Sweden, featuring a rated voltage of $100 \mathrm{kV}$. Much longer and more powerful mercury-arc HVDC links, both submarine and overhead, immediately followed, all of them upgraded to thyristor valves in the early 1970s. Today, several $\pm 800-\mathrm{kV}$ HVDC lines, crossing China from the western regions, where hydro, coal, and renewable generators abound, to the southeast populated areas, constitute the state of the art in line-commutated, point-to-point HVDC transmission [36].

From the very beginning, power engineers succeeded in designing automatic voltage and frequency control systems allowing synchronous generators to track and evenly share the daily evolution of the rather inelastic demand. However, several major blackouts in the 1960s and 1970s clearly showed that the giant interconnected grids that had developed since the advent of ac systems, stood on feet of clay [37]. In addition to automatic controllers, it was soon realized that the operation of those huge complex systems had to be more closely and accurately monitored with the help of remote terminal units (RTUs), communicated with a control center through private or public communication channels. A seminal paper by Dy Liacco [38], stressing the role of primitive digital computers in security assessment and real-time control, laid the foundations for what has since been called energy management systems (EMSs), built around existing and much simpler SCADA systems. The core tool of EMS is the state estimator, introduced by Schweppe in the early 1970s [39].

Except for the incorporation of the vertiginous technological advances that took place in those decades, both in hardware (mainframes replaced by workstations, LANs, use of full graphic screens, etc.) and software (open systems, data bases, etc.), the EMS functionality remained essentially unaltered until the 1990s, when the regulatory wave and separation of activities brought about new EMS needs and tools [40].

\section{One-Way Distribution Feeders}

Although transmission and distribution subsystems are similar in essence (both move electrical energy between two points) the latter constitutes a separate field in virtually all aspects: planning, topology, protection, and operation [41], [42].

For over a century, distribution systems have been designed, built, and operated to serve the needs of a huge number of passive and quite inelastic customers (residential, commercial, institutional, industrial, and agricultural). The basic principles and goals that have guided the design of distribution networks, in descending order of importance, are as follows.

- Safety: Users, operators and, if possible, infrastructure should not be subject to hazards from the electrical system.

- Cost-effective service continuity: There is an evident tradeoff between total cost (both initial investment and O\&M costs) and service continuity (usually measured through SAIFI/SAIDI indices, representing the system average number and duration of interruptions, respectively [41]). The more redundancy and technical sophistication of the electrical assets, the better the continuity of service but the higher the cost. Unfortunately, achieving the theoretically optimal balance between both contradictory goals is far from trivial. In practice, regulators impose upper bounds on individual and collective service interruption indices, in accordance with the nature of the customer (urban, suburban, rural, etc.), establishing benchmarking comparisons and penalties in case of violations. 
- Power quality: Depending on the voltage level and customer type, the root mean square (rms) voltage must lie within a narrow interval (e.g., $\pm 7 \%$ ), while the waveform should be as free as possible from harmonics and voltage transient phenomena.

- Flexibility and expandability: The grid layout and configuration should be flexible enough to allow for possible load relocations (e.g., in case of outages) and future load growth.

As a consequence, the operation of distribution systems has traditionally differed from that of transmission networks mainly in the following two aspects.

- Even though the underlying structure is frequently networked (redundant), strategically located switches remain normally open (NO) so that the operating topology is radial (see Fig. 4). This means that the N-1 security criterion customarily applied at transmission levels is not of application, the feeders being designed to withstand the expected (summer or winter) peak power, for an assumed simultaneity coefficient and reserve margin.

- Power always flows one way, from the medium voltage (MV) feeder head at primary substations down to the low voltage (LV) feeders through secondary substations. Any element can thus be univocally located (upstream or downstream) with respect to each other. This also means that both the bus voltage magnitude and short-circuit current monotonically decrease from the head to the customers.

Both aspects significantly simplify the protection of MV/LV feeders, compared to that of transmission systems, while the short-circuit levels get reduced, which leads to major investment savings.

At the risk of oversimplification, in terms of configuration, layout, and load density, MV/LV distribution grids can be roughly divided into two distinct categories with sometimes diffused borders.

- Rural grids: Usually characterized by tree-like, nonredundant structures, relatively long overhead lines serving rather dispersed loads through many laterals, and frequently constrained by voltage drops. In this context, electrical distances are well represented by the Euclidean distance.

- Urban grids: Usually characterized by networked or ring structures with NO switches, shorter (overhead or underground) lines with fewer laterals, each serving many more loads, frequently constrained by feeder ampacities. In this context, electrical distances are better characterized through the Manhattan distance.

In turn, across different regions and continents, urban distribution grids have historically adopted a diversity of arrangements, standards, and technological solutions, which pose notable implications in terms of cost, visual aesthetics, and reliability. In this sense, two basic patterns

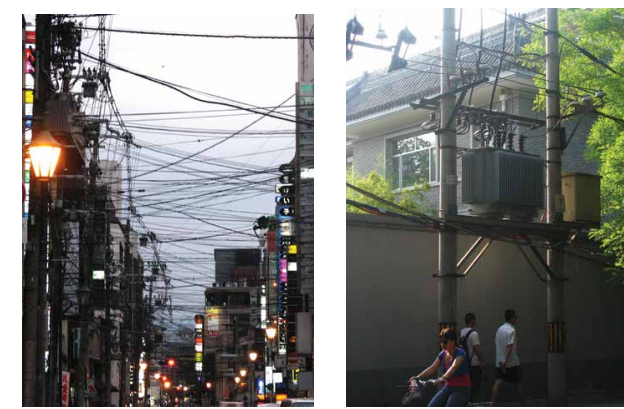

Fig. 1. Urban distribution grids in Tokyo (left) and Beijing (right), where both $M V$ and LV grids, transformers, and switchgear are frequently aerial.

or models can be distinguished, namely the European and the American (the latter with many followers in developing countries, owing to its reduced costs), which differ mainly in two aspects.

1) The extent and reach of three-phase systems. While most laterals in the United States are single phase (110 V), in Western Europe, LV urban grids are customarily three phase $(400 \mathrm{~V})$. This affects the population of secondary transformers, which are fewer and much larger in Europe (600- or 1000-kVA transformers are not rare), but also some power quality issues (voltage drops, losses, unbalances).

2) The percentage of underground assets, which should ideally be a function of the load density but in practice is determined by local regulations, budget constraints, and historical habits. Again, at the risk of oversimplification, the layout of urban grids can be categorized as follows.

- Core of huge conurbations: Both MV and LV grids are laid almost everywhere underground, with some notable exceptions. See, for instance, the overhead arrangements in downtown Tokyo and Beijing (Fig. 1).

- Suburbs and even downtowns of medium/large-sized cities: While bare MV\&LV conductors and small transformers can still be frequently seen pole-mounted in many American cities (see, for instance, Fig. 2),
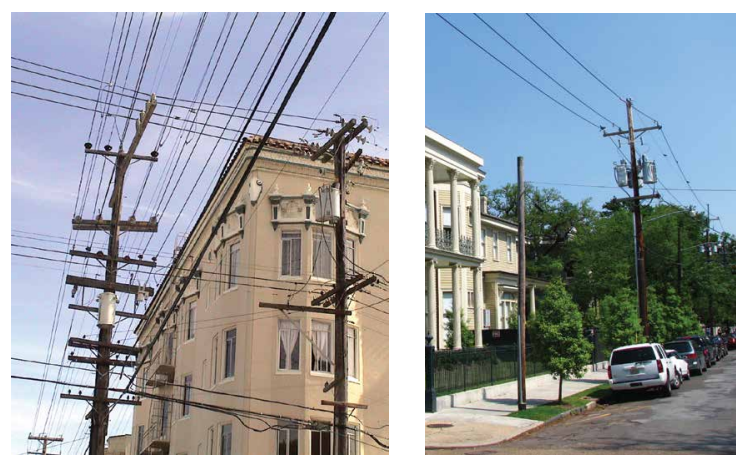

Fig. 2. Urban distribution grids in San Francisco (left) and New Orleans (right), where the same wood pole usually holds both MV and $L V$ feeders. 

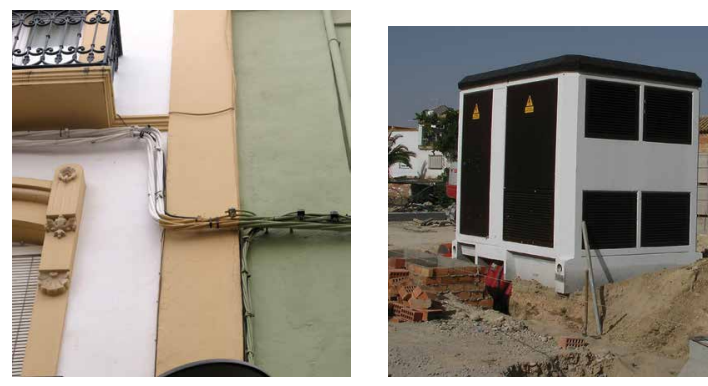

Fig. 3. Facade-mounted, LV aerial bundled cables (left) typically found in towns and medium-sized cities of some European countries, and underground MV cables (right) entering a compact, prefabricated concrete-made secondary substation, customarily used in urban and suburban areas in Europe.

underground feeders are the preferred choice in major European countries, for both MV and LV levels.

- Small cities and towns: Even in these cases, the MV assets in Western Europe are either laid underground or remain on the outskirts of urban areas, while a popular arrangement for LV feeders, particularly in Southern Europe, tries to "camouflage" them on the building facades (Fig. 3 left).

Aesthetically, it is out of the question that grids buried underground are preferable, but they cost much more(between 5 and 20 times, depending on the circumstances [43]). Whether the pole-suspended or facade-mounted LV arrangement is more aesthetic is a matter of personal taste.

However, as far as reliability is concerned, both the underground and the facade-mounted solutions are clearly better than the power pole choice, and the same can be said about the concrete-made secondary substations fed by underground MV feeders (Fig. 3, right), when compared with the pole-mounted individual transformers frequently seen in the U.S. suburbs (Fig. 2). In fact, the facade-mounted solution for LV bundled cables is even more reliable than the buried one, as it is free from flooding or dig-in failures.

Whereas $100 \%$ of distribution feeders are buried underground in cities like Paris or London, this barely exceeds 7\% in central Tokyo, where some 5.9 million poles exist in the downtown and surrounding areas. This could exacerbate a catastrophe in case a large earthquake hit Tokyo, as power poles tend to collapse during big quakes, blocking emergency vehicles from passing, increasing the risk of fires, etc. In California, San Francisco has already buried roughly half of its utility lines underground, but nearly $800 \mathrm{~km}$ of overhead sections still remain. Despite the bigger risk of outages, there are no short-term plans to bury the remaining assets owing to budget constraints. In spite of the disasters caused by Katrina in 2005, something similar happens in New Orleans, LA, where the wooden utility poles are still used in most neighborhoods.

Table 2 shows, for several large European countries [45] and the United States [46], the most commonly employed
Table 2 Five-Year (2009-2013) Average SAIDI for All Interruptions (All Voltage Levels, Planned, Unplanned, and Exceptional Events) for Several European Countries, 2013 Average SAIDI for the United States and Percentage of Underground Assets

\begin{tabular}{|l||c||c|c|}
\hline \multirow{2}{*}{ Country } & \multirow{2}{*}{$\begin{array}{c}\text { SAIDI } \\
\text { (min/year) }\end{array}$} & \multicolumn{2}{|c|}{ Underground (\%) } \\
\cline { 3 - 4 } (m) & LV & MV \\
\hline \hline United States & 230 & \multicolumn{2}{|c|}{18 (total) } \\
\hline Italy & 160 & 37 & 45 \\
\hline Spain & 125 & 43 & 37 \\
\hline France & 115 & 43 & 46 \\
\hline UK & 75 & 84 & 49 \\
\hline Germany & 30 & 89 & 78 \\
\hline
\end{tabular}

reliability index (SAIDI), along with the percentage of distribution lines which are underground. Even though the figures are not fully comparable (different definitions and regulations apply everywhere), it is evident that the average reliability indices in Europe are far better than those of the United States [44], at the cost of higher unitary investments. The rightmost columns of the table show that there is a clear inverse relationship between interruption rates and percentage of underground lines [43].

Unlike transmission grids, distribution systems have traditionally lacked RTUs and dedicated communication links. In most cases, only the circuit breaker (CB) at the MV feeder head, located in the primary substation and responsible for clearing any fault happening downstream, can be remotely monitored and operated. The remaining switchgear is only accessible to maintenance teams by physically visiting the secondary substations. This means that distribution systems are electrically unobservable, and that the main source of information of what is going on comes from customers calls. In this context, outage management in urban areas translates into a time-consuming, trial-and-error process in which one or several teams have to ride motorized vehicles between secondary substations under the coordination of the distribution management system (DMS). Consider, for instance, the typical ring layout shown in Fig. 4, which is very common in urban areas. When a fault occurs at an

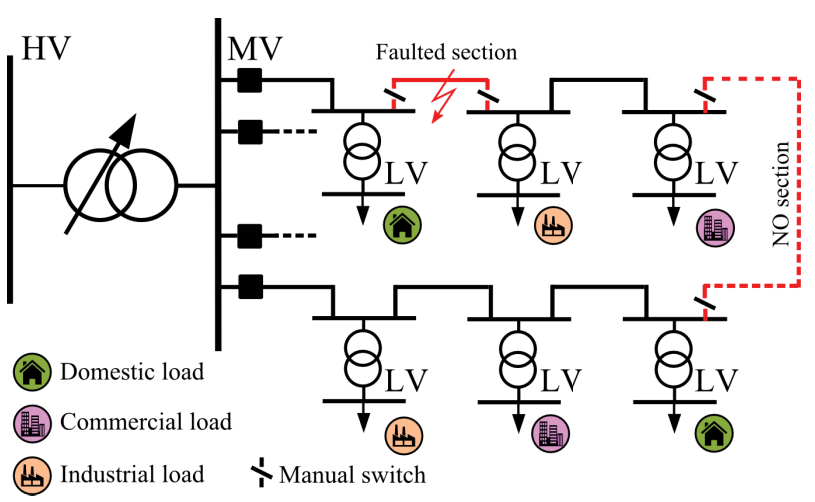

Fig. 4. Schematic layout of $M V$ urban distribution feeders in Europe, typically built as self-sufficient rings but radially operated. 


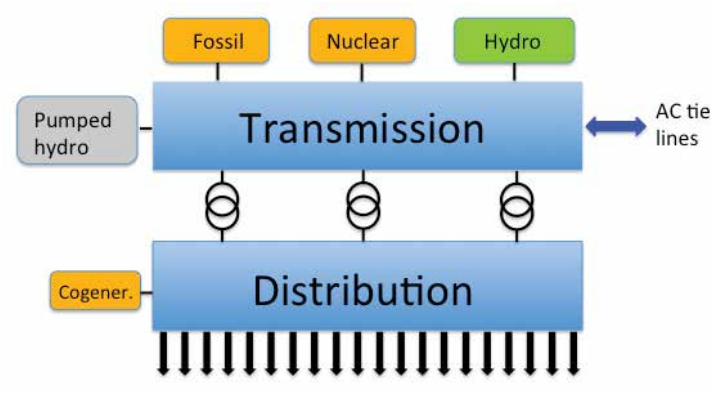

Fig. 5. Main components, relationships, and structure of power systems in the 20th century.

intermediate branch section, it is cleared by the head CB. Then, the faulted section (in red) must be identified by a succession of manual (i.e., local) opening/closing maneuvers on intermediate switches (not shown in the figure), until the CB does not detect any fault current and remains closed. Finally, the healthy sections downstream the fault are returned to service through the backup feeder by closing the NO switches. Note that this requires each half ring to have enough spare capacity to be able to feed its neighbor.

Fig. 5 presents a schematic of the major subsystems and main relationships of the centralized system that crystallized over the 20th century.

\section{SMART GRIDS: LEVERS TO FOSTER SMARTER CITIES}

For the whole century, the "centralized" power system framework briefly described above served the needs of the society quite well, at least in well-developed economies. However, the coincidence in time of several factors, such as the climate change and fossil-fuel dependency awareness, the relentless regulatory reforms, the explosive growth of digital technologies (internet, wireless communications) and the ensuing economic and social globalization, gave birth in the last decade of the 20th century to an unstoppable movement toward a customer-centric, decarbonized, and highly electrified energy system model [32]. It is firmly believed that this upcoming paradigm will only be possible if the aging power systems of the 20th century are steadily transformed into what has been termed the "smart grid."

A succinct definition for "smart grid" is the one provided by the European Technology Platform on Smart Grids, created in 2005 and replaced in 2016 by the European Technology and Innovation Platform "Smart Networks for Energy Transition" [47]: “An electricity network that can intelligently integrate the actions of all users connected to it-generators, consumers and those that do both-in order to efficiently deliver sustainable, economic and secure electricity supplies. A smart grid employs innovative products and services together with intelligent monitoring, control, communication, and selfhealing technologies." Similar definitions can be found elsewhere [48], [49], while a comprehensive view of the future of electric utilities, including economic and regulatory issues, is presented in [50].

The main goals pursued by smart grids can be summarized as follows [51]-[55].

- Accommodate a wide variety of distributed generation (renewables, cogeneration) and storage systems, in order to significantly reduce the environmental impact and increase the efficiency of the electricity supply chain.

- Provide consumers with relevant information so that they can make their choices and provide ancillary services in a more volatile context (demand management, integration of electric vehicles).

- Improve existing standards of reliability and quality of supply (self healing).

- Allow new business models to be developed at the local level (e.g., energy trading) in coordination with wholesale markets.

- Help utilities optimize the utilization and maintenance of existing assets.

In a nutshell, smart grids are tantamount to bidirectional flows of both energy and information. Although some newcomers pretend that smart grids constitute the only and revolutionary effort to modernize the electric sector, the truth is that power systems have always benefitted, to a large extent, from existing technology, be it the network analyzers widely used before the advent of digital computers, the mercury arc valves that preceded the thyristors, or the analog power line carriers (PLCs) subsequently replaced by fiber optics. In fact, as summarized in the previous section, transmission systems started to become "smart" when increasingly more sophisticated EMSs were deployed in the early 1970s, and continued this trend with the incorporation of digital protection systems (so-called intelligent electronic devices (IEDs) [58]). Therefore, today's smart grid efforts, much like in the past, are mainly aimed at increasing the capacity and flexibility of transmission systems and modernizing or upgrading distribution system infrastructures, so that they can cope with the real revolution currently taking place on the generation and demand sides.

Smart grid technologies can be broadly categorized as follows [49], [54]-[57].

- Information and communication systems, including smart meters, PLCs and digital wireless channels, data concentrators, new generation of sensors, digital relays (IEDs), and phasor measurement units (PMUs or synchrophasors [59]), along with the required protocols and standards (e.g., IEC61850).

- New architectures and niche roles for control systems, hierarchically dependent upon existing EMSs and DMSs, such as substation-level EMSs, distributed controllers for ac/dc microgrids, local controllers for virtual power plants (VPPs), etc. 
- Distribution automation devices and tools, providing advanced diagnosis and speeding up the service restoration process in case of faults or outages.

- Power electronics devices, allowing ac/dclong-distance transmission, acting as smart interfaces among ac/dc subsystems (e.g., DGs and microgrids), and delivering cost-effective ancillary services (e.g., var/voltage support, congestion management).

- Smart power assets, other than power electronics, providing advanced features, such as new generations of transformers, cables, switchgear, and insulating materials.

- In a digital world, continuously evolving software will be embedded everywhere, from ubiquitous firmware, middleware, signal processing algorithms, power plant controllers or smartphone "apps," to advanced simulation and optimization algorithms or data analytics, capable of extracting useful information from the exploding stream of raw data steadily provided by network sensors, consumer behavior, and DGs.

Fig. 6 illustrates the central role played in the smart grid context by the software, which lies at the core of every other technology, be it ICT, distributed controllers, distribution automation switchgear, or power electronics interfaces.

Overall, the juxtaposition and joint operation of all technologies succinctly described above give rise to the largest and more complex cyber-physical system ever built by human beings. Efficiently and reliably operating such time-varying, hybrid digital-analog, geographically distributed systems, particularly when the uncertainty of both renewables and consumers is taken into account, involves a blend of sensors, wide-area communications, and hierarchical control systems, altogether creating the required tight coupling between the cyber and physical smart grid subsystems [60].

In Sections III-A-III-E, the major actors playing a role in the smart grid paradigm will be briefly reviewed, paying special attention to their interactions and implications for the urban world.

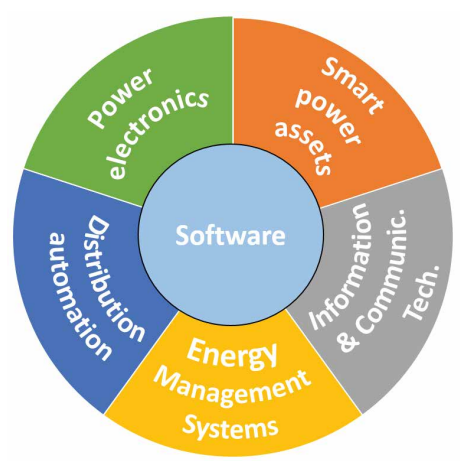

Fig. 6. Main categories of technologies involved in smart grids.

\section{A. The Potential and Limitations of Distributed Generation for Sustainable Cities}

As explained in Section II, the development of a centralized generation paradigm throughout the 20th century, along with the high concentration of demand in increasingly larger metropolitan areas, where fossil-fuel or nuclear power plants cannot be built, have led to important regional imbalances between consumption and generation, which can only be reconciled with the help of widespread transmission systems.

In the 21st century, though, power systems are facing an exponential growth of renewable generation that will necessarily become a major player in the energy mix by mid-century and beyond [50]. A significant yet undefined share of this upcoming generation will be distributed, particularly in those areas where the potential for solar energy is high. In fact, in view of the steadily decreasing costs of roof-mounted, modular PV systems, and the expected cost reductions of the associated storage devices, distributed generation is considered the ideal choice for all kinds of urban settlements, from isolated rural communities in India or Africa to huge megalopolis [61].

One of the main issues to be addressed in the smart city context is that of energy sustainability, which in turn is related to both energy efficiency and the potential for producing enough renewable energy within the (fuzzy) bounds of the city. While zero-energy buildings constitute a hot topic of research [62], one might legitimately wonder whether such an appealing concept can be directly extended to the scope of an entire city.

The answer to that question is far from trivial and case dependent, the key aspects to consider being the population density and local renewables potential. No matter how cost-competitive renewables become, if there is physically no space to achieve self-production, then the city will have to import the remaining net energy from the external world.

A detailed study of the energy balance of a city should contemplate the demand for thermal energy, electricity, and services (transport), as done, for instance, in the POLICITY project [63]. On the other hand, a distributed multigeneration holistic approach [64] should be adopted when assessing the supply side, combining a portfolio of technologies: cogeneration of electricity and heat (CHP), heat pumps, solar (thermal and PV), and trigeneration or wind turbines (as in the Montevideo case [65]).

Wind generation is not generally a solution, except for very specific sites with high enough wind capacity factors. Fuel cells, on the other hand, could be a solution provided the hydrogen comes from renewable sources, in which case a hydrogen supply network would be needed.

For the sake of simplicity, the rest of this section is devoted to study the possibility of supplying the electricity demand of a city exclusively based on distributed PV generation, without any doubt the most suitable technology for urban environments, owing to its modularity and 


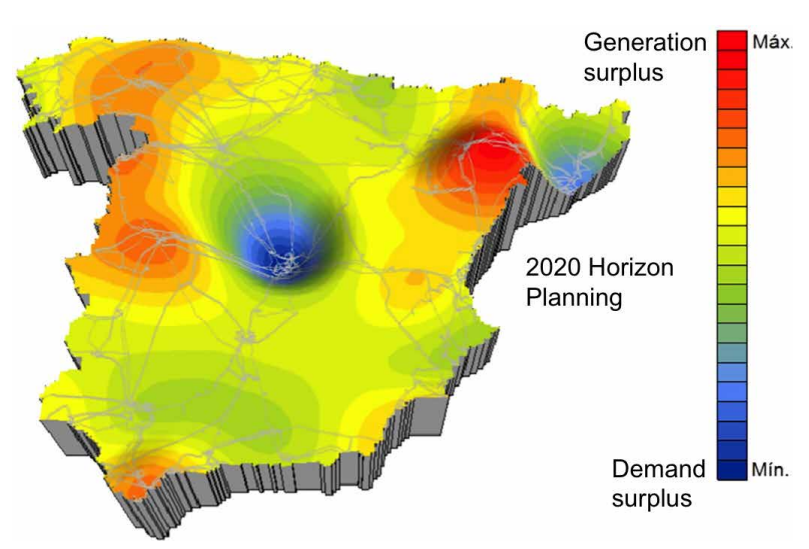

Fig. 7. Electrical generation-demand imbalance in Spain (source: REE).

adaptability to different surfaces and practical building constraints.

Consider, for instance, the case of Spain, not very densely populated when compared to other European neighbors. Fig. 7 shows a color map where huge demand sinks are represented in blue whereas major generation hubs are in red. Note the dark blue regions around Madrid (where over 96\% of the electricity comes from external sources [66]) and Barcelona cities, by far the largest metropolitan areas in the country. This very clearly shows the need for a powerful and reliable (meshed) transmission system, capable of pumping energy from the rest of Spain (yellow areas) to the big cities, which must be underground when the urban density is sufficiently high.

Fig. 8 schematically shows the layout of the $400-\mathrm{kV}$ ring around Madrid (comprising six substations) and the 220-kV transmission lines and underground cables delivering electricity to the city through a total of over 60 substations.

While the annual demand exceeds $14 \mathrm{TWh}$ (5.6\% of the country), the inner production, arising mainly from the use of biogas from wastewater and incineration of municipal solid waste, does not reach $500 \mathrm{GWh}$. The point is whether

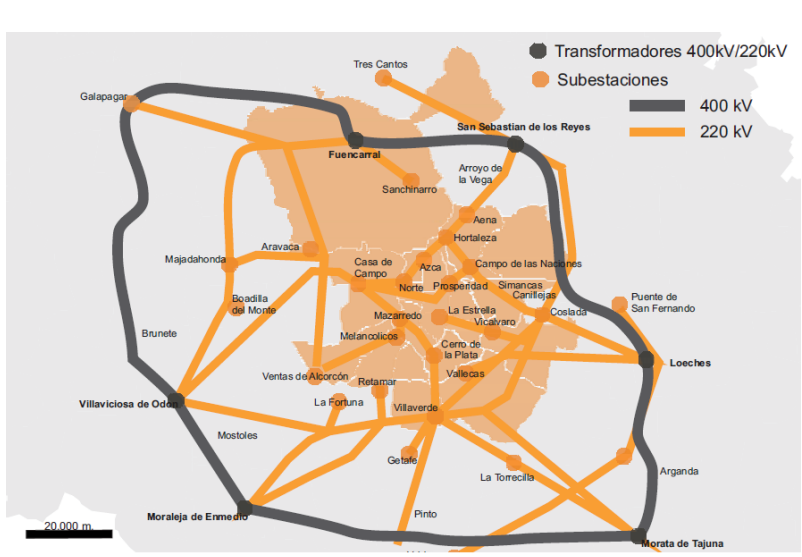

Fig. 8. Transmission system feeding Madrid (source [66]). it is possible to supply this demand exclusively based on PV generated within the city perimeter.

The city of Madrid spreads over an area of roughly $600 \mathrm{~km}^{2}$, of which only $219 \mathrm{~km}^{2}$ are urban. For the latitude of Madrid, the PVGIS tool of the JRC [67] yields a yearly production of $1550 \mathrm{kWh} / \mathrm{kWp}$, for the optimal panel orientation ( $30^{\circ}$ south). Considering a standard configuration of fixed modules in two rows, the horizontal surface needed to obtain $1 \mathrm{kWp}$ is roughly $10 \mathrm{~m}^{2}$ [68]. Based on the above data, it is easily concluded that, if the entire urban surface of the municipal district of Madrid $\left(219 \mathrm{~km}^{2}\right)$ were used to install solar panels, then the achievable production would exceed $34 \mathrm{TWh}$, which is over twice the electricity consumed by the city.

However, this scenario is completely unrealistic, as the installation of PV plants should compete with other uses of the urban surface [69], such as roads, public spaces, gas stations, fuel deposits, solar thermal applications, etc. Moreover, there are other space limitations arising from shading effects and the structure and layout of buildings.

Determining the exact amount of useful surface for the installation of PV systems on a real urban space is a lengthy and awkward process. In the last few years, several GIS-based tools have been made available, capable of automatically performing this task [70], [71], [74]-[76]. Among them, the one developed by the National Renewable Energy Laboratory, which has already made an inventory of the PV capacity in the United States, stands out.

A similar inventory has not yet been carried out in Spain. However, a GIS analysis based on data from the Institute of Statistics of Andalusia [71] suggests that, in urban areas, the maximum compatible occupation of the roofs is $9.4 \%$ on average. Assuming that the urban area of Madrid presents similar constraints to those of Andalusian cities, then the energy produced would be just $3.2 \mathrm{TWh}$, which is about $23 \%$ of the current demand (14 TWh) [72], [73]. This is based on the assumption that the electricity demand keeps at today's levels. Actually, it is expected that the electrification of the transport sector and other uses will significantly increase the electricity demand, further reducing the relative selfproduction potential of urban areas.

Therefore, despite the strong increase in PV generation efficiency [77], and the drastic reduction of costs [78], [79], it will not generally be possible to generate sufficient energy to satisfy the electrical demand of a city like Madrid (not to mention New York, Singapore, or Shanghai), exclusively using PV sources. Nonetheless, deploying as much DG as possible is always a good idea, as it will contribute to reduced emissions and losses and the need for new transmission and distribution assets.

Fortunately, though, the conclusions reached for Madrid and similar metropolis do not apply to other less densely populated urban conurbations. Consider, for instance, the city of Córdoba in Andalusia, where the population density is almost one half that of Madrid, the demand of industries 
Table 3 urban PV Potential for Madrid and Córdoba (Sources [67], [71]-[73])

\begin{tabular}{|l||c||c|}
\hline & Madrid & Córdoba \\
\hline \hline Urban Area $\left(\mathrm{km}^{2}\right)$ & 219 & 68.16 \\
\hline Annual PV production $(\mathrm{kWh} / \mathrm{kWp})$ & 1550 & 1560 \\
\hline Usable area $(\%)$ & $9.4 \%$ & $9.4 \%$ \\
\hline Maximun annual production $(\mathrm{TWh})$ & 3.21 & 0.99 \\
\hline Annual electricity demand $(\mathrm{TWh})$ & 14 & 1.07 \\
\hline
\end{tabular}

and services much lower, and the irradiation slightly higher. In this case the potential for PV energy self-production is about $1 \mathrm{TWh}$, which is indeed very close to the current demand of the city. Table 3 shows the main figures for the PV electricity potential in both cities.

If a similar analysis were repeated for a typical residential suburb, where major industries are missing, then it would surely be concluded that the maximum yearly production of the embedded PV generation is significantly higher than the local demand.

\section{B. The Role of Storage Systems for Smart Urban Grids}

Even in those favorable cases in which the city's annual $\mathrm{PV}$ production exceeds the demand, there is still a clear need for the deployment of storage systems to ensure electricity self-supply. The well-known daily curve of PV production looks pretty much like a Gaussian curve that begins at dawn, presents a maximum at noon, and returns to zero with the sunset. In absence of clouds, the shape of the curve depends only on the location and day for which the observations are made. Hence, at first glance, it seems that an electrical battery, properly dimensioned to store the energy of a certain number of days, say a week, would do the job.

However, except for very low latitudes, the differences between summer and winter periods can be drastic, leading to seasonal imbalances for which battery energy storage is not simply a choice. Therefore, unless other storage technologies not yet envisaged are developed for urban zones, there is no way but to resort to the energy coming from the outer world through the electrical grid. In this regard, a pioneering project worth mentioning is the one being tested in the city of Hamburg, where the excess of heat in summer periods is stored underground for later use in winter, in combination with heat pumps [80].

In practice, the optimal solution to complement the PV self-production is to resort to both battery storage and the distribution grid. The literature abounds in optimization studies and design tools aimed at determining the optimal size and location of storage systems, taking into account all the relevant constraints and costs, including the possibility of getting extra revenues by providing ancillary services [81]-[83]. In general, from a system-wide perspective, rather than that of a single user, the optimal solution will be a nontrivial combination of storage devices, ranging in size from few kilowatt hours to hundreds of megawatt hours,

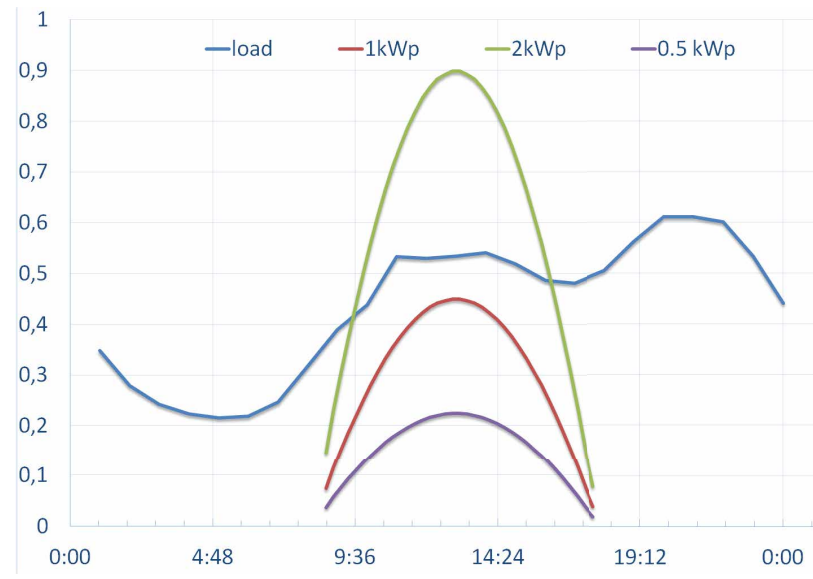

Fig. 9. Comparison of a winter daily load profile and the PV production for different installed capacities in Madrid.

spreading from primary and secondary substations to the consumers.

Although a detailed analysis is out of the scope of this paper, consider, for instance, the case of a typical residential customer demanding $3600 \mathrm{kWh} /$ year (the average residential consumption in Spain), who has enough available surface to install PV panels. Fig. 9 represents, for a winter day (January 15) in Madrid, the hourly profiles of the average residential consumption and the PV generation provided by the PVGIS-JCR tool for different levels of installed power, in per unit. Similar curves can be obtained for the remaining days of the year.

Then, in absence of energy storage and demand management strategies, a trivial hourly balance extended throughout the whole year provides, for each installed power, the total energy produced and the fraction that can be selfconsumed. As shown in Fig. 10 for an average consumer in Madrid, no matter how much PV power is installed, the total amount of self-consumed energy saturates at about $1500 \mathrm{kWh} /$ year (i.e., just $40 \%$ of its demand), even though $2.5 \mathrm{kWp}$ of PV panels would produce enough electricity all year round to cover the total demand. Therefore, a self-sufficient

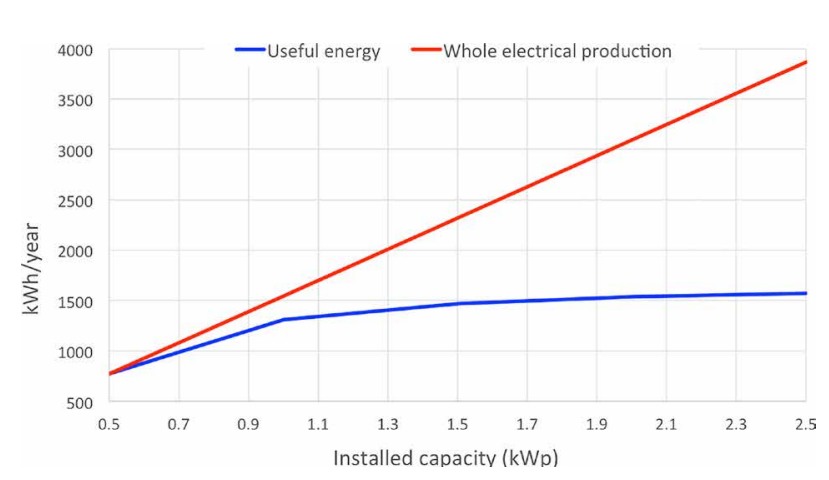

Fig. 10. Difference between useful energy for the average customer and direct production from the PV system for increasing installed powers in Madrid. 
system cannot be achieved unless a suitable storage device is deployed.

Note that the excess energy eventually produced by the rooftop PV system would be either lost or injected to the LV grid for the benefit of the neighbors, provided the regulation allows it. If all consumers of the local community are facing the same issue, then the excess energy could be still exported through secondary transformers and MV feeders, or even further away through the HV or UHV transmission system when the level of PV penetration becomes high enough. However, this will be only possible as long as other loads elsewhere can instantly absorb the excess of PV production. Within several decades, though, when $75 \%$ or higher renewables penetration rates are expected, this will become a national or even transnational problem, as the sun shines simultaneously over whole continents. Then, massive amounts of short- and long-term (i.e., seasonal) storage will be imperative.

To give a rough idea of the importance of this issue, let us consider a hypothetical extreme situation in which all the electricity demanded by a large country, such as Spain (246 TWh in 2016), is to be provided exclusively by solar energy. By comparing, on an hourly basis, the total demand with the production of a giant PV-based system (160 GW), capable of delivering enough electricity to meet the Spanish annual demand, intraday (night versus day), intraweek (labor-day versus weekend), and seasonal or intrayear (autumn-winter versus spring-summer) imbalances can be obtained, which would call for equivalent amounts of storage capacity. According to this analysis, the day with largest imbalance in the simulated scenario would be the second Sunday of August (the month when most Spaniards enjoy their holidays), with a total storage requirement of 269 GWh (837 GWh of PV production minus 568 GWh of demand). Note that this is not the day with maximum PV production. As far as the seasonal imbalance is concerned, the excess PV energy produced during spring and summer periods reaches a peak of 24 TWh late in September, which roughly represents $10 \%$ of the total annual demand in 2016. This huge amount of stored energy should be consumed between October and February, when the imbalance is negative.

Once again, selecting the right storage technology is far from trivial [84], [85], as it depends on many factors (maximum peak power, recharging time, number of daily cycles, etc.), but many believe today that the Li-ion choice is the winner, at least in the short term, owing mainly to the experience gained from the expansion of electric vehicles (EV) and the increasingly competitive prices. While in 2008 the price of $1 \mathrm{kWh}$ of Li-ion battery exceeded $\$ 1000$, it currently lies in the \$150-300 range [77], and major manufacturers such as Tesla claim that batteries will cost as little as $\$ 100 / \mathrm{kWh}$ by 2020 , with improved performance in terms of energy density (kilowatt hour per kilogram), useful life (number of cycles), and other technical characteristics.

\section{Smart Meters and ICT: Umbilical Cord Between Prosumers and Smart Cities}

Many experts state that one of the major distinguishing features of smart grids, compared to the previous paradigm, is the new and crucial role played by customers, that will quickly and drastically change from today's passive and inelastic consumers to much more active and conscious actors whose decisions will determine the fate of the grids, as we know them today.

In view of the scenarios analyzed in Sections III-A and III-B, regarding the decreasing costs of renewable DG and associated storage equipment, one might think that the grid defection is close [86], at least in geographically favorable places and for certain types of customers (beginning with those of higher social status). However, the seasonal imbalance problem discussed above, along with other technical and psychological factors (risk of internal failures, unforeseen weather conditions, feeling that a backup source may be needed in case of emergency, etc.), suggest that, at least for the next two decades, the average consumer will find it more beneficial to remain connected to the network [69]. The final outcome will be significantly conditioned by the specific regulations adopted in each case, which are crucial to determine how the network costs will be split among users with rather different profiles and interests, trying to avoid both cross subsidies and stranded costs.

In any case, the expected transformation of the electrical system would not be possible without the information provided by smart meters [7], digital measuring devices which can be remotely read and controlled (see Section IV-D). The DMS operators will find this information very useful to significantly optimize the planning and operation of the grid and to automate as much as possible the service restoration process [87], while a better matching of all embedded resources (DG and storage) is achieved. With the help of suitable data analytics techniques, retailers and aggregators will also be able to offer enhanced services to customers [27]. Finally, on the demand side, this bidirectional communication channel will allow consumers to make more informed decisions about their own demand and generation, if they receive the appropriate signals (price and incentives). This new role is better characterized by a more inclusive notion, the so-called prosumer [88].

As a matter of fact, it is believed that smart meters will transcend the electrical network and will be helpful to manage other public services in smart cities, such as security, waste, water, transport, public lighting, etc., constituting de facto a system of systems [7]. This amazing amount of information opens the door to a new model of relations between the prosumer and the utility, for the common benefit. Taking advantage of this new framework, Dimeas et al. [89] propose up to seven new business models, including the aggregation of networked households as agents participating in the market, a distribution system congestion management, tariff-based load and generation shifting or 
the possibility of offering reserve capacity in the ancillary services market [90].

Recent estimates for the United States based on FERC information [91] conclude that, under the appropriate incentive framework, the right use of the information provided by smart meters could account for $20 \%$ reduction of the peak load in ten years. This would reduce the need to deploy new network or generation assets or to upgrade the aging ones. At the same time, it would reduce the price for the consumer and increase the penetration of renewable energies, consequently reducing the levels of emissions.

But smart meters, and other network sensors, require that a more sophisticated and capillary communication network be deployed, capable of managing and sending to the DMS two or three orders of magnitude more information than in the past, when distribution systems were essentially black boxes. The reader is referred to Section IV-D for a more detailed description of the different ICT technologies that can be considered, from private PLC-based systems to public 3G/4G networks.

Several critical issues associated with ICTs for smart grids are [92] as follows.

- ICT architecture. Reference architectures have been proposed [93], [94] describing their main elements, mutual interactions, and restrictions. Both the physical layer and the middleware have an impact on the overall resiliency and the performance of the highlevel functions that can be supported by smart grids.

- Time latency. In smart grids, a variety of latency requirements arises depending upon the grid type (transmission or distribution), architecture, technology, and application [95], [96]. Some applications, such as demand response (e.g., remotely controlling street lights) have very relaxed latencies, whereas others, such as network protection or automation, require very low latencies.

- Cyber security. As the electric grid is evolving from a relatively closed system to a complex, diverse and highly interconnected set of agents, effective cybersecurity strategies must be adopted to minimize risks and vulnerabilities [97].

- Standardization. Last but not least, standards play a crucial role in ensuring interoperability, flexibility, and neutrality of the upcoming technologies, while at the same time preventing premature obsolescence [98]-[101].

\section{Hybrid AC/DC Transmission Supergrids}

As clearly concluded from the above discussion, major metropolitan areas will be far from being self-sufficient in terms of electricity generation when renewables are only considered in the equation. Therefore, transmission grids will continue to play as vital a role as in the past, despite the foreseeable progress in distributed generation.
Compared to the grids of the 20th century, transmission systems in a decarbonized future will be mainly characterized by:

- longer average distances between renewable generation hubs and major load sinks;

- operating points embodying unscheduled loop flows [102], [103] and more frequently approaching the security limits;

- steeper, more frequent, and less predictable power flow gradients.

Those features pose new challenges for TSOs, which are already being addressed with the help of smart grid technologies. In fact, as discussed earlier in this section, transmission systems pioneered the adoption of digital technologies, such as IEDs, over 20 years ago. However, further deployments of more sophisticated technologies, some of them still undeveloped or in their infancy, will be needed, as the transition to a decarbonized future takes place. Roughly speaking, those new technologies can be grouped into two main categories, namely power assets (infrastructures) and ICT-related, monitoring and control technologies, that will be separately reviewed in the sequel.

1) Power Infrastructures: On the one hand, more and more HVDC transmission corridors will supersede or run in parallel with existing ac lines, in those cases where the ac technology reaches its economic or physical limits [104]. These include an increasingly larger family of niche applications, listed as follows.

- Submarine cables connecting offshore wind farms or islands to mainland, when distances exceed roughly $100 \mathrm{~km}$.

- Interconnection of neighbor synchronous systems which cannot safely or economically run in synchronism, irrespective of the distance. This is the case of existing and planned submarine interconnections between Nordic European countries through the North Sea [105]. In the limit case, the interconnector can reduce to a set of back-to-back converters, as in the planned Tres Amigas superstation that will link the three synchronous systems of the United States [106] or the dc link deployed in China to split a huge ac system into two asynchronous grids in order to enhance the overall stability [107].

- Interconnection of two points within the same synchronous system. Typically, the two points are very far away, and the logical choice from an economic perspective is to build overhead lines. Examples of this application abound in very large countries, such as the United States [108] or China [34]. However, owing mainly to social opposition, the use of more expensive underground or submarine cables is becoming more and more common, even for long distances. This is the 
case, for instance, of the 65-km HVDC double-circuit cable $( \pm 320 \mathrm{kV}, 2 \mathrm{GW})$ connecting Spain and France through the Pyrenees [109]. In Germany, the three HVDC overhead corridors initially planned between the North coast and the Southern industrial regions [110] are behind schedule owing to low public acceptance, giving rise to periods in which offshore wind energy is wasted. Taking advantage of recent advances in HV cross-linked polyethylene (XLPE) cables, with the support of new legislation paving the way to this technology, some line sections are now being redesigned as underground cables [111].

As voltage source converters (VSCs) based on insulatedgate bipolar transistor (IGBT) increase their voltage and power ratings, both HVDC systems and flexible ac transmission systems (FACTSs) will switch from using thyristorbased, line-commutated technology to much more versatile, high-frequency, self-commutated arrangements [112]-[114]. The state of the art in line-commutated HVDC technology is represented by the Zhundong-Sichuan line, in China $( \pm 1,100 \mathrm{kV}, 10 \mathrm{GW}, 2600 \mathrm{~km})$, while the highest voltage, VSC-HVDC cable is Skagerrak 4, between Norway and Denmark ( \pm 500 kV, 700 MW, 240 km) [115]. According to the analysis made in [116] for the line-commutated technology, HVDC lines can optimally transport 2 GW of power with $2 \%$ losses between points located up to $10000 \mathrm{~km}$ apart.

One of the key advantages of VSC-based HVDC systems is that they can be arranged as multiterminal grids, which offers new and yet unexplored perspectives when combined with existing ac systems [117]. Recent or undergoing multiterminal HVDC projects are reported in [118] and [119].

At the same time, ac systems are becoming more flexible and can reach longer distances with the help of a plethora of FACTSs and more conventional control devices, such as phase shifters, which makes it difficult for the planner to make a choice between ac or dc systems for electricity transmission at intermediate distances [104], [120].

In a future plenty of underground and submarine cables, a major concern and uncertainty refers to cable life. The history of overhead transmission lines indicates that they can last for about 80 years, while the (still incomplete) history for XLPE cables suggests a rather shorter life of about 35-40 years. Those who fiercely oppose overhead lines for aesthetic reasons should be well informed of all the involved tradeoffs and environmental implications.

2) Control Systems: On the other hand, future transmission systems will have to be more tightly supervised and controlled with the help of a new generation of EMS, capable of interacting on several fronts. Fig. 11 schematically shows the major interactions (i.e., information flows and control actions) of control centers with a diversity of agents in this more complex world, which can be summarized as follows.

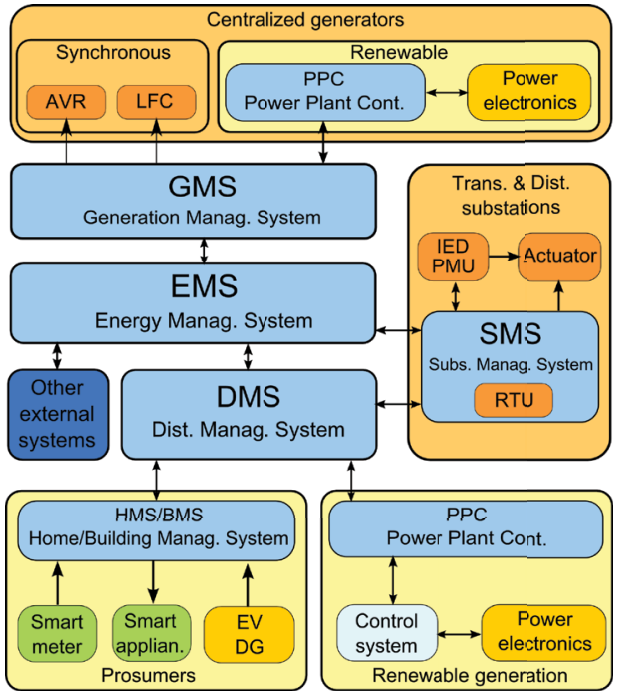

Fig. 11. Schematic diagram illustrating interactions among control centers and major subsystems.

- Much like in the past, the EMS must continue coordinating the ancillary services with conventional generators and distribution utilities, each with its own control center (GMS and DMS). These involve voltage and frequency regulation, including reserve generation. In a context where part of the generation is migrating from the TSO to the DSO domains, the EMS/DMS coordination, entailing exchanges of information, models and coordinated controls at the interface, becomes more crucial [121]-[124].

- Moreover, a new generation of state estimation, security analysis, and related preventive and corrective tools must be devised, taking advantage of increased bandwidths of communication channels, smarter measuring (PMUs), and protection devices (IEDs), providing many more data at much faster rates, and new standards for transmission substations (e.g., IEC 61850).

- New EMS must allow TSO/ISOs to interact with the power plant controllers (PPCs) of large, centralized renewable facilities, steadily gaining quota in the energy mix, which are becoming more and more flexible and controllable with the help of storage assets. A successful example is the add-on center (CECRE) developed in Spain by REE [125].

- Finally, the EMS must work in close coordination with neighbor TSO/ISOs, as interarea electricity markets develop and tie-line congestions become more frequent. This is the case, for instance, of Europe, where the internal energy market (IEM), a day-ahead integrated electricity market embracing seven regional markets, is successfully running since 2014 [126]. Realizing that effective regional coordination of the interconnected transmission systems that support the IEM is needed, an agreement was signed in late 2015 
by 36 TSOs to roll out the so-called regional security coordinators (RSCs). So far, five RSCs (CORESO, TSC, SCC, Nordic RSC, and Baltic RSC) have been created to support the national TSOs' decision making [127]. Furthermore, in the Clean Energy Package draft, released in late 2016 [128], the EC has proposed to take a step forward to ensure a better coordination of transmission system operations with the creation of new regional operational centers (ROCs).

The main implication of this trend is that the centralized decision-making process behind today's EMS [129] ought to be revisited in the smart grid era. As thoroughly discussed in [130]-[132], a partly distributed hierarchical framework must be rather considered, where substation management systems (SMSs) will be in charge of locally processing raw data and carrying out some subordinated tasks [133], [134].

Altogether, recent advances in FACTS and HVDC technology, along with the availability of PMUs and much faster wireless communication channels (5G), are opening up unprecedented opportunities for wide-area control (WAC) of smart grids [135]. This will be necessary if giant interconnected systems must securely and efficiently serve the needs of large-scale regional markets, like the IEM in Europe [126].

3) Forecasting Tools: Embedded into several EMS functionalities, forecasting tools merit a special note. Before the advent of deregulation, load forecasting [136] was mainly intended to create scenarios for centralized generation scheduling (both in the short and long term). Then, deregulated systems raised the need to also forecast the prices of electricity in wholesale markets [137]. Both demand and, to a large extent, prices are characterized by rather regular repetitive patterns, which lead to relatively low forecasting errors. Much more difficult is the task of accurately forecasting renewable production in order to schedule ancillary services [125], [138], which is becoming of paramount importance as wind and solar increase their share in the energy mix, particularly for weakly interconnected systems, such as the Iberian one. The reader is referred to [139] and [140], where the impact of wind energy forecast uncertainty on the reserve requirements and the market integration of wind energy in Spain is analyzed. A comparison of different methods and rules for defining the operating reserve requirements is made in [141].

Note however that, as discussed above, a future system supplied by $100 \%$ stochastic sources will not be feasible unless huge amounts of storage capacity (both distributed and centralized) are deployed in parallel to the growth of renewables. This will significantly affect not only the energy markets but also the provision of ancillary services, as flexibility and speed of response will be as important as firm capacity [142]. Indeed, in this future context, the few remaining thermal generators may not be flexible enough to provide certain ancillary services, such as fast ramping, which should be rather warranted by a mix of fast-acting storage devices, most of them connected to the grid through power electronic interfaces. In other words, the conventional notion of "generation reserves" will have to gradually shift to that of "storage-based reserves."

\section{E. Two-Way Distribution Systems}

With the advent of prosumers, many of them embedding DG, EVs, and demand management, distribution systems should no longer be called "feeders," as they will play basically the same role as transmission systems. Actually, apart from the voltage levels and power ratings, the major differences between both types of grids are being reduced to: 1) the number of components, including substations, switchgear, and lines, is two orders of magnitude larger in distribution systems; and 2) the operating topology of distribution systems remains typically radial (this difference might even vanish in the long term, as distribution automation progresses).

Unfortunately, existing MV and LV radial networks were not historically planned and designed keeping in mind this increasingly complex environment. Unlike traditional passive consumers, PV generators and EVs scattered throughout the distribution grid are characterized by much higher simultaneity coefficients, which are pushing the distribution systems to their technical limits. In this context, feeder congestions and/or voltage problems will be very common [50], and the final customer will be more and more concerned about the continuity of supply.

While reinforcing overhead feeders or deploying voltage regulation devices in rural environments is a relatively cheap and hassle-free process [41], this is not the case of underground urban feeders, at least in densely populated areas, where very expensive and lengthy sidewalk digging is involved and related annoyances (e.g., closed streets, loud noises) are unavoidable. Additionally, it has to be questioned whether the investment in traditional assets (lines and transformers) is always the best solution, taking into account their spare capacity over a large number of hours a year, particularly in second-home areas [143]. Regarding the continuity of supply indices, once the urban feeders become underground, the room for further improvement is quite reduced, as long as the service restoration process remains essentially an operator-assisted, trial-and-error process involving mobile maintenance teams.

As an alternative, the performance of the distribution systems can be more effectively boosted by resorting to smart grid technologies. The following subsections review the possibilities offered by those technologies in two different aspects: power assets and control technologies.

1) Power Infrastructures: The use of power electronics at the distribution level constitutes one of the key enablers of future smarter grids. Contrary to general belief, power 
electronics applications do not reduce to mere interfaces of generation and storage systems, but many other networkembedded uses can be envisioned aimed at maximizing the asset utilization, as shown in Fig. 12.

Two elements in this figure are of special relevance when compared with the 20th century traditional scheme shown in Fig. 4. First, the NO switches used for service restoration have been replaced by a dc link composed of two VSCs in a back-to-back topology. The installation of such controllable device creates a virtual "loop" between the interconnected feeders, which is of special interest in the presence of local network congestions, as the active power flow through the dc link can be adjusted in order to "equalize" the neighboring feeders. In the more general case, in which more than two feeders are connected to a sectionalizing center, the same philosophy can be applied by resorting to a multiterminal dc link. In addition to the flow of active power, the reactive power at each VSC terminal can be also controlled in an independent manner, providing voltage control capabilities. Despite these promising prospects, and the solid ground gained from the application of HVDC technology in transmission networks, dc links for MV/LV feeders have so far been applied only in pilot projects [144] (see Section IV-B).

Second, the mechanical tap changers customarily mounted on MV/LV transformers, which can only be adjusted by disconnecting the transformer and interrupting the service, are replaced in Fig. 12 by electronically assisted, on-load tap changers (OLTCs). By properly and dynamically selecting the right tap, LV customers can be shielded from possible voltage fluctuations taking place on the MV side, which is of paramount importance in scenarios with massive penetration of EVs and PV generation. Note that, typically, there is a time lapse between the peak production of PV generation (higher voltages) and the EV peak demand (lower voltages). Therefore, different taps (voltage ratios) are required throughout the day if the voltages must remain within regulatory limits [145], which is impossible to achieve with the existing off-load tap changers. Two OLTC

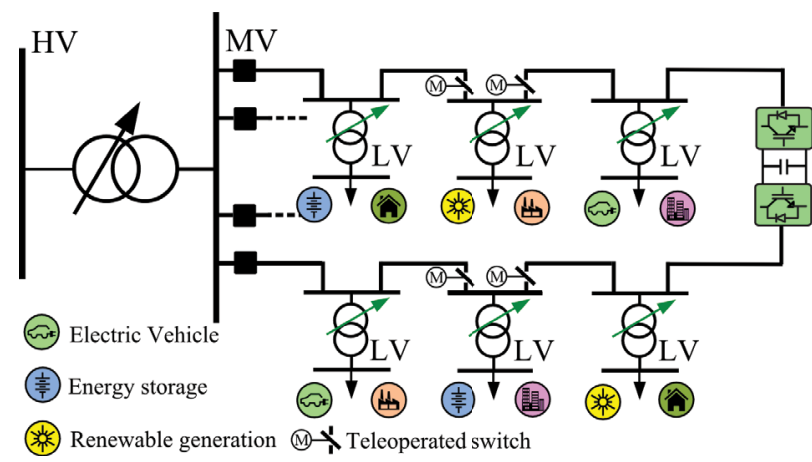

Fig. 12. Schematic layout of MV urban distribution feeders in the upcoming smart grid paradigm, showing additional agents and components. technologies are already available for MV/LV distribution transformers, based respectively on vacuum-type mechanical switches [146] and power electronic devices [147], each with its advantages and limitations.

2) Control Systems: Optimally operating the distribution systems of the future, particularly those in urban zones, with a plenty of distributed control resources (mostly based on power electronics interfaces) will involve a more sophisticated generation of ICTs, control centers, and software, replicating to a large extent the role and functionality of EMS for transmission systems. Above any other consideration, this requires that as many as possible secondary substations be equipped with a two-way communication channel, traditionally missing at these low levels. The added channel can send the information collected by local sensors, including fault-passage detectors and smart meters concentrators, but can be also used to remotely operate motor-assisted breakers and switches (see, for instance, Fig. 13, showing remotely operated rural and urban spots). However, while the number of transmission network assets, i.e., centralized generators and transmission substations, lies between $10^{2}$ and $10^{3}$ for a medium-size system (e.g., the Spanish one), the number of secondary distribution substations and customers is in the order of $10^{4}$ and $10^{6}$, respectively, which poses a huge investment challenge. For this reason, utilities can only afford to gradually and uniformly deploy these ICT and control infrastructures according to carefully designed investment plans, which take into account a series of performance indices (e.g., average duration of interruptions). The deployment strategy begins by upgrading a single secondary substation for each selected feeder, typically located at the midpoint, eventually extending the ICT infrastructure to other strategically located substations. This leads to the third major difference that can be noticed between Figs. 4 and 12: while secondary substations have traditionally been "black boxes" for the DMS operator, they will progressively become observable and controllable in the smart grid paradigm.

In addition to the investment problem, this upcoming environment also poses an extraordinary challenge
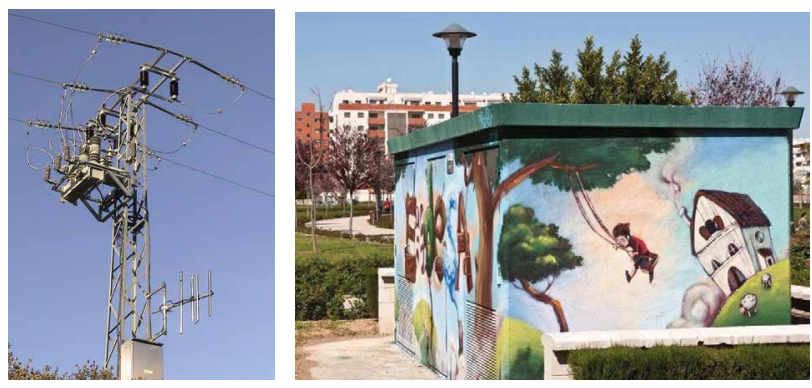

Fig. 13. Remotely operated $\mathrm{MV}$ breaker in a rural area (left) and fully controlled urban secondary substation in the Smartcity district of Málaga (right). The large antenna of the private communication channel is clearly visible on the left, while the inner small antenna for the $4 G$ public network cannot be seen on the right. 
for existing DMSs, traditionally designed to deal with the information received from a relatively low number of primary substations, including the head of MV feeders and the customer calls in case of outage. As discussed above for the EMS case, the conceptual design of future DMSs should be thoroughly revised to account for the boom of information and new actors arising in the smart grid era [129], [130]. Indeed, the traditional decision-making process, based on fully centralized DMSs, where all the raw information is regularly collected and processed, should be replaced by a more decentralized framework in which the intelligence is distributed to a large extent, as shown by the lower blocks in Fig. 11. In this context, a diversity of local information hubs, which can be generically termed local management systems (LMSs), with data processing and computing capability, will perform monitoring and control tasks under the supervision of the DMS. These include the SMS, when the IEC-61850 standard becomes the norm in distribution substations [133], [134], [148], the PPC of medium-size renewable facilities [149], typically connected at the MV level, or the LMS associated to prosumers, either individually, through the home management system (HMS) [150], [151], or via aggregators through building management systems (BMSs) [152], [154].

This plethora of distributed control systems should be endowed with suitable software tools, capable of providing in a coordinated and robust fashion the adequate control actions (setpoints) for those controllable resources within their area of influence. These can be conventional devices already deployed in the distribution system, such as DG with adjustable active and reactive power [155], [156], or the more futuristic solutions described above (dc links and OLTCs).

A powerful emerging notion is that of microgrids, which are essentially MV and/or LV subsystems capable of working autonomously, i.e., without necessarily being connected to an external supporting grid [157]. By definition, a microgrid must have DG and, eventually, energy storage capability, for which some kind of LMS is also needed. A future of networked microgrids is even envisioned by some experts [158], [159], locally managing the needs of the users and subordinated to the respective DMS.

One of the critical functions that will make the most of distribution automation infrastructures is the service restoration process that follows an outage. First, the fault location time can be drastically reduced with the help of fault passage indicators located at secondary substations. Second, the faulted zone can be isolated and the service restored much more quickly by using remotely operated switches, like those shown in Fig. 12. Eventually, distribution automation devices, duly supervised by a new generation of selflearning software (similar to that installed on autonomous cars) will lead to a self-healing distribution system capable of recovering from a faulted condition with minimum or no human intervention [160]-[162].

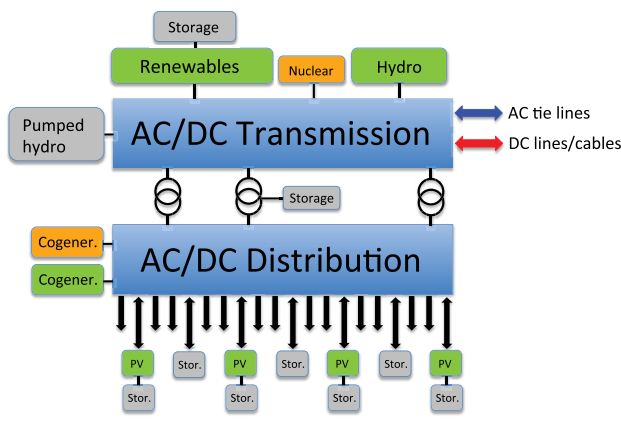

Fig. 14. Upcoming structure and relationships of power systems in the 21st century.

We end this section with Fig. 14, where the more complex structure and interactions arising in the smart grid paradigm are schematically presented, to be compared with the simpler scheme of Fig. 5. Note the ubiquitous presence of storage systems at all levels, the bidirectional flows involved in prosumers, and the seamless coexistence of ac and de grids.

In this upcoming paradigm it is crucial for smart grid technologies to be compatible with existing grid codes and operational procedures, in order to meet the current standards of secure and stable operation. Reciprocally, new technologies offer still unexplored possibilities to help future decarbonized systems to satisfy a new generation of grid codes, much more demanding than in the past. For instance, a PV plant equipped with suitable batteries can easily emulate a conventional synchronous generator, but it can go a step further: it may behave like a generator with time-varying electrical and mechanical parameters, which can be adaptively set in accordance with the actual grid conditions. From this perspective, smart grid technologies (mainly power electronics and ICTs), in addition to being compatible with existing grid codes, can drive or enable new ones. In fact, new grid codes are being developed in Europe [163], [164] and elsewhere, providing a set of common rules and technical requirements to be fulfilled by every agent connected to the power system (generator, demand, ac or dc asset, etc.). This way, the objective of decarbonizing the society through harmonization and standardization will be facilitated [165].

\section{REPRESENTATIVE PROJECTS IN SPAIN}

Owing to several geopolitical factors (very close to North Africa, privileged relationship with Latin American countries, etc.), Spain has been traditionally a major player in the energy arena. As far as the electric sector is concerned, Spain has pioneered a number of regulatory and industrial initiatives. In 1984, the Spanish government created Red Eléctrica de España (REE), which can be legitimately considered a predecessor of today's ISO/TSO companies, a 
decade ahead of the regulatory wave aimed at unbundling activities and promoting competition. Also on the positive side, for over a decade (1984-1996) the electric utilities were required to invest $0.3 \%$ of the electricity bill income on $\mathrm{R} \& \mathrm{D}$ projects, which helped many small engineering companies, vendors, and research groups to flourish. Perhaps the best exponent of those pioneering efforts is the Solar Platform in Almería [166], which surely explains why Spain is leading, along with the United States, in the concentrated solar power technology. Much more recently, in 2007, in a very early and faulty attempt to promote the penetration of renewables, Spain designed an ambitious feed-in tariff policy which has since been a continuous source of trouble and a case study for business school of what should never be done [167].

Regarding the scope of this paper (smart grids for smart cities), following the EU track, Spain created in 2007 the Technological Platform for Electrical Grids [168], and Barcelona hosted the first Smart City Expo \& World Congress in 2011, which has become the largest event in this sector, including sustainable energy delivery topics in urban environments (LED lighting, EVs, public transportation, DG, demand management, etc.).

Government funding agencies have partnered worldwide with industry, utilities, research centers, and local governments in technology development and demonstration projects dealing with smart grids [169], [171], and Spain has not been an exception. According to [168], since 2002 Spanish companies and research institutions have been involved in 116 smart grid projects supported by the EU, with a total investment of some 360 million. A plethora of nationally and locally funded projects should be added to those figures. So, trying to simply enumerate them all within the scope of this paper would be impossible. Table 4 collects a representative subset of projects that includes those reported in [170], along with the main funding source (EU, national or private) and the smart grid technologies addressed in each case.

Table 4 Sample of R\&D Projects Led by Spanish Entities and Utilities in the Last Decade, Along With the Smart Grid Technologies Tested or Demonstrated (EMS: Energy Management Systems; ICT: Information and Communication Technologies; DA: Distribution Automation; PE: Power Electronics; SA: Smart Power Assets)

\begin{tabular}{|l|c|c|c|c|c|c|c|}
\hline \multicolumn{1}{c|}{ Project } & Fund. & \multicolumn{1}{c|}{ Start. } & \multicolumn{5}{|c|}{ Smart grid technologies } \\
\cline { 4 - 8 } & Source & Year & EMS & ICT & DA & PE & SA \\
\hline SmartCity & Nat. & 2008 & $\checkmark$ & $\checkmark$ & $\checkmark$ & $\checkmark$ & \\
SmarTie & Nat. & 2008 & $\checkmark$ & & & $\checkmark$ & \\
VERDE & EU & 2009 & & $\checkmark$ & & $\checkmark$ & \\
CASCADA & Nat. & 2010 & & & & $\checkmark$ & \\
PRICE & Nat. & 2011 & $\checkmark$ & $\checkmark$ & $\checkmark$ & $\checkmark$ & \\
GREENeMOTION & EU & 2011 & & & & $\checkmark$ & \\
GRID4EU & EU & 2012 & $\checkmark$ & $\checkmark$ & $\checkmark$ & & \\
ZEM2ALL & EU & 2013 & & $\checkmark$ & & $\checkmark$ & \\
iGREENGRID & EU & 2013 & $\checkmark$ & & & $\checkmark$ & \\
IDE4L & EU & 2013 & $\checkmark$ & $\checkmark$ & $\checkmark$ & & \\
Dry Xformer & Priv. & 2014 & & & & & $\checkmark$ \\
GROWSMARTER & EU & 2015 & & $\checkmark$ & & $\checkmark$ & \\
UPGRID & EU & 2015 & & & $\checkmark$ & & \\
MONICA & Nat. & 2015 & $\checkmark$ & $\checkmark$ & & & \\
Cable DTR & Priv. & 2015 & $\checkmark$ & $\checkmark$ & & & $\checkmark$ \\
Gorona del Viento & Nat. & 2015 & $\checkmark$ & & & & $\checkmark$ \\
\hline
\end{tabular}

Some of those projects have already been thoroughly described elsewhere (e.g., [172] and [173]), but the reader is referred to the respective web page, which is always the main source of information for FP7 or H2020 European projects. In the sequel, about one half of the projects listed in Table 4 will be described with a certain level of detail (motivation and goals, technologies involved, and illustrative results). The selection has been made keeping in mind the specific scope of this paper (smart grids for urban environments), while at the same time trying to avoid overlaps.

\section{A. Dynamic Thermal Rating of Underground Transmission Cables}

The Spanish TSO (REE) has undertaken a pilot research project to gain experience in the possibility of optimizing the operation of underground cables, as described in the sequel.

1) Project Background: The foreseeable growth of demand, along with the difficulties of building new transmission infrastructures in urban environments, calls for a better use of the available ampacity in underground lines, eventually improving the O\&M procedures and reducing the associated costs.

According to [174], the average load of cable systems is relatively low (typically lower than $30 \%$ of the rated capacity). However, even though the risk of thermal overloading is rather low in steady-state, normal operating conditions, the situation may get much worse in case of N-1 outages, particularly when peak loading conditions are faced.

The International Standard IEC 60287 [175] defines the current carrying capacity of a conductor (ampacity) as the maximum continuous constant current that asymptotically heats the conductor insulation up to its maximum operating temperature (i.e., without causing overheating). For example, $90{ }^{\circ} \mathrm{C}$ for low-density degassed XLPE insulated cables.

As currently defined, though, the ampacity of underground lines is conservative since the large thermal inertia available is customarily neglected. Indeed, the temperature of a conductor that undergoes a load step may take up to years to reach the steady-state maximum operating temperature. Among the factors affecting both the steady state and the thermal transient, the burial depth, the ambient temperature, and the soil thermal properties stand out [176]. Note that the latter two change with time, which should be taken into account. For instance, the experience in the city of Barcelona shows that the thermal resistivity can easily change from $0.3 \mathrm{~m} \cdot \mathrm{K} / \mathrm{W}$ after a rainfall to $2.6 \mathrm{~m} \cdot \mathrm{K} / \mathrm{W}$ for dry soil, and the volumetric thermal capacity can range between 0.3 and $3.7 \mathrm{MJ} /\left(\mathrm{m}^{3} \cdot \mathrm{K}\right)$.

There are various strategies to duly consider the thermal inertia of underground cables, in order to estimate their dynamic ampacity for a few hours, days, or even months. For the case of cyclic loads, a first strategy is to 
calculate an increased ampacity either using a load factor, as in the seminal paper [177], or a cyclic rating factor as in IEC 60853 [178].

A second strategy is possible if soil parameters are known or assumed (from real measurements or from the same parameters used to calculate the conventional ampacity [175]). Given a load curve, the conductor temperature can be numerically calculated for several scenarios.

- For a load step, it is possible to calculate the time it takes to reach the maximum operating temperature from a previous load, which is useful in a contingency case.

- A representative cyclic load curve can be designed to bring the cable to its maximum operating temperature, which is a useful ampacity value for the base case.

- It is possible to combine the two previous alternatives, achieving a balance between the ampacity increase, both in base and contingency scenarios, and the operational security.

- Updating the temperature of the conductor with the real-time current, which provides a margin of reaction of hours in view of the slow evolution of the temperature. This strategy is being successfully applied to a few overhead lines in northern Spain, connecting wind farms to the subtransmission network.

A third strategy, with improved accuracy and flexibility, is to monitor in real time the temperature of the cable with a distributed temperature sensing (DTS) system and optical fiber (OF) embedded in the sheath or the jacket (Fig. 15). This kind of measurement is based on either the Raman or the Brillouin effects. DTS measurements allow the underground lines to be operated according to the actual evolution of the temperature, which is extremely slow (due to the inertia), providing more margin for reaction.

Another possibility for temperature monitoring, in cables without $\mathrm{OF}$, is to use a temperature probe in the jacket of limiting and accessible cable sections. This strategy is currently being implemented by REE in five $220-\mathrm{kV}$ and two 66-kV underground cables in service.

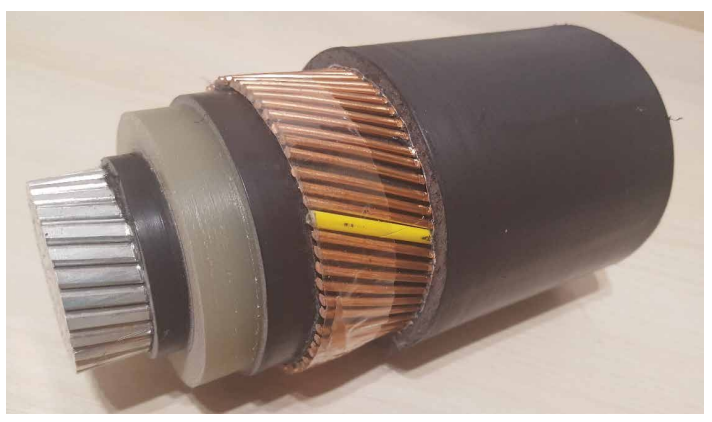

Fig. 15. A 66-kV insulated cable with optical fiber in the sheath (yellow).
2) Project Implementation: The pilot project is based on the use of the aforementioned DTS technology, complemented with the real-time estimation of three parameters external to the cable (ambient temperature, soil thermal resistivity, and soil volumetric thermal capacity). The estimated parameters allow the conductor temperature to be more accurately predicted for future load curves. This more sophisticated system is currently being developed and implemented in two operative underground lines, namely, a $220-\mathrm{kV}, 10-\mathrm{km}$ cable and two $66-\mathrm{kV}$ short cables, the goal being to make 48 -h predictions of conductor temperature with less than $3{ }^{\circ} \mathrm{C}$ error.

The DTS implemented in this project provides the average temperature for every meter of the OF, which is updated every 5 min. Both spatial and time steps are tunable.

Thermal models have been developed for the usual arrangements of underground cables using finite element models (FEMs) with COMSOL software (see Fig. 16). But these simulations require the knowledge of external parameters, i.e., ambient temperature $\left(T_{a}\right)$ and soil thermal parameters which are hard to know in real time. Kalman filtering is a major estimation technique that can be used for this purpose provided a set of state-variable equations are available. This can be obtained from a ladder-type dynamic model of the cable and the surrounding earth, as in [179] and [180], yielding the analytic model

$$
\dot{x}_{\theta}(t)=A x_{\theta}(t)+B u(t)
$$

together with a measurement equation

$$
y(t)=C x_{\theta}(t)
$$

where $x_{\theta}(t)$ is the vector with all the temperatures in the ladder-type model, including cable temperatures (conductor and sheath) and those of several concentric slices of the soil; $u(t)$ is the input vector, including the currents causing the heating and the ambient temperature; $A$ and

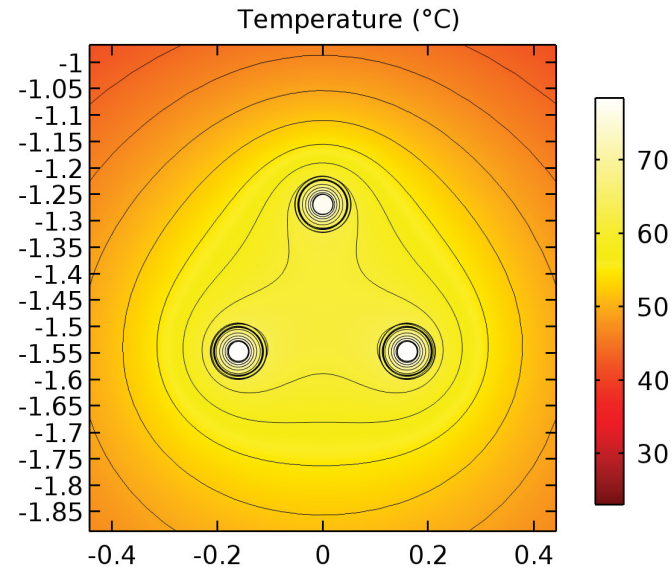

Fig. 16. Thermal simulation of underground cable with FEM (axes in meters). 
$B$ matrices depend on the geometry of the model, the soil thermal resistivity $\rho_{s}$, and the volumetric thermal capacity of the soil $c_{v}$; while $C$ relates the state and measurement vectors.

The results of the analytic model were compared with those provided by FEM (under different scenarios of current ambient temperature evolution, and soil thermal resistivity and volumetric thermal capacity), yielding errors below $3{ }^{\circ} \mathrm{C}$, as shown in Fig. 17 .

Kalman filtering provides the possibility of estimating the temperatures in the state vector $x_{\theta}$, even in the presence of measurement and model noises, but also, as stated before, the unknown parameters $p=\left[\rho_{s}, c_{v}, T_{a}\right]^{t}$ by using an augmented state vector $x=\left[x_{\theta}^{t}, p^{t}\right]^{t}$. With the help of this filtering technique, every time a DTS sample is available, the whole state vector is updated.

The accuracy of the Kalman-based estimates has been evaluated by comparing the cable temperature predictions provided by the state-variable analytic model, over a 48 -h sliding window of historic data, with the actual DTS measurements. The maximum prediction error for each window of data is taken as a metric of the overall method performance. Fig. 18 shows, for a section of a real cable buried to $1.68 \mathrm{~m}$, the prediction errors for the DTS temperature (sheath) over a year. Once the filter ends its initialization transient, the error is smaller than $1.4^{\circ} \mathrm{C}$, except in those periods in which the load reaches $65 \%$ of its ampacity, when the error reaches $2 \%$.

Future efforts will extend this tool to larger currents and to several 132 - and $220-\mathrm{kV}$ circuits, including cables inside galleries and an overhead-underground transition tower.

The main innovations worth remarking in this research project are the simultaneous, real-time estimation of the external parameters arising in the thermal cable models, as well as their use in tools that seek to improve the operation of underground cables.

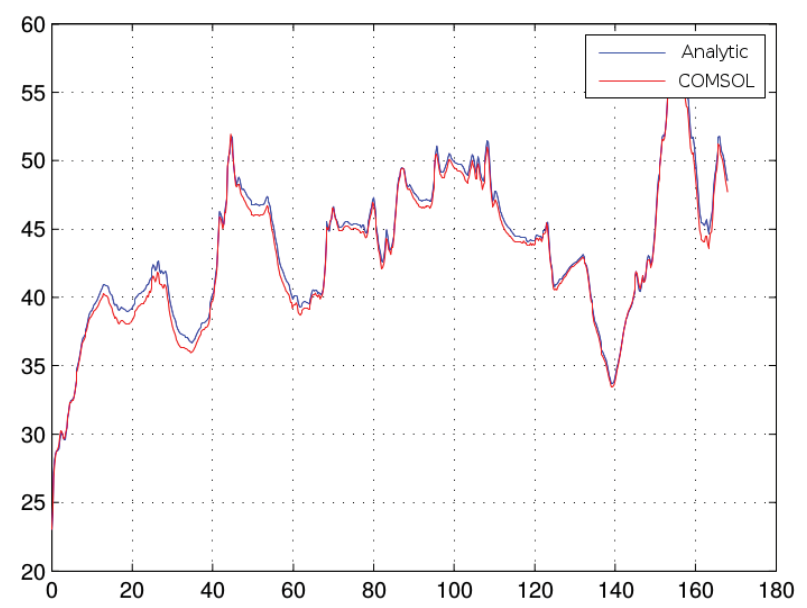

Fig. 17. Comparison of analytic versus FEM simulation (temperature in degrees Celsius and time hours).

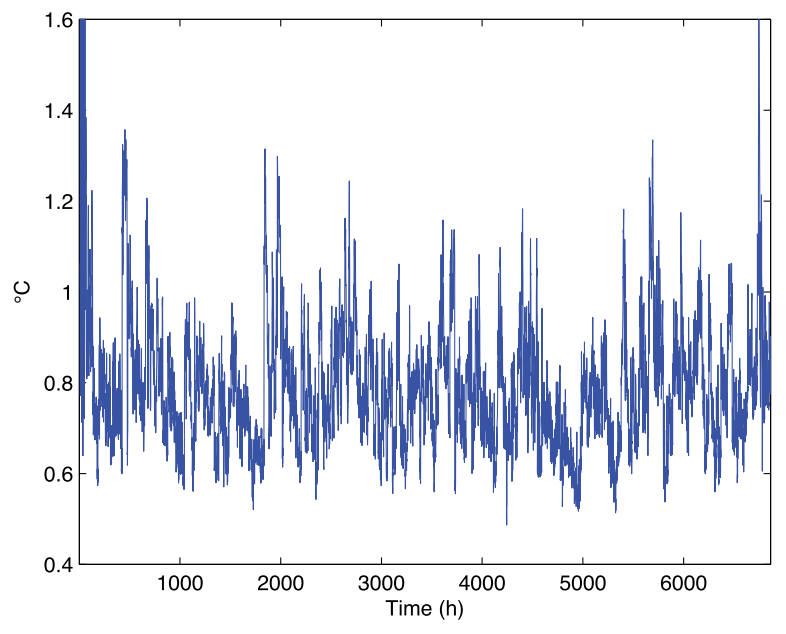

Fig. 18. Maximum absolute error between predicted temperature and DTS temperature (sheath) for one year.

\section{B. Optimal Utilization of Urban Assets: Removing Distribution Feeder Constraints}

As discussed in Section III-E, the performance of future distribution feeders can be significantly improved by introducing two power electronics technologies for controlling the power flows and the bus voltages, namely, dc links and OLTCs for MV/LV transformers. This section will provide a brief account of two pilot projects, one for each tested technology, both supported by well-established, private-public funding schemes.

The objectives of the project Smartie (Smart Tie) were threefold: 1) to assess different converter topologies (backto-back VSC, ac/ac matrix converter, UPFC, etc.) for this particular application (power flow control of MV or LV feeders) and choose the most suitable one; 2 ) to evaluate the impact of dc links on the operation of distribution systems; and 3) to develop and build a dc-link prototype to show that the technology is mature and reliable enough to be deployed in actual networks.

Regarding the second objective, three complementary operational goals were considered: 1) to increase the EV and DG hosting capacity of urban distribution systems [181]-[183]; 2) to maximize the use of existing network assets (minimize congestions) by duly equalizing the loads of neighbor feeders, possibly deferring new investments in grid reinforcement; and 3) to reduce the power losses [184], [185].

A multiobjective optimization framework was developed in which the control variables are selected in accordance with the pursued objective while all network constraints are taken into account [184]. The optimization engine allows arbitrary scenarios, involving combinations of rural, suburban, and urban networks, with or without DG, to be tested [186]. The following conclusions are worth reporting. 
- The benefits attained from the use of dc links are more significant when the interconnected feeders supply different types of load/generation, e.g., commercial or residential customers, owing to the complementary nature of the daily load profiles. This is frequently the case of suburban areas, where a diversity of residential and industrial customers, as well as PV plants, are fed from the same primary substation. As an example, Fig. 19 compares the DG hosting capacity of the MV benchmark network proposed by the CIGRE TF C06.04.02, with and without a dc link between the two main feeders [186]. Note the significant increase of the active power injected by PV and wind power plants, owing to the power flow and voltage control capability provided by the dc link. Higher penetration levels, particularly at midday hours, would be achieved at extra cost by installing a dc link with higher rated power. Similar results have been obtained for real distribution systems [187].

- The operation mode of the dc link is quite different for rural and urban distribution networks. In the former case (longer feeders), voltage violations are more frequently encountered, for which reactive power injections are most effective. In urban feeders, though, ampacity problems are more likely, typically requiring active power flow shifts between the interconnected feeders. This may be determinant when selecting the most suitable and cost-effective power converter topology, which is not necessarily the conventional back-to-back configuration [188].

- A straightforward cost-benefit analysis reveals that the required investment in the dc link is a profitable choice for DG owners, when network constraints limit the hosting capacity of the radial system [184], [186].

During the project, a 500-kVA back-to-back, VSC-based dc link prototype was built and tested in an MV lab environment (Fig. 20). The performance of the dc link matched those of simulated scenarios, both in steady state and transient conditions.

A static OLTC for MV/LV transformers has been also developed in the course of the projects CASCADA and CATEST (supported by national and local funding sources,

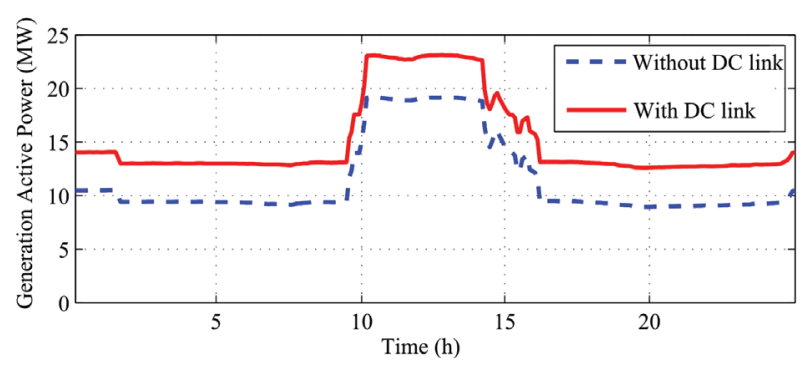

Fig. 19. DG hosting capacity of the CIGRE benchmark distribution system with and without a dc link.

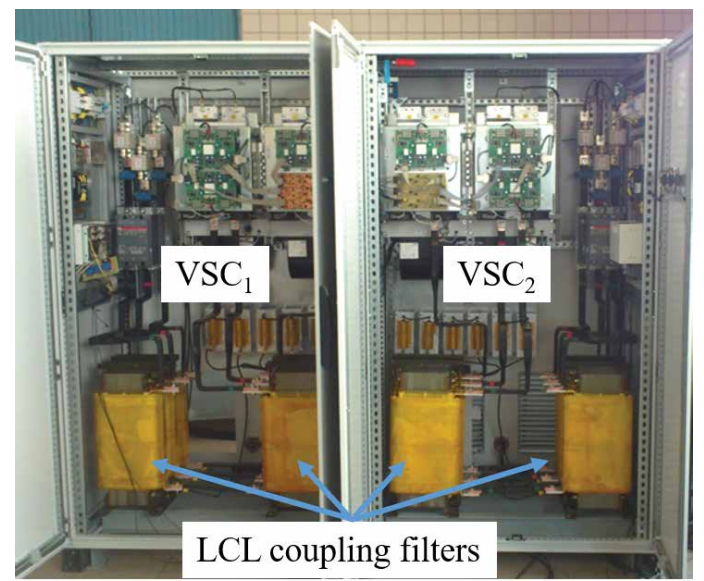

Fig. 20. A 500-kVA Smartie prototype tested in the MV lab of the University of Sevilla.

respectively). The objective is to design from scratch, build, and test a thyristor-based tap changer to safely replace the mechanical taps of conventional, three-phase $20 \pm 2.5 \% \pm$ $5 \% / 0.4 \mathrm{kV}$ European distribution transformers, with rated powers in the range $250-1000 \mathrm{kVA}$. The industrial version of the OLTC, shown in Fig. 21, has been successfully tested with dry and oil insulated transformers. Fig. 21 also shows the LV rms values arising during a full-load test, where the discrete voltage steps are clearly visible, in accordance with the selected tap.

\section{Smart Urban Substations: Dry Transformers for Urban Cores}

Having a modern and extensive communication layer is a necessary but not sufficient condition for a grid to be

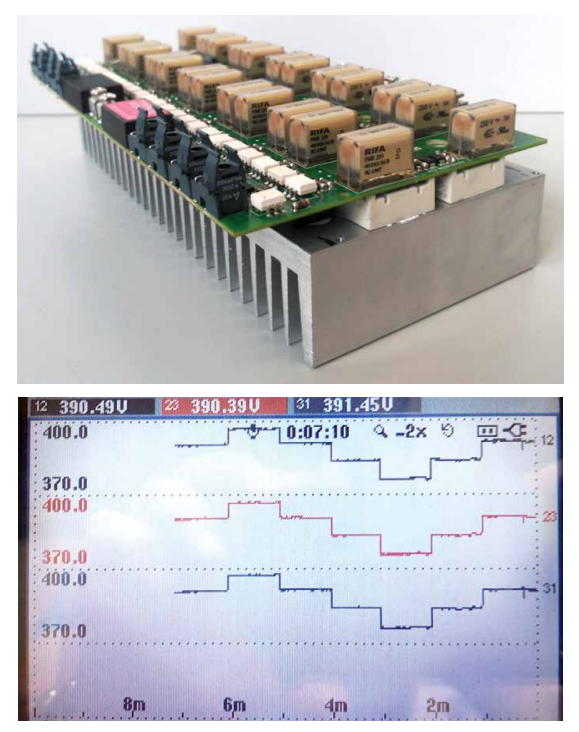

Fig. 21. Electronically assisted OLTC (top) and LV rms values during a test in which all taps are sequentially selected (bottom). 
called "smart." In addition, particularly in urban areas, a smart grid must be safe for the citizens and their properties, aesthetic, and respectful with the environment.

One of the main hurdles for network planners to overcome in urban zones is the lack of space in densely populated cores, particularly in the old districts of historic European cities. Indeed, it is not uncommon to find primary distribution substations located back to back with adjacent condominium blocks. This problem will be aggravated in the future with the introduction of electro-mobility and selfproducing DG. Another relevant barrier to elude is the wellknown "not in my backyard" syndrome, which frequently explains the lengthy permission and licensing process associated to new infrastructure developments in urban areas.

In this context, it is clear that repowering and upgrading existing assets will be preferable to new deployments occupying alternative sites, and that more efficient and less hazardous technologies will be the right choice, even if they are more expensive. The customary planning goals, namely reducing losses and maximizing asset utilization, will increasingly compete with the need to reduce the required ground-floor space while at the same time keeping the required safety levels.

Traditionally, despite the nonnegligible fire risk, primary distribution substations in urban environments have been equipped with conventional, oil-cooled transformers, ranging in size from 10 to 40 MVA. Accordingly, local fire regulations require that urban indoor substations, especially those located in buildings with public attendance, be protected with expensive antifire systems.

In the search for alternative solutions, Endesa Distribución undertook a few years ago a pioneering plan for upgrading critically located urban substations with dry-type transformers. So far, two urban substations in the historic district of Seville have undergone the replacement of their old, oil-cooled transformers by unique 34-MVA, $66 / 20-\mathrm{kV}$ air-cooled machines, equipped also with drytype, on-load tap changers [189]. Fig. 22 shows one of the

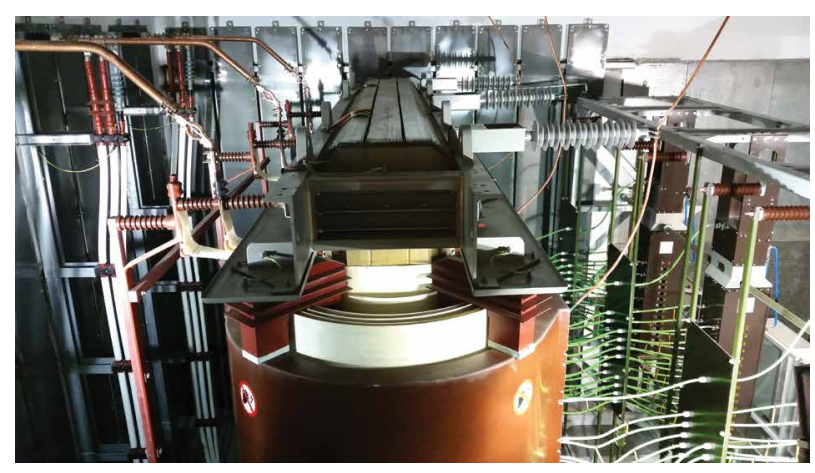

Fig. 22. Top view of a 72.5-kV, 34-MVA dry transformer located in downtown Seville. The separate on-load tap changer using vacuum switches is located on the right while the steel sheets intended to mitigate the magnetic field can be seen vertically arranged on the walls. new transformers, so far the largest in their class, working on site.

Note that dry transformers, ranging typically in size from 400 to $1600 \mathrm{kVA}$, are not uncommon at urban secondary substations, but larger sizes have not enjoyed such a widespread industrial deployment, owing to several design and installation challenges, higher initial investment, and lack of experience.

Actually, the whole upgraded substations have become oil free, as existing oil breakers were substituted by SF6 insulated ones while auxiliary service transformers were also replaced by dry-type counterparts, eliminating in this way any related risk for the neighborhood. Dry-type transformer technology was chosen among other possible alternatives, such as SF6 insulated transformers or high flash point dielectric fluids [190], owing mainly to two reasons.

- Dry transformers do not use inflammable liquids and the fire load per unit mass, around $2.5 \mathrm{MJ} / \mathrm{kg}$, is less than a fifth of that in equivalent oil transformers.

- Dry transformers are cost effective, as the higher initial costs are compensated in the long run with savings in fire-fighting systems, oil pit, and lower losses.

The new devices offer exactly the same functionality as oil-immersed transformers, including the customary onload tap changer for voltage regulation on the high-voltage windings $( \pm 8 \times 1.25 \%)$. Unlike in conventional transformers, the three vacuum-type tap changers are mounted separately, leading to larger space requirements (about 50\% more footprint than an oil-type transformer). This leaves a significant room for improvement. From the resiliency perspective, the ability to withstand short circuits was one of the first concerns to be addressed, for which successful homologation tests were carried out [191].

Owing to the lack of previous experience worldwide, this endeavor was faced as a true research and development project. The following main challenges were successfully addressed.

1) Arcing Phenomena Due to Inrush Current: During the first onsite energizations of the first deployed transformer, important sparks were observed on its structural elements and the surrounding fence. These were due to the voltages induced in the external metallic elements by the magnetic leakage flux transiently created by the inrush current (up to six times higher than rated value) and core saturation.

To avoid the sparks, a first batch of modifications was tried onsite, consisting of shorting the gaps of the "dummy" coils with copper bridges to give a low-impedance path to the induced currents. In view of the positive experience, it was decided that those remedies should be better implemented in factory. In addition, the grounding system had to be more carefully designed and coordinated.

Another successfully tested alternative was to reduce as much as possible the inrush currents by resorting to synchronized switching. This is achieved with the help of 
more sophisticated and more expensive relays, capable of memorizing the state of the protected component after the last disconnection (residual flux, trapped charge, etc.) and determining the right switching instant to minimize or even prevent transients [192].

The experience gained during those early commissioning tests will be valuable in the future, particularly for the weaker systems of the Spanish islands, where some transient stability problems have been experienced due to inrush currents of large transformers.

2) Limitation of EMI/EMC Effects: Lacking the natural shield provided by the oil tank, dry-type transformers create different and less attenuated $50-\mathrm{Hz}$ magnetic field patterns in their surroundings, which calls for specific and detailed studies aimed at designing suitable solutions so that legal limits are enforced.

Several computer simulations, factory experiments, and field measurements were carried out to determine the optimal design and shielding material. The chosen design consists of several layers of magnetic sheet arranged as rectangular frames, installed on the perimeter building walls (see Fig. 22). This was sufficient to limit the magnetic field in the vicinity of the substation, where people can transit, to the required $100 \mu \mathrm{T}$ (the regulation allows for higher levels in the interior of substations).

3) Attenuation of Acoustic Noise: Noise levels produced by dry-type transformers are above typical values of those generated by oil-immersed transformers, also due to the lack of the acoustic insulation provided by the oil tank. This fact has to be carefully taken into account in the design of the building and associated equipment, such as the air conditioning system, which is very important in cities like Seville where $40^{\circ} \mathrm{C}$ are frequently exceeded in summer. In order to fulfill the noise level limits imposed by local regulations in urban areas, strategically located acoustic screens, certified by third-party measurements, were installed on the surrounding walls.

4) Assessment of Actual Rated Power: As the commissioned units were the first of their kind, it was decided to carry out specific laboratory heating tests to determine the real nameplate power rating of the transformers. The tests showed that the nameplate power could be safely increased from the initially expected 31.5 to 34 MVA (10\% increase), with full warranties from the manufacturer.

Current efforts are aimed at extending this technology to higher voltage levels (123- and $145-\mathrm{kV}$ voltage class), allowing dry transformers to enter new niche markets [193].

\section{Smartcity District in Málaga: a True Living Lab}

With a population of over 550000 , Málaga is the sixth largest city in Spain and the capital of the Costa del Sol major touristic hub, one of the most popular in Europe. Squeezed between the coastline and the mountains, the metropolitan area stretches mostly along a narrow strip. The city, one of the oldest in the world, saw a rather chaotic growth in the 1960s and suffered a second real estate bubble during the last decade, even more acute than in the rest of the country. As a consequence, the city features a chronic deficit of infrastructures, which has been addressed in the last years with more ambitious investments in highways, university campus, public transportation (partly underground tram), airport and seaport expansions, etc. [194].

In this modernization context, the so-called Smartcity initiative was launched in 2008, aimed at being one of the largest real-scale demonstrations of new technologies and best practices in the field of smart grids, in response to the energy and environmental requirements mandated by the EU 2020 policy [195]. With an initial budget of over 30 million, partly funded by CDTI (Ministry of Industry), Junta de Andalucía (local government), and Málaga Council, a consortium of 11 engineering \& ICT companies and vendors, along with 14 research institutions, was created under the leadership of the distribution company Endesa.

In addition to the customary limitations of urban distribution systems discussed in Section II-C (unidirectional system, no real-time information, and centralized control), Endesa was then facing specific problems typically associated with periods of economic effervescence, such as steadily increasing energy demands and high peak loads for only a few hours a year. In addition, an ill-designed and naive energy policy, providing uncapped and very generous feedin tariffs, had led to a speculative PV bubble, which brought about an exponential growth of DG for two or three years, connected to both MV and LV networks. Last but not least, the imminent massive deployment of EVs, particularly relevant in touristic areas, was another factor worth considering. As discussed in Section III-E, both DG and EVs lead to much higher simultaneity coefficients than conventional passive customers. Therefore, from the traditional planning perspective, this state of affairs called for costly investments in urban grid expansion, frequently characterized by lengthy license granting processes.

Instead, taking advantage of the undergoing regeneration of a $4-\mathrm{km}^{2}$ coastal zone in the western district known as La Misericordia, the Smartcity project adopted the philosophy of smart grids to deploy a fully interconnected network, where the control center can interact through bidirectional channels with secondary substations, customers, and DG. This was considered the only way to achieve an efficient, sustainable, and self-healing grid, in which the load curve can be flattened by shaving peaks and filling valleys with the help of DG resources, storage, flexible demand, or vehicleto-grid (V2G) technology [196], [197].

The Smartcity project, a true urban living lab, involves a population of 50000 inhabitants (roughly one tenth of Málaga city), including 12000 residential customers, 300 industries, and 900 service customers. Fig. 23 shows the 


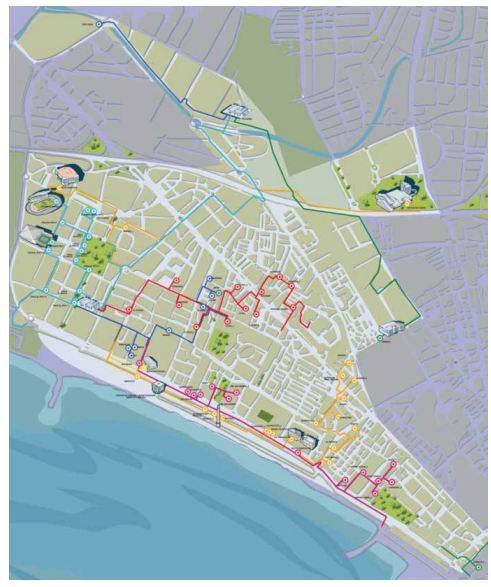

Fig. 23. Geographical scope of Smartcity project in the western coastal area of Málaga. The layout of the five $M V$ feeders and the location of secondary substations are also shown.

geographical scope of Smartcity, along with the layout of the five MV feeders and the location of secondary substations.

The following guiding principles and supporting technologies were considered when defining the Smartcity framework and goals:

1) harnessing the best existing experience and equipment, and employing them as a starting point for the development and implementation of functionalities not yet available in the market;

2) intelligent connection: "plug it smart" integration rather than simply "connection" should be one of the added values of the project;

3) automation of the MV and LV grid and deployment of communication (broadband PLC network) and advanced metering infrastructure (AMI) for realtime monitoring and control;

4) integration of renewable generation and storage into the MV and LV grids, by developing supervision and control techniques for the optimal use of the natural resources;

5) demand side management for residential, small- and medium-sized companies, public lighting, and public buildings with energy-efficiency facilities;

6) deployment of an electric vehicle fleet and charging posts, and validation of V2G charging technology [198].

The most relevant figures behind Smartcity are as follows:

- 12200 smart meters (11000 households, 1200 industrial/service clients);

- 72 secondary substations connected to smart meters by PLC (20 of them fully automated), with a total MV feeder length of $40 \mathrm{~km}$;

- $13 \mathrm{MW}$ of MV generation and $110 \mathrm{~kW}$ of LV generation;

- $106 \mathrm{kWh}$ of MV storage and $110 \mathrm{kWh}$ of LV storage;
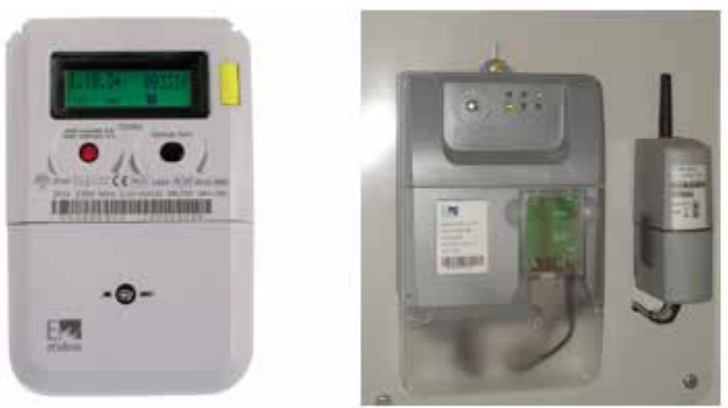

Fig. 24. Smart meter and concentrator installed in Smartcity Málaga (courtesy of Endesa).

- three public buildings, eight small- and medium-sized companies, and 50 residential users equipped with energy-efficiency systems;

- efficient public lighting: 79 streetlights upgraded to LED and halide technologies (60 equipped with point-to-point consumption control and 19 equipped with solar and wind renewable generation) and 139 streetlights equipped with group segment consumption control;

- a control center, featuring also the role of showroom, from which everything can be remotely supervised.

In the sequel, each major subsystem of the Smartcity complex project will be succinctly described.

1) Smart Metering: The massive deployment of smart meters in Spain started in 2010 in the Smartcity district of Málaga (12200 smart meters). Since then, the meters have been managed automatically and the system is completely integrated into Endesa Distribución's commercial and technical systems.

The smart metering system deployed in Smartcity is an upgraded version of the well-proven technology developed by Enel, which is already operating for over 35 million customers (see Fig. 24). The smart meters and concentrators communicate with each other through the electricity grid by PLC, based on the open protocol Meters \& More. In turn, the communication between the concentrators and Endesa IT systems is also based on this safe and reliable protocol, ensuring privacy and security for the flow of information [199]-[201].

This AMI system provides important improvements in the relationship between the user and the utility. The main functions that can be carried out remotely include connections, disconnections, cutoffs, reconnections, power quality monitoring, and advanced tariff schedules allowing more flexible invoicing. This can be done almost immediately without the need for the users or the company staff intervention. In addition to hourly energy consumptions, the AMI system yields other valuable information at the control center, such as active and reactive powers (see Fig. 25), making it possible to identify consumption habits and to 


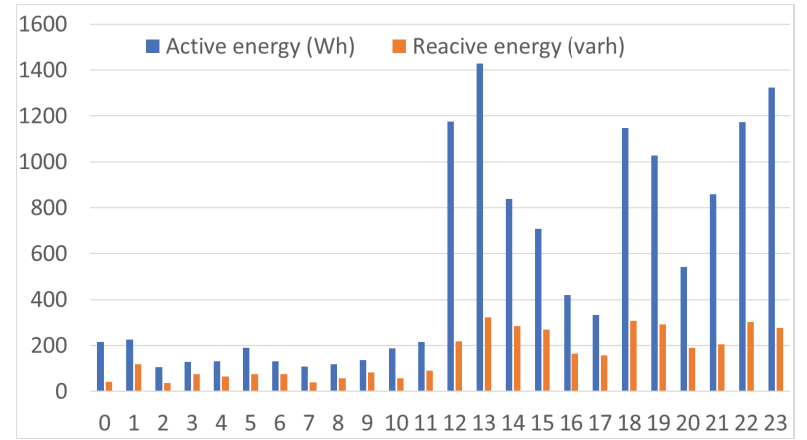

Fig. 25. Sampling curves showing hourly consumption of active and reactive energy.

consider possible ways of increasing the energy efficiency, both at the customer and grid levels.

Last but not least, the AMI can provide reliable and timely information on the state and behavior of the grid, thus improving the operational decision making, and improving the efficiency and quality of service for the whole system. The reader is referred to in Section IV-F, where the add-on Monica project is described.

2) Communications: After a preliminary analysis of the state of the art, it became clear that no single technology would fulfill the requirements of the Smartcity communication infrastructure. To optimize the network in terms of cost, capacity, and performance, different technologies were integrated into a redundant architecture ensuring sufficient reliability levels. This way, in case of failure, saturation of the communication channels, or any other event, the integrity of data and control actions on critical devices is guaranteed. These include both broadband and narrowband PLC, Worldwide Interoperability for Microwave Access (WiMAX), and the public telephone network (3G/4G).

The adopted decentralized architecture is shown in Fig. 26. The control center of the DSO communicates with a set of local intelligent devices called iNodes. These units, capable of acting autonomously if so decided, are responsible for executing the algorithms and procedures eventually defined in the project, such as those related to distribution automation (self-healing). According to the decentralization philosophy, two hierarchical levels have been established for iNodes, located respectively at the primary and secondary substations.

In turn, iNodes can interact with any element connected to the grid (load, generation, and storage) through iSockets, which follow the commands and directives of the upstream iNodes and report all the local information to the upper level for the correct operation of the system.

Digital protection devices (IEDs), hierarchically distributed on the different levels of the electrical network, are also linked with iNodes. They can gather electrical data (for example, active and reactive powers flowing at secondary substations or voltage sensors in low voltage lines) and

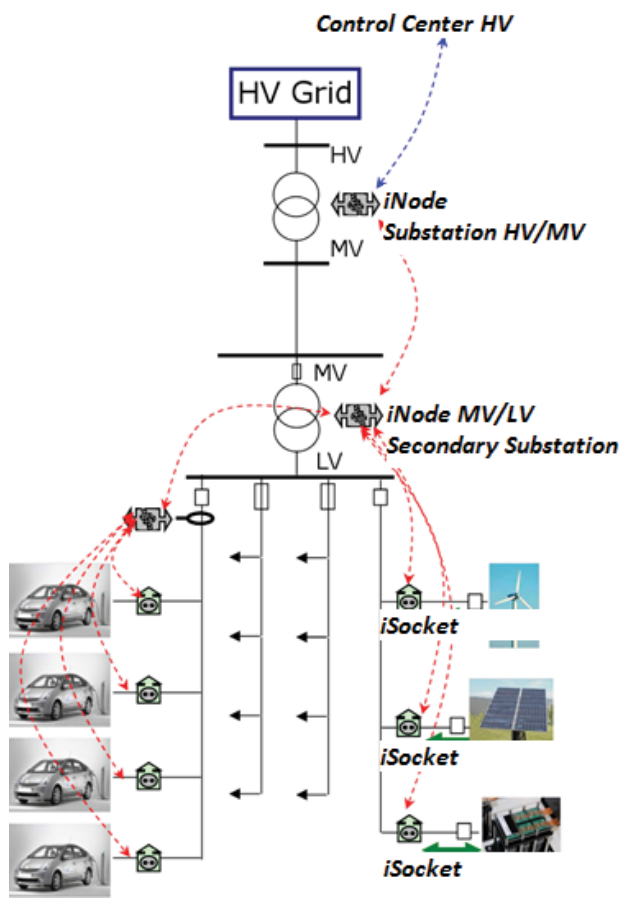

Fig. 26. Decentralized control architecture adopted in Smartcity based on local intelligent devices (iNodes, isockets).

receive and execute external orders, but local decision making is also possible according to predefined strategies to achieve a truly decentralized operation of the network. This distributed intelligence facilitates the management of the complex and multidirectional flows of energy and information, while at the same time faithfully respecting the decisions set by the operators of the control center.

While the communication of the iSockets with the power converters of DG and storage is based on a proprietary protocol, the standard IEC 61850 has been adopted for the communication between each iNode and the subordinated iSockets [202]-[205]. Details of the communication network topology, based on a hierarchy of three rings, are out of the scope of this paper, but can be found in [206]-[210].

A key component for the success of the PLC-based communication is the coupling device, allowing the PLC signal to be injected into the MV conductors (see Fig. 27).

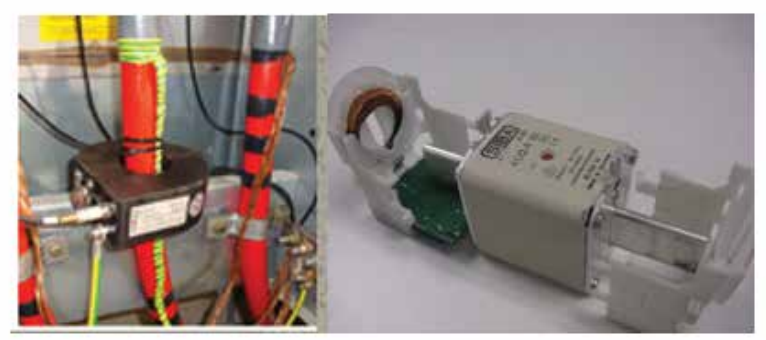

Fig. 27. Coupling system for PLC communication (left) and LV current sensor (right). 


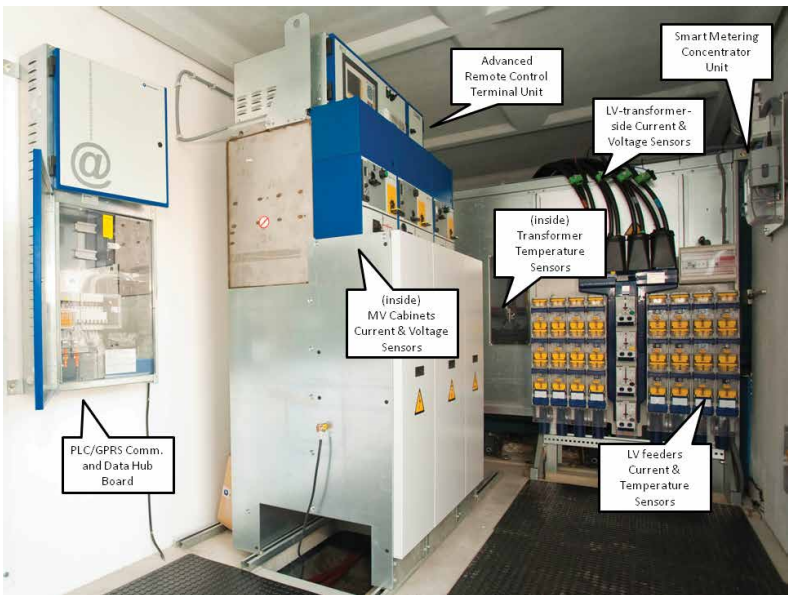

Fig. 28. Secondary substation with advanced MV/LV automation systems.

Both inductive and capacitive coupling systems have been installed in SF6 and vacuum circuit breaker cabins.

3) Distribution Automation: Twenty, out of 72, strategically located secondary substations have been fully equipped with monitoring devices, such as power and voltage sensors (at both MV and LV levels) or fault passage detectors, but also with remote terminal units allowing full control of the switching devices (see the pictures shown in Figs. 27 and 28).

In case of faults with service interruption, the faulted zone can be quickly identified and isolated. Then, the service is restored to downstream customers from neighbor feeders by closing the most suitable switch. So far, the whole process is performed under the remote supervision of the DMS operator, without intervention of maintenance teams, but more sophisticated and fully automated self-healing procedures for service restoration can be implemented in the future.

4) Distributed Generation and Storage: The following DG resources have been deployed within Smartcity Málaga:

- 10-MW cogeneration plant, located in the Urban Waste Water Treatment Plant (Guadalhorce river);

- 2.74-MW natural gas trigeneration plant, located in the Provincial Council building;

- several PV installations (over $300 \mathrm{~kW}$ ), located on the Trade Fair rooftop and other public buildings;

- $10 \mathrm{~kW}$ of wind generation, integrated in an LV microgrid aimed at testing different solutions for smart public lighting;

- three storage facilities using batteries (106, 72, and $38 \mathrm{kWh}$, respectively).

The LV microgrid runs along the seafront promenade of La Misericordia beach, and comprises the following controllable resources (see Fig. 29):

- ten PV-assisted streetlamps, each with $95 \mathrm{~W}$;
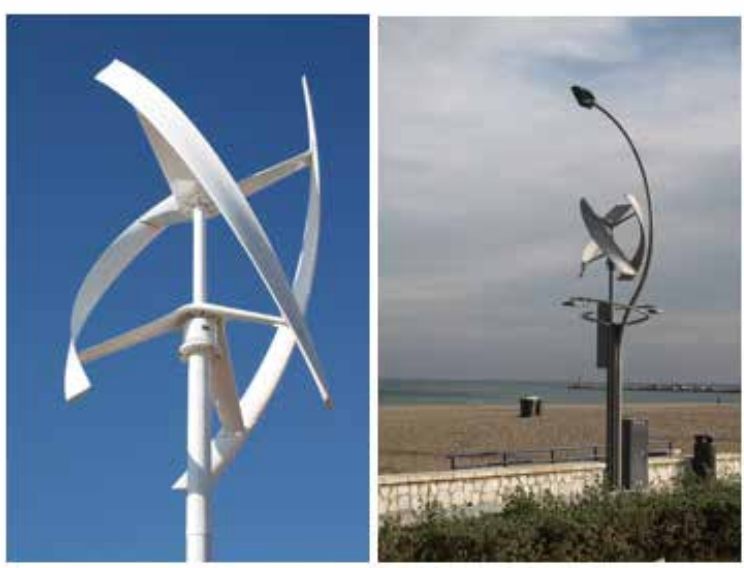

Fig. 29. A 4-kW isolated wind turbine, model UGE-4K (left); and 680-W mini wind turbine combined with a streetlamp, model UGE-600 (right).

- nine streetlamps equipped with 680-W wind generators;

- isolated 4-kW, vertical axis wind turbine;

- 24-kWh storage system;

- EV charging point with V2G function [211].

Among the storage facilities, the one connected to the MV level at the Málaga Congress Center stands out. It consists of 60 highly efficient Li-ion modules, altogether storing up to $106 \mathrm{kWh}$, which can be delivered at rated current to the grid in an hour.

5) Energy Efficiency and Demand Management: The active demand management system (ADMS) implemented in Smartcity pivots around two complementary subsystems, namely ADMS Energy and ADMS Power, aimed at reducing the net daily energy and maximum peak power, respectively. This involves the coordinated action of four main parties.

- Aggregator or energy services company: This can act as a purchasing agent on behalf of customers with multiple locations. It sends dynamic price signals to customers, duly considering temporary network constraints, and interacts with retailers.

- Distributor: In the smart grid context, distribution utilities are expected to play the "distribution system operator" role [212], [213], for which a set of network codes should be developed to properly operate active distribution networks, much like the TSOs have been doing in the past decades. Depending on the grid operating conditions, it can send requests for short- or long-term power reductions by area in order to maximize the social welfare.

- Retailer: This is the company in charge of selling energy to regular customers, at an agreed hourly price and boundary conditions. 
- Customers: Active customers are expected to manage their energy consumption based on the information provided by the other agents.

In the Smartcity case, the ADMS considers two different possibilities for controlling the energy consumed by the customers: 1) each retailer sends price signals to its customers for each period; and 2) the DSO directly asks DG, EVs, and qualified customers for energy reductions in case of operational needs.

6) Sampling Preliminary Results: The control center in charge of Smartcity has real-time information of what is going on in the grid and full control of the DG, energy storage, and flexible consumption. Whenever possible, the energy demand is satisfied by local renewable generation. On the other hand, the LV storage is used in the reduction of street lighting demand, while the MV storage contributes to midday and evening peaks shaving. The V2G technology can also give the system some support during peaks, especially in the evening (see more details in Section IV-E). In a nutshell, Smartcity allows the local energy generation to be maximized, the EVs to be charged according to the available energy, and the consumption patterns of customers to be analyzed in order to anticipate their needs and possible network impacts.

Bringing the generation closer to consumers enables a better use of the existing distribution assets and contributes to a reduction of energy losses. Fig. 30 provides daily and monthly averages of renewable energy penetration, in percentage with respect to the overall related consumption, between October 2012 and January 2013. The graph shows that, despite the daily fluctuations of renewable energy production, more acute in winter, the monthly average penetration approached $15 \%$.

When the Smartcity project was launched, the expected target in the reduction of $\mathrm{CO}_{2}$ emissions was $20 \%$, in accordance with the EU 2020 goals, which translates roughly into 6000 ton/year of $\mathrm{CO}_{2}$ only in the geographical scope of the project. As shown in Fig. 31 for the same period of time, the average monthly savings consistently remained at around $15 \%$. This reduction in $\mathrm{CO}_{2}$ emissions essentially comes from the savings achieved in public lighting consumption, customers with higher contracted power, the use of electric

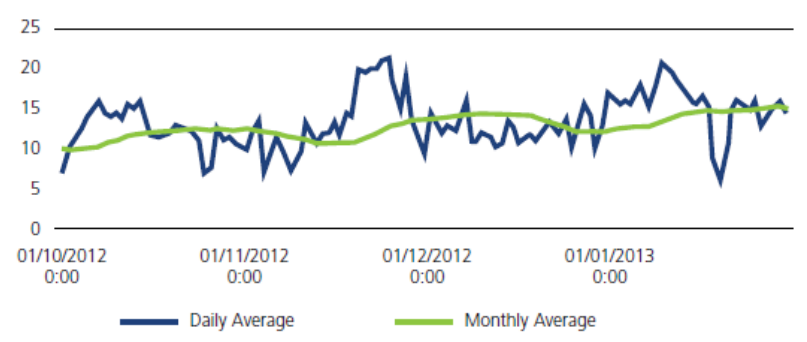

Fig. 30. Percentage of local renewable generation versus overall energy consumption in the area as a result of Smartcity project.

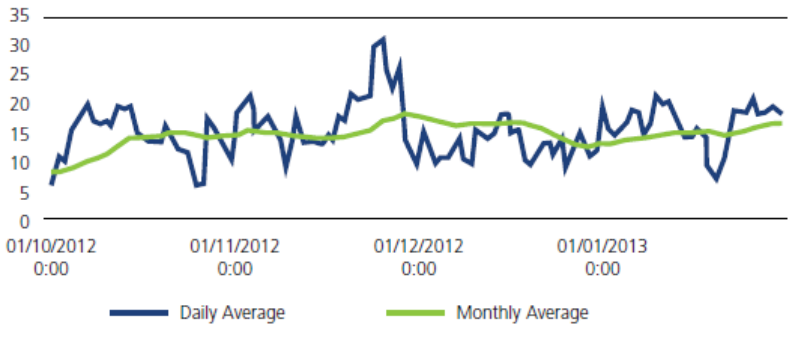

Fig. 31. Percentage of reduction in $\mathrm{CO}_{2}$ emissions in the area as a result of Smartcity project.

vehicles, and the production of renewable generators, but also from the reduction of distribution system losses.

Another performance index worth registering refers to the energy saving achieved through the energy-efficiency initiatives promoted in the project, altogether aimed at better using the available resources, reducing losses, and providing end users with different technologies and tools helping them to more efficiently consume energy. Fig. 32 shows, again for the same period and the same averaging intervals, how the improvement in energy efficiency developed over time.

In this case, the monthly average values keep above $25 \%$ almost all the time. This energy-efficiency improvement stems from the following:

- the efficiency gain of the distribution system, which undergoes a global reduction of the energy demand in the area, due primarily to the high availability of the cogeneration plant, a flatter demand curve, and a reduction of losses at all voltage levels;

- increased efficiency in the energy consumption, which includes all the local actions developed within the project: reduction in the consumption of public lighting, reduction in the consumption of large customers, each with its own peculiarities, increase in the use of renewable sources through storage systems and V2G technology, and enhanced network monitoring and data processing capability compared to the past.

As far as ADMS is concerned, in view of current regulatory limitations, only a hotel, a hospital, and several large consumers connected to the MV grid were initially included

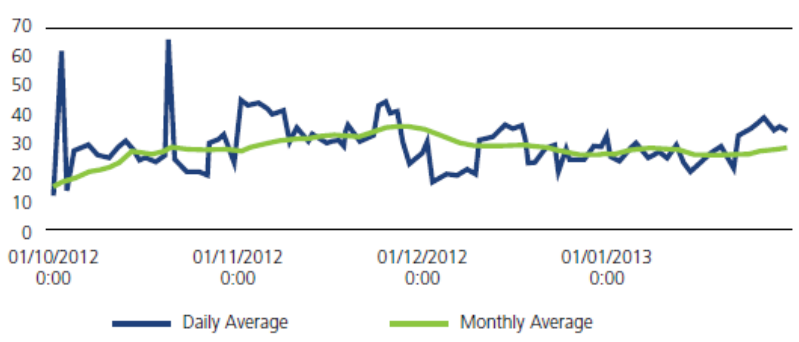

Fig. 32. Percentage of reduction in energy consumption in the area as a result of the Smartcity project. 
in a fleeting pilot experience, where the controllable elements were basically air conditioning and ventilation systems. The customers were able to define a temperature comfort interval, while the DSO controlled the real-time consumption keeping in mind both the electricity prices and the network constraints. Overall, approximately 10\% of the total energy demand could be flexibly managed (i.e., shifted in time) by the DSO, somewhat mimicking the interruptibility service provided by large customers connected to the HV level [214].

The Smartcity project in Málaga immediately attracted synergetic funds for other national and international projects, mostly related with electric mobility but also with energy efficiency and advanced monitoring of distribution grids. Owing to space limitations, only the Zem2all and Monica projects will be briefly described in the sequel (the interested reader can find more details of Zem2all in [215]).

\section{E. Monitoring and Supervision of EV Charging Spots}

Launched in 2012, Zem2all is a consortium of six major Spanish and Japanese companies, supported by the Málaga City Hall, CDTI (Spain), and NEDO (Japan). With a 60 million budget, Zem2all tries to assess the impact of over 200 electric vehicles circulating in the big metropolitan area of Málaga during four years. According to the ownership and uses, the vehicles (160 i-MiEV and 40 Leaf) are distributed as follows: 65 private vehicles, 65 fleet vehicles, 50 distribution company vehicles, and 20 rent-a-car vehicles.

Zem2all has deployed three types of charging infrastructures, including 23 fast-charging points in several Costa del Sol cities and six vehicle-to-grid (V2G) street charging systems with bidirectional energy transfer capability (see Fig. 33). This infrastructure is fully integrated in the data acquisition and management system of the Smartcity project, simplifying the development of a complete set of tests and demos for both charging points and electric vehicles. An information and control center was created capable of collecting all the relevant data of the participating cars (load, routes, average speed, usage times, etc.).

This has allowed relevant conclusions to be reached about the actual use of Zem2all infrastructures, their possibilities, and next steps and recommendations to follow for
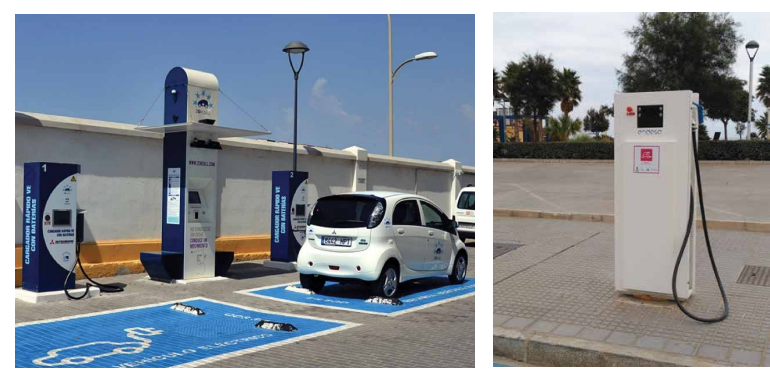

Fig. 33. Fast (left) and V2G (right) charging spots deployed in Zem2all project. its seamless and progressive implementation in the future electric system [216]-[219].

The degree of customer satisfaction is very high. On average, the vehicles are used every day for $45 \mathrm{~km}$ and are recharged every 1.5 days. Normal charging at home is the preferred choice, as it is cheaper and more comfortable compared to the fast charging at public places.

Much information and experience have been gained over the last three years regarding the different charging and usage patterns, which will be very useful for the distribution utility to plan its future infrastructure upgradings. The most relevant figures and conclusions are summarized below.

Patterns of normal charging at home are as follows:

- $70 \%$ of vehicles are charged every two days;

- $4 \%$ of vehicles need more than one conventional recharge a day;

- private owners concentrate the charging process starting at 9:00 P.M.;

- utility and fleets recharge mainly at peak times;

- $20 \%$ of refills are made outside the base;

- $100 \%$ of private vehicles recharge daily;

- $43 \%$ of vehicles recharge only in the evening, and $57 \%$ recharge throughout the day.

Fig. 34 shows, in percentage over the total energy, the energy demanded by different types of EVs (car rental, private, fleet, and utility) when connected to normal chargers throughout the average day. Note that, while fleet EVs typically recharge late in the morning, private owners charging concentrates late in the evening/night.
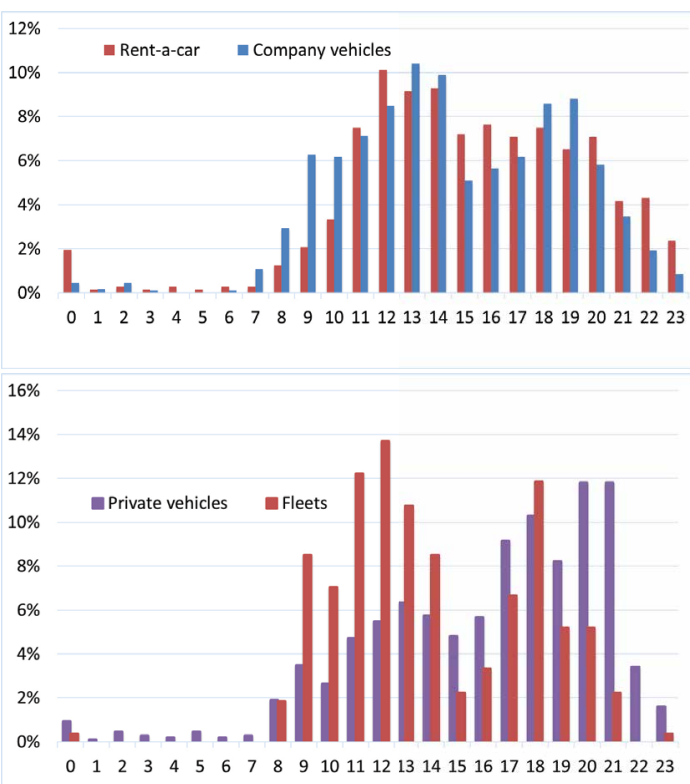

Fig. 34. Percentage of average energy demanded by EVs throughout the day from conventional charging points for different categories of users. 
Regarding the fast charging patterns, we have the following:

- $38 \%$ of vehicles have never used fast charging;

- 33\% have only used fast charging due to time constraints (less than five times in total);

- $4 \%$ of vehicles recharge two times a week;

- $80 \%$ of vehicles recharge with less than $1 / 3$ of the battery capacity available;

- $20 \%$ of vehicles recharge with more than $1 / 2$ of the battery capacity available;

- $31 \%$ of vehicles charge from 8 A.M. to 2 P.M., while $64 \%$ of them do it from 2 P.M. to 9 P.M. and only 5\% after 10 P.M.;

- $12 \%$ of vehicles use different fast chargers within $10 \mathrm{~km}$ of their base;

- $88 \%$ of vehicles use only a few quick chargers more than $16 \mathrm{~km}$ away from their base.

Fig. 35 is the counterpart of the previous figure for the fast charging patterns. On average, fast charging tends to concentrate earlier in the morning than normal charging.

The Zem2all project is a demonstration that citizens are rapidly adapting to new technologies and eager to change their consumption habits toward more sustainable and efficient options, contributing in this way to improve the city where they live.

\section{F. State Estimation of MV and LV Feeders}

While much of the efforts and investments made in Smartcity were initially devoted to new infrastructure and hardware, the software was mainly intended at this early stage to gathering raw data (from the grid, the DG, and the

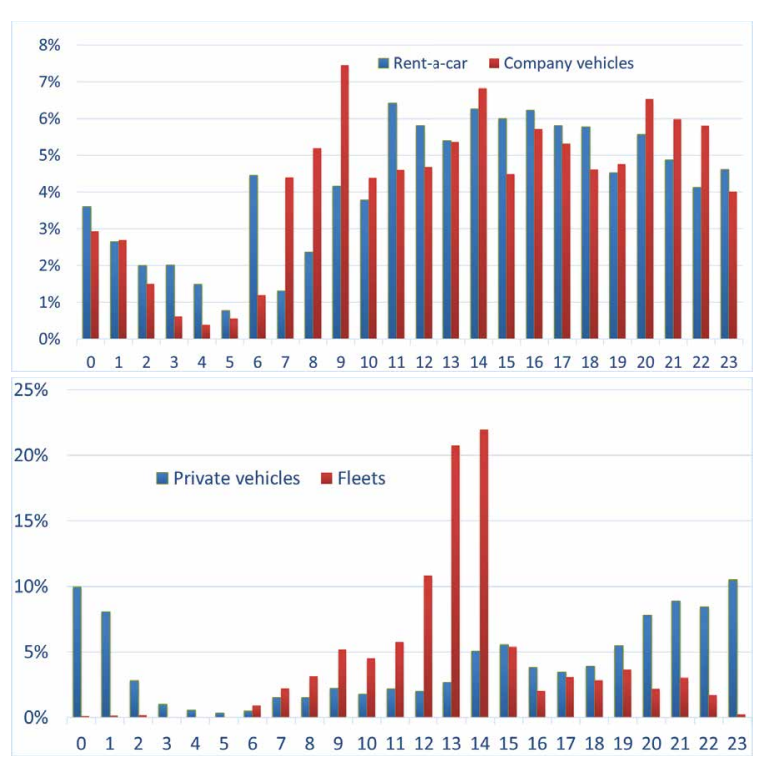

Fig. 35. Percentage of average energy demanded by EVs throughout the day from fast charging points for different categories of users. users), handling data bases, interacting with the utility's ICT and control systems, presenting results through nice interfaces, etc.

Once those basic goals were attained, it was soon realized that more advanced software was needed, aimed at improving the grid operation by exploiting the stream of new information that was regularly collected at the control center. As a consequence, the project named Monica (Spanish acronym of Advanced Monitoring and Control) was launched in the Smartcity framework.

The main objective of Monica project is to develop suitable monitoring and diagnostic tools specifically designed for distribution networks (MV and LV), similar to those that have traditionally existed at higher voltage levels. As thoroughly discussed in this paper, it is expected that the number of active elements connected to the distribution network, such as DG, energy storage, EVs, or self-producing consumers, will increase exponentially. Therefore, the availability and use of such tools will be crucial to assure an efficient and safe operation of distribution networks. The core of the monitoring process included in Monica is a state estimator (SE) tool [220]. Even though the underlying philosophy and objectives are the same as that of transmission-level SE, namely to filter Gaussian noise while rejecting outliers, an ad hoc development has been undertaken owing to the following distinguishing features of MV and LV grids [221], [222]: radial structure, high R/X ratios, very reduced lengths of some LV cable sections, much lower measurement redundancy and need to incorporate more pseudomeasurements, much lower scanning rates, and significant imbalance of LV feeders. Unlike in the United States, all LV urban laterals in Spain (and most European countries) are made of structurally balanced, three-phase (plus neutral) bundled cables. However, most LV consumers are single phase, which means that the phase conductors are far from being perfectly balanced. For this reason, the neutral conductor is grounded at regular intervals.

Taking those peculiarities into account, the SE developed for Smartcity comprises two stages: 1) a three-phase, four-wire unbalanced SE is first run for each LV feeder; and 2) a single-phase balanced SE is performed on MV feeders. Instead of the customary bus voltages in polar form, a novel and more suitable state vector has been adopted, as in [223], comprising the squared bus voltage magnitudes, the squared branch currents, and an extra branch variable embodying the information about the power flow direction. This leads to a quadratically constrained, linear measurement model, which is prescaled to prevent ill conditioning of the gain matrix.

The initial scope of the project covers two MV feeders, with a total of 57 secondary substations and the associated capillary system of LV feeders delivering electricity to over 5000 customers, each equipped with a smart meter. As described earlier, a whole network of sensors, at both MV and LV levels, has been deployed in the Smartcity project. 


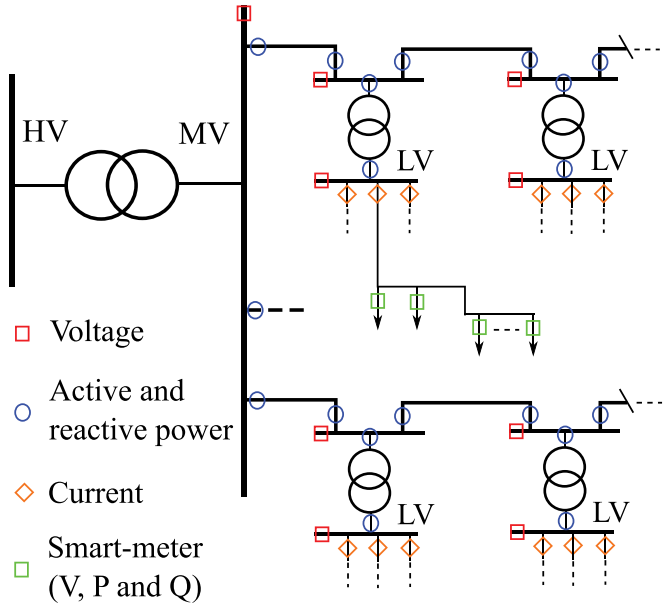

Fig. 36. One-line diagram showing the location and type of measurements along the $M V$ feeders, at secondary substations and on the customer side.

Fig. 36 schematically shows the location and type of sensors for a generic MV feeder with several secondary substations and LV customers. For convenience, the MV/LV transformer is included in the MV SE model.

At the MV level, the following measurements are available every 5 min:

- voltage magnitude and active \& reactive powers at both the input and output feeder sections of secondary substations;

- voltage and current magnitudes and active \& reactive powers on the MV side of the transformer;

- voltage magnitude and active \& reactive powers consumed by MV customers, if any;

- voltage magnitude and active \& reactive powers injected by DG at this level, if any.

For the LV level, with a 15-min time lapse, the available measurements can be summarized as follows:

- voltage magnitude and active $\&$ reactive powers at the $\mathrm{LV}$ side of the transformer;

- current magnitudes at the head of each LV feeder;

- voltage magnitude and active \& reactive powers provided by the smart meter of every customer connected to the LV feeders.

When null-injection constraints are considered, this yields a typical average redundancy of 2.38 and 1.37 for the MV and LV subsystems, respectively. It is worth stressing that, for such low redundancy levels, properly characterizing the actual uncertainty of each available measurement is crucial to ensure that the right estimate is computed [224]. The SE has been satisfactorily tested with both simulated and actual data. It provides the maximum-likelihood voltage magnitudes at all buses, the currents and power flows across all feeder sections, and the resulting losses. In addition, for LV feeders it allows abnormal or unacceptable system

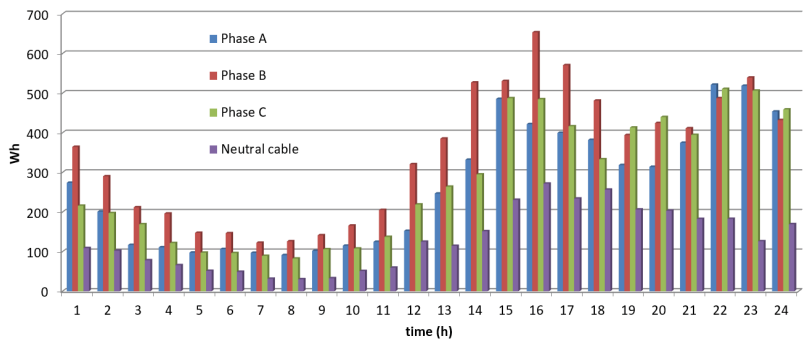

Fig. 37. Hourly ohmic losses incurred by each phase and the neutral cable for a whole day.

imbalances to be detected. Just as a sample, Fig. 37 shows, for each hour on August 20, 2016, the resulting ohmic losses for the set of three phases and the neutral cables fed from the secondary substation No. 307 in Smartcity Málaga. As can be seen, the resulting imbalance is not negligible, which has prompted the utility to undertake corrective actions aimed at more optimally relocating individual customers to achieve a better balance.

Based on the results provided by the SE, other diagnostic and corrective tools are being developed, such as var \& voltage control, congestion alleviation, automatic feeder reconfiguration, detection of nontechnical losses, etc.

\section{CONCLUSION}

For over a century, electric power systems have been steadily growing and adapting to serve the needs of a greedy-forenergy society as efficiently as possible, according to the possibilities offered at any time by the existing technology. If just a single driver of such a long and sustained economic development had to be named, this would be without any doubt "fossil fuels." But fossil fuels are also responsible for the tenfold increase of $\mathrm{CO}_{2}$ atmospheric concentration during this period and the chronic and harmful contamination of the air in large cities, with very likely catastrophic consequences. Realizing this threat, an unstoppable shift toward a decarbonized energy system emerged late in the 20th century, which is drastically and quickly changing the status quo. In the upcoming paradigm, increasingly larger cities will have to be much more sustainable in many aspects (energy and water consumption, air quality, waste management, etc.), for which smarter power systems are needed, particularly at the distribution levels.

The first half of this paper has first presented a brief historical overview of how ac power systems evolved to efficiently interconnect a handful of large synchronous generators, most of them driven by steam turbines, to millions of passive customers. Then, a thorough discussion is provided on how a plethora of smart grid technologies and infrastructures are coming to the rescue of relatively inefficient and aging assets, which need to be urgently transformed into a customer-centric, digitalized, and sustainable system. These technologies include cost-effective and partly distributed 
renewable generation, smart meters and ICT enabling demand management and distribution automation, $\mathrm{HV}$ and LV dc systems, energy storage, etc.

In the second part of the paper, several representative examples of undergoing or recent smart grid projects in Spain, related with smart cities, have been presented and their potential impact analyzed. While some projects address very specific problems, such as optimal and secure utilization of urban transmission and distribution grids, the Smartcity project in Málaga involves, to a certain extent, virtually all of the key technologies that are expected to proliferate in future smart cities.

A relevant conclusion of those projects is that, in addition to sophisticated ICT networks and devices, data analytics services, and advanced DMSs, the availability of resilient enough, aesthetic, and efficiently used power assets is most important in future smart cities as, no matter how intelligent a power system is, electrons need a physical supporting infrastructure to move around. The role of pilots and demonstrators in reinventing the utility business model has become also evident.

\section{REFERENCES}

[1] UN World Population Prospects. [Online]. Available: https://esa.un.org/unpd/wpp/ DataQuery/

[2] K. Vu, M. M. Begouic, and D. Novosel, "Grids get smart protection and control," IEEE Comput. Appl. Power, vol. 10, no. 4, pp. 40-44, Oct. 1997.

[3] F. Brazier et al., "Agents negotiating for load balancing of electricity use," in Proc. 18th Int. Conf. Distrib. Comput. Syst., Amsterdam, The Netherlands, May 1998, pp. 622-629.

[4] R. G. Pratt, "Transforming the U.S. Electricity system," in Proc. IEEE PES Power Syst. Conf. Expo., vol. 3. Oct. 2004, pp. 1651-1654.

[5] S. M. Amin and B. F. Wollenberg, "Toward a smart grid: Power delivery for the 21st century," IEEE Power Energy Mag., vol. 3, no. 5, pp. 34-41, Sep./Oct. 2005.

[6] R. DeBlasio and C. Tom, "Standards for the smart grid," in Proc. IEEE Energy 2030 Conf., Atlanta, GA, USA, Nov. 2008, pp. 1-7.

[7] H. Farhangi, "The path of the smart grid," IEEE Power Energy Mag., vol. 8, no. 1, pp. 18-28, Jan./Feb. 2010.

[8] J. McDonald, "Leader or follower [The Business Scene]," IEEE Power Energy Mag., vol. 6, no. 6, pp. 18-90, Nov. 2008.

[9] "Benchmarking smart metering deployment in the EU-27 with a focus on electricity," Eur. Commiss., Brussels, Belgium, Tech. Rep., Jun. 2014.

[10] R. E. Hall, “The vision of a smart city," in Proc. 2nd Int. Life Extension Technol. Workshop, Paris, France, Sep. 2000, pp. 1-7.

[11] A. Caragliu, C. Del Bo, and P. Nijkamp, "Smart cities in Europe," J. Urban Technol., vol. 18, no. 2, pp. 65-82, Apr. 2011.

[12] F. Russo, C. Rindone, and P. Panuccio, "The process of smart city definition at an EU level," in Proc. Sustain. City 9th, Urban Regenerat. Sustainability, vol. 191. 2014, pp. 979-989.

[13] R. G. Hollands, "Will the real smart city please stand up?" City, vol. 12, no. 3, pp. 303-320, Dec. 2008.

[14] M. Al-Hader, A. Rodzi, A. R. Sharif, and N. Ahmad, "Smart city components architecture," in Proc. Int. Conf. Comput. Intell., Modelling Simulation, 2009, pp. 93-97.

[15] S. Karnouskos and T. N. de Holanda, "Simulation of a smart grid city with software agents," in Proc. 3rd Eur. Symp. Comput. Modeling Simulation, Athens, Greece, Nov. 2009, pp. 424-429.

[16] P. Shah and K. Gehring, "Smart solutions to power the 21st century: Managing assets today for a better grid tomorrow," IEEE Power Energy Mag., vol. 14, no. 2, pp. 64-68, Mar./Apr. 2016.
[17] T. Atasoy, H. E. Akinç, and Ö. Erçin , “An analysis on smart grid applications and grid integration of renewable energy systems in smart cities," in Proc. Int. Conf. Renew. Energy Res. Appl. (ICRERA), Palermo, Italy, Nov. 2015, pp. 547-550.

[18] M. Li, H. Xiao, W. Gao, and L. Li, "Smart grid supports the future intelligent city development," in Proc. Chin. Control Decision Conf. (CCDC), Yinchuan, China, May 2016, pp. 6128-6131.

[19] M. Castro, A. J. Jara, and A. F. G. Skarmeta, "Smart lighting solutions for smart cities," in Proc. 27th Int. Conf. Adv. Inf. Netw. Appl. Workshops, Barcelona, Spain, Mar. 2013, pp. 1374-1379.

[20] A. Y. S. Lam, Y. W. Leung, and X. Chu, "Electric vehicle charging station placement: Formulation, complexity, and solutions," IEEE Trans. Smart Grid, vol. 5, no. 6, pp. 2846-2856, Nov. 2014.

[21] S. Karnouskos, "Demand side management via prosumer interactions in a smart city energy marketplace," in Proc. 2nd IEEE PES Int. Conf. Exhibit. Innov. Smart Grid Technol., Manchester, U.K., Dec. 2011, pp. 1-7.

[22] B. Morvaj, L. Lugaric, and S. Krajcar, "Demonstrating smart buildings and smart grid features in a smart energy city," in Proc. 3rd Int. Youth Conf. Energetics (IYCE), Leiria, Portugal, Jul. 2011, pp. 1-8.

[23] M. Brenna et al., "Challenges in energy systems for the smart-cities of the future," in Proc. IEEE Int. Energy Conf. Exhibit. (ENERGYCON), Florence, Italy, Sep. 2012, pp. 755-762.

[24] A. Zanella, N. Bui, A. Castellani, L. Vangelista, and M. Zorzi, "Internet of Things for smart cities," IEEE Internet Things J., vol. 1, no. 1, pp. 22-32, Feb. 2014.

[25] H. Chourabi et al., "Understanding smart cities: An integrative framework," in Proc. 45th Int. Conf. Syst. Sci., Maui, HI, USA, Jan. 2012, pp. 2289-2297.

[26] L. Lugaric, S. Krajcar, and Z. Simic, "Smart city_Platform for emergent phenomena power system testbed simulator," in Proc. IEEE PES Innov. Smart Grid Technol. Conf. Eur. (ISGT Eur.), Gothenburg, Sweden, Oct. 2010, pp. 1-7.

[27] M. Naphade, G. Banavar, C. Harrison, J. Paraszczak, and R. Morris, "Smarter cities and their innovation challenges," Computer, vol. 44, no. 6, pp. 32-39, Jun. 2011.

[28] S. Pellicer, G. Santa, A. L. Bleda, R. Maestre, A. J. Jara, and A. G. Skarmeta, "A global perspective of smart cities: A survey," in Proc. 7th Int. Conf. Innov. Mobile Internet Services Ubiquitous Comput., Taichung, Taiwan, Jul. 2013, pp. 439-444.

[29] Smithsonian Institution. (2002). Powering a Generation of Change. Powering the Past: A
Look Back. [Online]. Available: http:// americanhistory.si.edu/powering/

[30] D. P. Tuttle et al., "The history and evolution of the U.S. electricity industry," White Paper UTEI/2016-05-2, 2016. [Online]. Available: http://energy.utexas.edu/the-full-cost-ofelectricity-fce/

[31] R. F. Hirsh, Technology and Transformation in the American Electric Utility Industry. Cambridge, U.K.: Cambridge Univ. Press, 1989.

[32] A. Gómez-Expósito, “The unstoppable changing of the electricity guard [commentary]," IEEE Technol. Soc. Mag., vol. 36, no. 4, pp. 30-33, Dec. 2017.

[33] J. LeMay, "Hydro-Quebec's high-voltage interconnections," IEEE Power Eng. Rev., vol. 12, no. 6, pp. 7-8, Jun. 1992.

[34] X. Dong and M. Ni, "Ultra high voltage power grid development in China," in Proc. IEEE PES General Meeting, Minneapolis, MN, USA, Jul. 2010, pp. 1-8.

[35] N. G. van Luijk, "Delivering energy through the world longest submarine HV AC cable," in Proc. IEEE Power Energy Soc. General Meeting, Denver, CO, USA, Jul. 2015, p. 1.

[36] Z. Liu, J. Yu, X. Guo, T. Sun, and J. Zhang, "Survey of technologies of line commutated converter based high voltage direct current transmission in China," CSEE J. Power Energy Syst., vol. 1, no. 2, pp. 1-8, Jun. 2015.

[37] G. C. Loehr, “The 'good' blackout: The northeast power failure of 9 November 1965," IEEE Power Energy Mag., vol. 15, no. 3, pp. 84-96, May/Jun. 2017.

[38] T. E. Dy Liacco, "System security: The computer's role," IEEE Spectrum, vol. 15, no. 6, pp. 43-50, Jun. 1978.

[39] F. C. Schweppe and E. J. Handschin, "Static state estimation in electric power systems," Proc. IEEE, vol. 62, no. 7, pp. 972-982, Jul. 1974.

[40] F. Maghsoodlou, R. Masiello, and T. Ray, "Energy management systems," IEEE Power Energy Mag., vol. 2, no. 5, pp. 49-57, Sep./Oct. 2004.

[41] H. L. Willis, Power Distribution Planning Reference Book, 2nd ed. New York, NY, USA: Marcel Dekker, 2004.

[42] A. A. Sallam, O. P. Malik, Electric Distribution Systems. Hoboken, NJ, USA Wiley, 2011.

[43] K. L. Hall, "Out of sight, out of mindRevisited: An updated study on the undergrounding of overhead power lines," Edison Electr. Inst., Washington, DC, USA, Tech. Rep., Dec. 2009.

[44] J. McDaniel, W. Friedl, and H. Caswell, "Benchmarking of reliability: North American and European experience," in 
Proc. 23rd Int. Conf. Electr. Distrib. (CIRED), Lyon, France, Jun. 2015, paper 0182.

[45] "CEER benchmarking report 5.2 on the continuity of electricity supply," Council Eur. Energy Regulators, Brussels, Belgium, Tech. Rep. C14-EQS-62-03, 2015.

[46] U.S. Energy Information Administration, Survey Data 2013. [Online]. Available: https:// www.eia.gov/electricity/data/eia861/

[47] [Online]. Available: http://www.etip-snet.eu/ about/etip-snet/

[48] U.S. DOE (Office of Electricity Delivery \& Energy Reliability). [Online]. Available: https://energy.gov/oe/services/technologydevelopment/smart-grid

[49] V. Hamidi, K. S. Smith, and R. C. Wilson, "Smart grid technology review within the transmission and distribution sector," in Proc. IEEE PES Innov. Smart Grid Technol. Conf. Eur. (ISGT Eur.), Gothenburg, Sweden, Oct. 2010, pp. 1-8.

[50] I. Pérez-Arriaga et al., The Utility of the Future. MIT Energy Initiative, 2016.

[51] DOE, Energy Independence and Security Act of 2007, Title XIII. [Online]. Available: https:// www.ferc.gov/industries/electric/indus-act/ smart-grid/eisa.pdf

[52] M. Kezunovic, J. D. McCalley, and T. J. Overbye, "Smart grids and beyond: Achieving the full potential of electricity systems," Proc. IEEE, vol. 100, pp. 1329-1341, May 2012.

[53] G. W. Arnold, "Challenges and opportunities in smart grid: A position article," Proc. IEEE, vol. 99, no. 6, pp. 922-927, Jun. 2011.

[54] H. Müller, T. Connor, and Y. Gang, "Chances and challenges for smart grids in distribution," in Proc. CICED, Nanjing, China, Sep. 2010, pp. 1-6.

[55] S. W. Pullins, "The NETL modern grid initiative: What will the US modern grid cost?" in Proc. IEEE Power Eng. Soc. General Meeting, Tampa, FL, USA, Jun. 2007, pp. 1-6.

[56] A. Ipakchi and F. Albuyeh, "Grid of the future," IEEE Power Energy Mag., vol. 7, no. 2, pp. 52-62, Mar./Apr. 2009.

[57] J. R. Aguero, E. Takayesu, D. Novosel, and R. Masiello, "Modernizing the grid: Challenges and opportunities for a sustainable future," IEEE Power Energy Mag., vol. 15, no. 3, pp. 74-83, May/Jun. 2017.

[58] J. D. McDonald, "Substation automation. IED integration and availability of information," IEEE Power Energy Mag., vol. 1, no. 2, pp. 22-31, Mar. 2003.

[59] A. G. Phadke and J. S. Thorp, Synchronized Phasor Measurements and Their Applications, New York, NY, USA: Springer-Verlag, 2008.

[60] R. Baheti and H. Gill, "Cyber-physical systems" in The Impact of Control Technology, T. Samad and A. M. Annaswamy, Eds.2011. [Online]. Available: http://www.ieeecss.org

[61] R. Schmalensee, "The future of solar energy: An interdisciplinary MIT study," 2015.

[62] A. Kylili and P. A. Fokaides, "European smart cities: The role of zero energy buildings," Sustain. Cities Soc., vol. 15, pp. 86-95, Jul. 2015.

[63] B. Bellosio, L. Giaccone, A. Guerrisi, P. Lazzeroni, M. Martino, and M. Tartaglia, "Energy networks in sustainable cities: Towards a full integration of renewable systems in urban area," in Proc. 37th Annu. Conf. IEEE Ind. Electron. Soc. (IECON), Nov. 2011, pp. 3146-3151.

[64] P. Mancarella, "Distributed multi-generation options to increase environmental efficiency in smart cities," in Proc. IEEE Power Energy Soc. General Meeting, Jul. 2012, pp. 1-8.

[65] M. Vignolo, L. Narbondo, J. Cataldo, and F. G. Madina, "Feasibility studies for the installation of wind microgeneration in urban areas in Montevideo," in Proc. IEEE PES Innov. Smart Grid Technol. Latin Amer. (ISGT LATAM), Oct. 2015, pp. 734-739.

[66] J. Oyarzabal de Miguel et al., "Barómetro de Economía de la ciudad de Madrid," no. 19, Jan. 2009. [Online]. Available: http://www. madrid.es/UnidadesDescentralizadas/ UDCObservEconomico/ BarometroEconomia/2009/Ficheros/Enero/ Bar\%C3\%B3metro\%2019.pdf

[67] M. Šúri, T. A. Huld, and E. D. Dunlop, "PV-GIS: A Web-based solar radiation database for the calculation of PV potential in Europe," Int. J. Sustain. Energy, vol. 24, no. 2, pp. 55-67, 2005.

[68] S. Lo Piano and K. Mayumi, "Toward an integrated assessment of the performance of photovoltaic power stations for electricity generation," Appl. Energy, vol. 186, pp. 167-174, Jan. 2017.

[69] I. Capellán-Perez, C. de Castro, and I. Arto, "Assessing vulnerabilities and limits in the transition to renewable energies: Land requirements under $100 \%$ solar energy scenarios," Renew. Sustain. Energy Rev., vol. 77, pp. 760-782, Sep. 2017.

[70] S. Izquierdo, C. Montañés, C. Dopazo, and N. Fueyo, "Roof-top solar energy potential under performance-based building energy codes: The case of Spain," Solar Energy, vol. 85, no. 1, pp. 208-213, 2011.

[71] J. Ordóñez, E. Jadraque, J. Alegre, and G. Martínez, "Analysis of the photovoltaic solar energy capacity of residential rooftops in Andalusia (Spain)," Renew. Sustain. Energy Rev., vol. 14, no. 7, pp. 2122-2130, 2010.

[72] Anuario Estadístico de la Comunidad de Madrid. 1985-2017 Urbanismo, vivienda y construcción. [Online]. Available: http:// www.madrid.org/iestadis/fijas/estructu/ general/anuario/ianucap10.htm

[73] C. J. Romera, "Tamaño y densidad urbana: análisis de la ocupación de suelo por las áreas urbanas españolas," Ph.D. dissertation, Arquitectura, 2015

[74] P. Gagnon, R. Margolis, J. Melius, C. Phillips, and R. Elmore, "Rooftop solar photovoltaic technical potential in the United States: A detailed assessment," Nat. Renew. Energy Lab., Golden, CO, USA, Tech. Rep. NREL/TP-6A20-65298, 2016.

[75] D. M. Kammen and D. A. Sunter, "Cityintegrated renewable energy for urban sustainability," Science, vol. 352, no. 6288, pp. 922-928, 2016.

[76] L. K. Wiginton, H. T. Nguyen, and J. M. Pearce, "Quantifying rooftop solar photovoltaic potential for regional renewable energy policy," Comput., Environ. Urban Syst., vol. 34, no. 4, pp. 345-357, 2010.

[77] L. Sussams and J. Leaton, "Expect the unexpected: The disruptive power of lowcarbon technology," Grantham Inst. Imperial College, London, U.K., 2017.

[78] CEER Position Paper on Renewable Energy SelfGeneration, Sep. 2016.

[79] N. S. Rau and Y.-H. Wan, "Optimum location of resources in distributed planning," IEEE Trans. Power Syst., vol. 9, no. 4, pp. 2014-2020, Nov. 1994.

[80] [Online]. Available: https://cleantechnica. com/2017/02/17/hamburg-considers- innovative-underground-heat-storagescheme/

[81] M. Nick, R. Cherkaoui, and M. Paolone, "Optimal allocation of dispersed energy storage systems in active distribution networks for energy balance and grid support," IEEE Trans. Power Syst., vol. 29, no. 5, pp. 2300-2310, Sep. 2014.

[82] D. Pudjianto, M. Aunedi, P. Djapic, and G. Strbac, "Whole-systems assessment of the value of energy storage in low-carbon electricity systems," IEEE Trans. Smart Grids, vol. 5, no. 2, pp. 1098-1109, Mar. 2014.

[83] V. A. Boicea, "Energy storage technologies: The past and the present," Proc. IEEE, vol. 102, no. 11, pp. 1777-1794, Nov. 2014

[84] B. Nykvist and M. Nilsson, "Rapidly falling costs of battery packs for electric vehicles," Nature Climate Change, vol. 5, no. 4, pp. 329-332, 2015.

[85] M. S. Whittingham, "History, evolution, and future status of energy storage," Proc. IEEE, vol. 100, pp. 1518-1534, May 2012.

[86] P. Bronski, "The economics of grid defection: When and where distributed solar generation plus storage competes with traditional utility service," Rocky Mountain Inst., Basalt, CO, USA, 2014.

[87] A. Michiorri, R. Girard, G. Kariniotakis, C. Lebossé, and S. Albou, "A local energy management system for solar integration and improved security of supply: The nice grid project," in Proc. 3rd IEEE PES Int. Conf. Exhibit. Innov. Smart Grid Technol. (ISGT Europe), Oct. 2012, pp. 1-6.

[88] S. Karnouskos, "Demand side management via prosumer interactions in a smart city energy marketplace," in Proc. 2nd IEEE PES Int. Conf. Exhibit. Innov. Smart Grid Technol. (ISGT Europe), Dec. 2011, pp. 1-7.

[89] A. Dimeas, "Smart houses in the smart grid: Developing an interactive network," IEEE Electrific. Mag., vol. 2, no. 1, pp. 81-93, Mar. 2014

[90] F. Rahimi and A. Ipakchi, "Using a transactive energy framework: Providing grid services from smart buildings," IEEE Electrific. Mag., vol. 4, no. 4, pp. 23-29, Dec. 2016.

[91] The Brattle Group, Freeman Sullivan \& Co, and Global Energy Partners, "A national assessment of demand response potential," Fed. Energy Reg. Commission, Washington, DC, USA, 2009.

[92] "Communications requirements of smart grid technologies," DOE Rep., 2010.

[93] "Smart grid reference architecture," CENCENELEC-ETSI Smart Grid Coordination Group, 2012

[94] SCE-Cisco-IBM SGRA Team. Smart Grid Reference Architecture, vol. 1. [Online]. Available: http://www.pointview.com/data/ files/1/636/2181.pdf

[95] P. Kansal and A. Bose, "Bandwidth and latency requirements for smart transmission grid applications," IEEE Trans. Smart Grid, vol. 3, no. 3, pp. 1344-1352, Sep. 2012.

[96] B. Ran, E. Negeri, N. Baken, and F. Campfens, "Last-mile communication time requirements of the smart grid," in Proc. Sustain. Internet ICT Sustain. (SustainIT), Palermo, Italy, 2013, pp. 1-6.

[97] "Guidelines for smart grid cybersecurity," in Smart Grid Interoperability Panel-Smart Grid Cybersecurity Committee, 2014 [Online]. Available: http://dx.doi.org/10.6028/NIST. IR.7628r1 
[98] IEC Smart Grid Standards Map. [Online]. Available: http://smartgridstandardsmap.com/

[99] IEEE Approved \& Proposed Standards Related to Smart Grid. [Online]. Available: https:// smartgrid.ieee.org/resources/standards/ ieee-approved-proposed-standards-relatedto-smart-grid

[100] NIST Framework and Roadmap for Smart Grid Interoperability Standards, Release 1.0, 2010.

[101] Framework and Roadmap for Strong \& Smart Grid Standards, State Grid Corp. China, Beijing, China, 2010.

[102] T. J. Overbye and J. D. Weber, "Visualizing the electric grid," IEEE Spectr., vol. 38, no. 2, pp. 52-58, Feb. 2001.

[103] S. Cvijić and M. D. Ilić, "Part I: A new framework for modeling and tracing of bilateral transactions and the corresponding loop flows in multi-control area power networks," IEEE Trans. Power Syst., vol. 29, no. 6, pp. 2706-2714, Nov. 2014.

[104] P. Wang, L. Goel, X. Liu, and F. H. Choo, "Harmonizing AC and DC: A hybrid AC/DC future grid solution," IEEE Power Energy Mag., vol. 11, no. 3, pp. 76-83, May 2013.

[105] ENTSOe. Ten Year Network Development Plan 2016. [Online]. Available: http://tyndp. entsoe.eu/

[106] M. A. Reynolds, "Tres Amigas super station-Large scale application of VSC back-to-back technology," in Proc. PES T\&D, Orlando, FL, USA, 2012, pp. 1-5.

[107] P. Fairley, "Why Southern China broke up its power grid: An abundance of highvoltage DC makes big AC grids unstable," IEEE Spectr., vol. 53, no. 12, pp. 13-14, 2016.

[108] W. Litzenberger and P. Lips, "Pacific HVDC intertie," IEEE Power Energy Mag., vol. 5, no. 2, pp. 45-51, Mar./Apr. 2007.

[109] [Online]. Available: http://www.inelfe.eu/en

[110] P. Fairley, "Germany jump-starts the supergrid," IEEE Spectr., vol. 50, no. 5, pp. 36-41, May 2013.

[111] [Online]. Available: https://www.tennet. eu/our-grid/onshore-projects-germany/ suedlink/

[112] P. Lundberg, A. Gustafson, and M. Jeroense, "Recent advancements in HVDC VSC systems, HVDC and power electronics technology and development," CIGRE, Tech. Rep., 2015.

[113] T. J. Hammons et al., "State of the art in ultrahigh-voltage transmission," Proc. IEEE, vol. 100, no. 2, pp. 360-390, Feb. 2012.

[114] N. Flourentzou, V. G. Agelidis, and G. D. Demetriades, "VSC-based HVDC power transmission systems: An overview," IEEE Trans. Power Electron., vol. 24, no. 3, pp. 592-602, Mar. 2009.

[115] O. E. Oni, I. E. Davidson, and K. N. I. Mbangula, "A review of LCC-HVDC and VSCHVDC technologies and applications," in Proc. IEEE 16th Int. Conf. Environ. Elect. Eng. (EEEIC), Florence, Italy, Jun. 2016, pp. 1-7.

[116] W. F. Pickard, "The limits of HVDC transmission," Energy Policy, vol. 61, pp. 292-300, Oct. 2013.

[117] D. Van Hertem and M. Ghandhari, "Multiterminal VSC HVDC for the European supergrid: Obstacles," Renew. Sustain. Energy Rev., vol. 14, no. 9, pp. 3156-3163, Dec. 2010

[118] [Online]. Available: http:// atlanticwindconnection.com/awc-projects/ atlantic-wind-connection

[119] X. Li, Z. Yuan, J. Fu, Y. Wang, T. Liu, and Z. Zhu, "Nanao multi-terminal VSC-HVDC project for integrating large-scale wind generation," in Proc. IEEE PES Gen. Meeting, National Harbor, MD, USA, Jul. 2014, pp. 1-5.

[120] D. Imamovic, T. Kern, and M. Muhr, "System and technology comparison of UHV transmission concepts," in Proc. Int. Conf. High Voltage Eng. Appl., New Orleans, LA, USA, Oct. 2010, pp. 192-195.

[121] A. Z. M. S. Muttalib, G. A. Taylor, and M. E. Bradley, "Developing and enhancing business processes to enable higher levels of TSO-DSO interaction," in Proc. CIRED Workshop, Helsinki, Finland, 2016, pp. 1-4.

[122] D. A. Sbordone, E. M. Carlini, B. Di Pietra, and M. Devetsikiotis, "The future interaction between virtual aggregatorTSO-DSO to increase DG penetration," in Proc. Int. Conf. Smart Grid Clean Energy Technol. (ICSGCE), Offenburg, Germany, 2015, pp. 201-205.

[123] N. Silva, C. M. Pinto, A. M. Bernardo, A. Carrapatoso, R. Pestana, and S. Dias, "The interaction between DSO and TSO to increase DG penetration-The Portuguese example," in Proc. CIRED Workshop, Integr. Renew. Distrib. Grid, Lisbon, Portugal, May 2012, pp. 1-4.

[124] H. Hooshyar et al., "Synchrophasor applications facilitating interactions in transmission and distribution operations," in Proc. IEEE Manchester PowerTech, Manchester, U.K., Jun. 2017, pp. 1-6.

[125] [Online]. Available: http://www.ree.es/ sites/default/files/downloadable/ folletocecre_v6_ingles_0.pdf

[126] Epexspot. Price Coupling of Regions. [Online]. Available: https://www.epexspot. com/en/market-coupling/pcr

[127] ENTSO-E. [Online]. Available: https:// www.entsoe.eu/regions/Pages/default.aspx

[128] L. Hancher and B. M. Winters Feb. 2017. The EU Winter Package. [Online]. Available: http://fsr.eui.eu/wp-content/uploads/TheEU-Winter-Package.pdf

[129] W. R. Cassel, "Distribution management systems: Functions and payback," IEEE Trans. Power Syst., vol. 8, no. 3 , pp. 796-801, Aug. 1993.

[130] A. Gómez-Expósito, A. Abur, A. de la Villa Jaen, and C. Gómez-Quiles, "A multilevel state estimation paradigm for smart grids," Proc. IEEE, vol. 99, no. 6, pp. 952-976, Jun. 2011.

[131] Y. Wang, P. Yemula, and A. Bose, "Decentralized communication and control systems for power system operation," IEEE Trans. Smart Grid, vol. 6, no. 2, pp. 885-893, Mar. 2015.

[132] A. Bose, "Smart transmission grid applications and their supporting infrastructure," IEEE Trans. Smart Grid, vol. 1, no. 1, pp. 11-19, Jun. 2010.

[133] Q. Huang, S. Jing, J. Li, D. Cai, J. Wu, and W. Zhen, "Smart substation: State of the art and future development," IEEE Trans. Power Del., vol. 32, no. 2, pp. 1098-1105, Apr. 2017.

[134] A. V. Villa, P. C. Romero, and A. G. Exposito, "Substation data validation by a local three-phase generalized state estimator," IEEE Trans. Power Syst., vol. 20, no. 1, pp. 264-271, Feb. 2005.

[135] A. E. Leon, J. M. Mauricio, A. GómezExpósito, and J. A. Solsona, "Hierarchical wide-area control of power systems including wind farms and FACTS for shortterm frequency regulation," IEEE Trans.
Power Syst., vol. 27, no. 4, pp. 2084-2092, Nov. 2012.

[136] G. Gross and F. D. Galiana, "Short-term load forecasting," Proc. IEEE, vol. 75, no. 12, pp. 1558-1573, Dec. 1987.

[137] A. T. Lora, J. M. R. Santos, A. G. Exposito, J. L. M. Ramos, and J. C. R. Santos, "Electricity market price forecasting based on weighted nearest neighbors techniques," IEEE Trans. Power Syst., vol. 22, no. 3, pp. 1294-1301, Aug. 2007.

[138] J. W. Taylor, P. E. McSharry, and R. Buizza, "Wind power density forecasting using ensemble predictions and time series models," IEEE Trans. Sustain. Energy, vol. 24, no. 3, pp. 775-782, Sep. 2009.

[139] A. Gil, M. de la Torre, T. Dominguez, and R. Rivas, "Influence of wind energy forecast in deterministic and probabilistic sizing of reserves," in Proc. 9th Int. Workshop LargeScale Integr. Wind Power Power Syst. Transmiss. Netw. Offshore Wind Power Plants, 2010.

[140] I. González-Aparicio and A. Zucker, "Impact of wind power uncertainty forecasting on the market integration of wind energy in Spain," Appl. Energy, vol. 159, pp. 334-349, Dec. 2015.

[141] R. J. Bessa and M. A. Matos, "Comparison of probabilistic and deterministic approaches for setting operating reserve in systems with high penetration of wind power," in Proc. 7th Medit. Conf. Exhib. Power Generat., Transmiss., Distrib. Energy Convers., Agia Napa, Cyprus, 2010, pp. 1-9, paper MED10/127.

[142] "Flexible and fast response capacity measures in energy markets," in Proc. EUCI Conf. Workshop, Sacramento, CA, USA, May 2017.

[143] "Assessing the impact of low carbon technologies on great Britain's powe distribution networks, version: 3.1," Energy Netw. Assoc., London, U.K., Tech. Rep. 82530. Jul. 2012.

[144] N. Okada, M. Takasaki, H. Sakai, and S. Katoh, "Development of a 6.6 kV-1 MVA transformerless loop balance controller," in Proc. IEEE Power Electron. Spec. Conf., Orlando, FL, USA, Jun. 2007, pp. 1087-1091.

[145] D. Monroy, A. Gómez-Expósito, and E. Romero-Ramos, "Improving the voltage regulation of secondary feeders by applying solid-state tap changers to MV/LV transformers," in Proc. 9th Int. Conf. Elect. Power Quality Utilisation, Barcelona, Spain, Oct. 2007, pp. 1-6.

[146] B. Cloet and E. Mimnagh, "Smart distribution transformer and algorithms for voltage control," in Proc. CIRED Workshop Challenges Implem. Active Distrib. Syst. Manage., Rome, Italy, Jun. 2014, pp. 1-3, Paper 0288.

[147] J. de Oliveira Quevedo et al., "Analysis and design of an electronic on-load tap changer distribution transformer for automatic voltage regulation," IEEE Trans. Ind. Electron., vol. 64, no. 1, pp. 883-894, Jan. 2017.

[148] S. Lu, S. Repo, D. D. Giustina, F. A.-C. Figuerola, A. Löf, and M. Pikkarainen, "Real-time low voltage network monitoring-ICT architecture and field test experience," IEEE Trans. Smart Grid, vol. 6, no. 4, pp. 2002-2012, Jul. 2015

[149] A. D. Hansen, P. Sørensen, F. Iov, and F. Blaabjerg, "Centralised power control of wind farm with doubly fed induction generators," Renew. Energy, vol. 31, no. 7, pp. 935-951, Jun. 2006. 
[150] A. Zipperer et al., "Electric energy management in the smart home: Perspectives on enabling technologies and consumer behavior," Proc. IEEE, vol. 101, no. 11, pp. 2397-2408, Nov. 2013.

[151] D.-M. Han and J.-H. Lim, "Design and implementation of smart home energy management systems based on zigbee," IEEE Trans. Consum. Electron., vol. 56, no. 3, pp. 1417-1425, Aug. 2010.

[152] G. S. Pavlak, G. P. Henze, and V. J. Cushing, "Optimizing commercial building participation in energy and ancillary service markets," Energy Buildings, vol. 81, pp. 115-126, Oct. 2014.

[153] C. Chen, J. Wang, Y. Heo, and S. Kishore, "MPC-based appliance scheduling for residential building energy management controller," IEEE Trans. Smart Grid, vol. 4 no. 3, pp. 1401-1410, Sep. 2013.

[154] J. L. Mathieu, P. N. Price, S. Kiliccote, and M. A. Piette, "Quantifying changes in building electricity use, with application to demand response," IEEE Trans. Smart Grid, vol. 2, no. 3, pp. 507-518, Sep. 2011.

[155] S. W. Alnaser and L. F. Ochoa, "Advanced network management systems: A risk-based AC OPF approach," IEEE Trans. Power Syst., vol. 30, no. 1, pp. 409-418, Jan. 2015.

[156] A. Kulmala, S. Repo, and P. Järventausta, "Coordinated voltage control in distribution networks including several distributed energy resources," IEEE Trans. Smart Grid, vol. 5, no. 4, pp. 2010-2020, Jul. 2014.

[157] F. Katiraei, R. Iravani, N. Hatziargyriou, and A. Dimeas, "Microgrids management," IEEE Power Energy Mag., vol. 6, no. 3, pp. 54-65, May/Jun. 2008

[158] Z. Li, M. Shahidehpour, F. Aminifar, A. Alabdulwahab, and Y. Al-Turki, "Networked microgrids for enhancing the power system resilience," Proc. IEEE, vol. 105, no. 7, pp. 1289-1310, Jul. 2017.

[159] Z. Wang, B. Chen, J. Wang, and C. Chen, "Networked microgrids for self-healing power systems," IEEE Trans. Smart Grids, vol. 7, no. 1, pp. 310-319, Jan. 2016.

[160] V. Madani et al., "Distribution automation strategies challenges and opportunities in a changing landscape," IEEE Trans. Smart Grid, vol. 6, no. 4, pp. 2157-2165, Jul. 2015.

[161] R. Das et al., "Distribution automation strategies: Evolution of technologies and the business case," IEEE Trans. Smart Grid, vol. 6, no. 4, pp. 2166-2175, Jul. 2015.

[162] A. Riccobono et al., "Systematic method for the development of future active distribution network automation architectures," in Proc. IEEE Eindhoven PowerTech, Eindhoven, The Netherlands, Jul. 2015, pp. 1-6.

[163] [Online]. Available: https://ec.europa.eu/ energy/en/topics/wholesale-market/ electricity-network-codes

[164] H. Urdal et al., "National implementation challenges and support by ENTSO-E for European connection network codes," in Proc. 14th Wind Integr. Workshop ENERGYNAUTICS, 2015.

[165] H. Urdal, S. Martinez-Villanueva, J. Kilter, J. Jahn, J. Sprooten, and A. Baranauska, "Future system challenges in Europe. Contributions to solutions from connection network codes," in Proc. CIGRE USNC Int. Colloquium Evol. Power Syst. Planning Support Connection Generat., Distrib. Resour. Alternative Technol., 2016.

[166] [Online]. Available: http://www.psa.es/en/ index.php
[167] C. Steger. Spain's Solar Experiments Offer Useful Policy Lessons. 2010. [Online]. Available: https://www.nrdc.org/experts/ cai-steger/spains-solar-experiments-offeruseful-policy-lessons

[168] [Online]. Available: http://www.futured. es/en/

[169] V. Giordano et al., "Smart Grid projects in Europe: Lessons learned and current developments 2012 update," Inst. Energy Transp. (JRC), Eur. Commission, Brussels, Belgium, Tech. Rep., 2013.

[170] C. F. Covrig et al., "Smart grid projects outlook 2014," Inst. Energy Transp. (JRC), Eur. Commission, Brussels, Belgium, Tech. Rep., 2014.

[171] U.S. DOE (Office of Electricity Delivery and Energy Reliability), Smart Grid Programs. Featured Case Studies. [Online]. Available: https://www.smartgrid.gov/ recovery_act/featured_case_studies.html

[172] J. Varela, N. Hatziargyriou, L. J. Puglisi, M. Rossi, A. Abart, and B. Bletterie, "The IGREENGrid project: Increasing hosting capacity in distribution grids," IEEE Power Energy Mag., vol. 15, no. 3, pp. 30-40, May/Jun. 2017.

[173] S. Repo et al., "The IDE4L project: Defining, designing, and demonstrating the ideal grid for all," IEEE Power Energy Mag., vol. 15, no. 3, pp. 41-51, May/Jun. 2017.

[174] "Thermal monitoring of cable circuits and grid operators' use of dynamic rating systems," CIGRE, Paris, France, Tech. Rep. WG B1.45.

[175] Electric Cables-Calculation of the Current Rating, Standard IEC 60287.

[176] G. J. Anders, Rating of Electric Power Cables. New York, NY, USA: McGraw-Hill, 1997.

[177] J. H. Neher and M. H. McGrath, "The calculation or the temperature rise and load capability of cable systems," RATIO, vol. 50, no. 2, p. 5, 1994.

[178] Calculation of the Cyclic and Emergency Current Rating of Cables, Standard IEC 60853.

[179] M. Diaz-Aguiló, F. De León, S. Jazebi, and M. Terracciano, "Ladder-type soil model for dynamic thermal rating of underground power cables," IEEE Power Energy Technol. Syst. J., vol. 1, pp. 21-30, Dec. 2014.

[180] M. Diaz-Aguiló and F. De León, "Introducing mutual heating effects in the ladder-type soil model for the dynamic thermal rating of underground cables," IEEE Trans. Power Del., vol. 30, no. 4, pp. 1958-1964, Aug. 2015.

[181] N. Okada, H. Kobayashi, K. Takigawa, M. Ichikawa, and K. Kurokawa, "Loop power flow control and voltage characteristics of distribution system for distributed generation including PV system," in Proc. 3rd World Conf. Photovolt. Energy Convers., vol. 3. Osaka, Japan, May 2003, pp. 2284-2287.

[182] A. Marano-Marcolini, E. Romero-Ramos, A. Gómez-Expósito, J. M. Maza-Ortega, and J. L. Martínez-Ramos, "Enhancing the integration of renewable sources in distribution systems using DC-links," in Proc. IEEE PES/IAS Conf. Sustain. Alternative Energy (SAE), Valencia, Spain, Sep. 2009, pp. 1-5.

[183] F. P. García-López, M. Barragán-Villarejo, J. M. Maza-Ortega, and A. GómezExpósito, "Multiterminal electrical charging station for LV networks," in Proc. IEEE Eindhoven PowerTech, Eindhoven, The Netherlands, Jun. 2015, pp. 1-5.

[184] E. Romero-Ramos, A. Gómez-Expósito, A. Marano-Marcolini, J. M. Maza-Ortega, and J. L. Martínez-Ramos, "Assessing the loadability of active distribution networks in the presence of DC controllable links," IET Generat., Transmiss. Distrib., vol. 5, no. 11, pp. 1105-1113, Nov. 2011.

[185] W. Cao, J. Wu, N. Jenkins, C. Wang, and T. Green, "Benefits analysis of soft open points for electrical distribution network operation," Appl. Energy, vol. 165, pp. 36-47, Mar. 2016.

[186] A. Gómez-Expósito, J. M. Maza-Ortega, E. Romero-Ramos, and A. MaranoMarcolini, "Enhancing the integration of renewables in radial distribution networks through smart links," in Smart Grid Infrastructure \& Networking. New York, NY, USA: McGraw-Hill, 2013, pp. 155-179.

[187] A. Gómez-Expósito, J. M. Maza-Ortega, E. Romero-Ramos, and A. MaranoMarcolini, "Smart links for distribution networks: The right way to further integrate renewables," in Proc. IEEE Int. Conf. Power Eng., Energy Elect. Drives (POWERENG), Torremolinos, Spain, 2011, p. 1.

[188] J. M. Maza-Ortega, A. Gomez-Exposito, M. Barragan-Villarejo, E. Romero-Ramos, and A. Marano-Marcolini, "Voltage source converter-based topologies to further integrate renewable energy sources in distribution systems," IET Renew. Power Generat., vol. 6, no. 6, pp. 435-445, Nov. 2012.

[189] M. Carlen and M. Berrogain, "Safe and powerful: Dry transformers for subtransmission," ABB Rev., vol. 2, pp. 68-74, 2015.

[190] S. A. Nair, K. S. Gupte, T. S. Lin, J. M. Cogen, B. I. Chaudhary, and A. L. Flory, "Triglyceride based, low viscosity, high flash point dielectric fluids," U.S. Patent WO 054048 A1, Oct. 18, 2012.

[191] M. Berrogaín et al., "HiDry72: Short-circuit withstand test upon the biggest ever dry-type power transformer," in Proc. IEEE PES T\&D Conf., Dallas, TX, USA, May 2016, pp. 1-5.

[192] R. Cano-González, A. Bachiller-Soler, J. A. Rosendo-Macías, and G. AlvarezCordero, "Controlled switching strategies for transformer inrush current reduction: A comparative study," Electr. Power Syst. Res., vol. 145, pp. 12-18, Apr. 2017.

[193] B. Cranganu-Cretu, R. Murillo, M. Berrogaín, M. Cuesto, C. Roy, and L. Sánchez, "Dry-type subtransmission transformer: dry power transformers for the $123 \mathrm{kV}$ and $145 \mathrm{kV}$ voltage class," in Proc. CIGRE, Paris, France, 2016.

[194] Forbes. The Top Five Smartest Cities in Spain and Why the US Should Care. [Online]. Available: http://www.forbes.com/sites/ jaynejung/2011/10/24/the-top-fivesmartest-city-in-spain-and-why-the-usshould-care/

[195] (Jul. 2009). CE Directive 2009/72/CE from EU Parliament and Council. [Online]. Available: http://eur-lex.europa.eu/ LexUriServ/LexUriServ.do?uri=OJ:L:2009: 211:0055:0093:ES:PDF

[196] W. Kempton and J. Tomic, "Vehicle-to-grid power implementation: From stabilizing the grid to supporting large-scale renewable energy," J. Power Sources, vol. 144, no. 1, pp. 280-294, 2005.

[197] W. Shireen and S. Patel, "Plug-in hybrid electric vehicles in the smart grid environment," in Proc. IEEE PES Transmiss. Distrib. Conf. Expo., Apr. 2010, pp. 1-4.

[198] Y. Ota, H. Taniguchi, T. Nakajima, K. M. Liyanage, J. Baba, and A. Yokoyama, "Autonomous distributed V2G (vehicle-togrid) considering charging request and 
battery condition," in Proc. Innov. Smart Grid Technol. Conf. Eur. (ISGT Europe), Oct. 2010, pp. 1-6.

[199] M. D. Ngar-Yin, J. M. van der Vleuten, P. Hills, and J. Tao, "Consumer perceptions of smart grid development: Results of a Hong Kong survey and policy implications," Energy Policy, vol. 49, pp. 204-216, Oct. 2012.

[200] B. Römer, P. Reichhart, J. Kranz, and A. Picot, "The role of smart metering and decentralized electricity storage for smart grids: The importance of positive externalities," Energy Policy, vol. 50, pp. 486-495, Nov. 2012.

[201] D. von Dollen, "Intelligrid architecture: Metering and consumer systems," EPRI, Palo Alto, CA, USA, Tech. Rep., 2008.

[202] Substation Automation, Standard IEC61850.

[203] Communication Networks and Systems in Substations. Part 7-2: Basic Communication Structure for Substation and Feeder Equipment-Abstract Communication Service Interface (ACSI), Standard IEC-61850-7-2.

[204] Communication Networks and Systems in Substations. Part 7-4: Basic Communication Structure for Substation and Feeder Equipment-Compatible Logical Node Classes and Data Classes, Standard IEC-61850-7-4.

[205] Communication Networks and Systems in Substations. Part 7-3: Basic Communication Structure for Substation and Feeder Equipment-Common Data Classes, Standard IEC-61850-7-3.

[206] IEEE Standard for Local and Metropolitan Area Networks-Common Specification. Part 3: Media Access Control (MAC) BridgesAmendment 2: Rapid Reconfiguration, IEEE Standard 802.1w, 2001.

[207] IEEE Standard for Local and Metropolitan Area Networks: Media Access Control (MAC) Bridges, IEEE Standard 802.1D, Jun. 2004.
[208] IEEE Standard for Local and Metropolitan Area Networks-Media Access Control (MAC) Bridges and Virtual Bridged Local Area Networks, IEEE Standard 802.1Q, Aug. 2011.

[209] IEEE Standard for a Precision Clock Synchronization Protocol for Networked Measurement and Control Systems, IEEE Standard 1588-2002, 2002.

[210] IEEE Standard for a Precision Clock Synchronization Protocol for Networked Measurement and Control Systems, IEEE Standard 1588-2008 (Revision of IEEE Standard 1588-2002), Jul. 2008.

[211] H. Lund and W. Kempton, "Integration of renewable energy into the transport and electricity sectors through V2G," Energy Policy, vol. 36, no. 9, pp. 3578-3587, 2008.

[212] L. N. Ochoa, F. Pilo, A. Keane, P. Cuffe, and G. Pisano, "Embracing an adaptable, flexible posture: Ensuring that future european distribution networks are ready for more active roles," IEEE Power Energy Mag., vol. 14, no. 5, pp. 16-28, Sep./Oct. 2016.

[213] D. Apostolopoulou, S. Bahramirad, and A. Khodaei, "The interface of power: Moving toward distribution system operators," IEEE Power Energy Mag., vol. 14, no. 3, pp. 46-51, May/Jun. 2016.

[214] [Online]. Available: http://www.ree.es/en/ activities/operation-of-the-electricitysystem/interruptibility-service

[215] R. del Rio and H. Tamura, "ZEM 2 all project (zero emission mobility to all)," in Proc. IEEE 18th Int. Conf. Intell. Transp. Syst., Sep. 2015, pp. 2971-2975.

[216] F. Mwasilu, J. J. Justo, K. Eun-Kyung, D. T. Duc, and J.-W. Jung, "Electric vehicles and smart grid interaction: A review on vehicle to grid and renewable energy sources integration," Renew. Sustain. Energy Rev., vol. 34, pp. 501-516, Jun. 2014.
[217] J. Martinez-Lao, F. Montoya, M. Montoya, and F. Manzano-Agugliaro, "Electric vehicles in Spain: An overview of charging systems," Renew. Sustain. Energy Rev., vol. 77, pp. 970-983, Sep. 2017.

[218] N. Baucells Aleta, C. Moreno Alonso, and R. Arce Ruiza, "Smart mobility and smart environment in the Spanish cities," Sci. Direct. Transp. Res. Procedia, vol. 24, pp. 163-170, Dec. 2017.

[219] S. Carillo-Aparicio, J. R. Heredia-Larrubia, and F. Perez-Hidalgo, "SmartCity Málaga, a real-living lab and its adaptation to electric vehicles in cities," Energy Policy, vol. 62, pp. 774-779, Nov. 2013.

[220] A. Abur and A. Gómez-Expósito, Power System State Estimation: Theory and Implementation. New York, NY, USA Marcel Dekker, 2004.

[221] I. Roytelman and S. M. Shahidehpour, "State estimation for electric power distribution systems in quasi real-time conditions," IEEE Trans. Power Del., vol. 8, no. 4, pp. 2009-2015, Oct. 1993.

[222] A. Gómez-Expósito, C. Gómez-Quiles and I. Dzafic, "State estimation in two time scales for smart distribution systems," IEEE Trans. Smart Grid, vol. 6, no. 1, pp. 421-430, Jan. 2015.

[223] A. Gómez-Expósito, A. de la Villa Jaen, and J. L. R. Izaga, "An alternative state estimation formulation for radial distribution networks," in Proc. IEEE Power Tech, Lausanne, Switzerland, Jul. 2007, pp. 396-400.

[224] A. de la Villa Jaen, J. B. Martinez, A. Gómez-Expósito, and F. G. Váázquez, "Tuning of measurement weights in state estimation: Theoretical analysis and case study," IEEE Trans. Power Syst., to be published, doi: 10.1109/ TPWRS.2017.2786403.

\section{ABOUT THE AUTHORS}

Antonio Gómez-Expósito (Fellow, IEEE) received the Electrical Engineering and Ph.D. degrees (both with honors) from the University of Seville, Sevilla, Spain, in 1982 and 1985, respectively.

Since 2007, he has been the Endesa Red Chair Professor at the University of Seville. In addition to some 300 technical publications, he has coauthored a dozen textbooks and monographs about circuit theory and power systems,

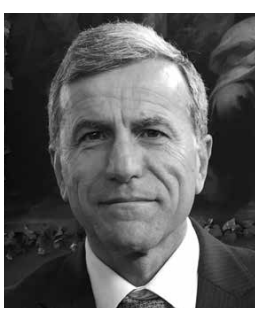
among which Power System State Estimation: Theory and Implementation (New York, NY, USA: Marcel Dekker, 2004) and Electric Energy Systems: Analysis and Operation (Boca Raton, FL, USA: CRC Press, 2008, 2nd ed. 2018), stand out.

Prof. Gómez-Expósito served on the Editorial Board of the IEEE TransaCtions on Power Systems from 2011 to 2016.

Angel Arcos-Vargas received the Industrial Engineering M.Sc. and Ph.D. degrees from the University of Seville, Sevilla, Spain, in 1989 and 2002, respectively.

He has served for over 25 years in Endesa and Enel, achieving EVP positions at the Network Business. He has been founding member of the Board of EDSO 4 Smartgrid. Since 1992, he has been a part-time Professor and member of

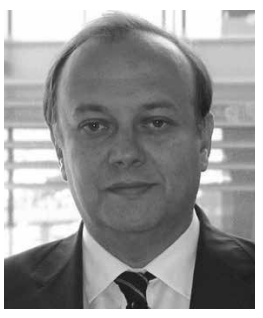

the research group in power systems at the University of Seville. His primary areas of interest are regulation, business models, new technologies, renewables, reliability, and efficient and energy policy.

José M. Maza-Ortega received the Electrical Engineering and Ph.D. degrees from the University of Seville, Sevilla, Spain, in 1996 and 2001, respectively.

Since 1997, he has been with the Department of Electrical Engineering, University of Seville, where he is currently an Associate Professor. His primary areas of interest are power quality, harmonic filters, integration of renewable energies, and power electronics.

José A. Rosendo-Macías (Senior Member, IEEE) received the Electrical Engineering and Ph.D. degrees from the University of Seville, Sevilla, Spain, respectively.

Since 1992, he has been with the Department of Electrical Engineering, University of Seville, where he is currently a Professor. His primary areas of interest are dynamic state estimation, digital signal processing, digital relaying,

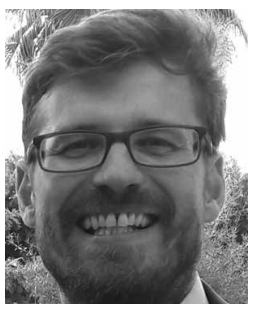
and distribution reliability. 
Gabriel Alvarez-Cordero received the Electrical Engineering degree from the University of Seville, Sevilla, Spain.

Since 2003, he has been with REE (Spanish TSO), where he is currently with the Electrical System Reliability Department. He previously worked at Unión Fenosa group and Isotrol. For three years he lectured at the Department of Electrical Engineering, Pontificia Comillas Uni-

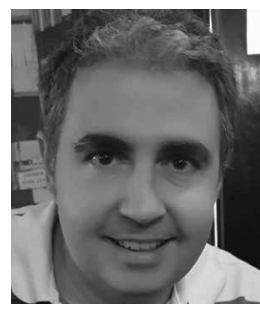
versity (ICAI). His primary areas of interest are the dynamic and static thermal ratings in cables and overhead lines, electromagnetic transient studies, controlled switching of high voltage devices, and transient stability studies.

Susana Carillo-Aparicio received the Industrial Engineering and Ph.D. degrees from the University of Málaga, Málaga, Spain

She began her career as a lecturer and researcher in the Structural Dynamics and Vibration Department, University of Málaga. Since 1998, she has been with Endesa Distribution, where she was the Network Planning Manager at the Andalusia Center working with

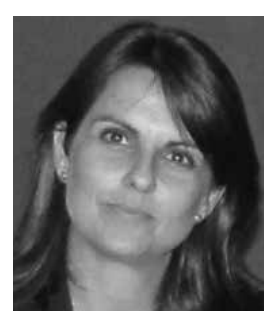
high-, medium-, and low-voltage networks. She was the coordinator of the Smartcity Málaga Project, and is leading its transformation into the Smartcity Málaga Living Lab, where Enel is testing different Smartgrid projects (smart energy management, smart buildings, smart and informed consumer, smart mobility, smart energy generation and storage, advanced distribution automation and information, and communication technology).

Juan González-Lara received the Electrical Engineering degree from the University of Seville, Sevilla, Spain.

Since 1998, he has been with Endesa Distribución Eléctrica, the largest Spanish distribution utility, where he is currently responsible for network components standardization. His primary areas of interest are power system planning, optimal power system operation, and new components development.
Daniel Morales-Wagner received the Electrical Engineering and M.Sc. degrees from the University of Seville, Sevilla, Spain.

Since 2013, he has been with Ingelectus, where he is currently the Chief Technical Officer (СTO). He previously worked at Abengoa. His primary areas of interest are renewable energies, power plant controllers, dynamic and static power system simulations, state estimation, and controlled switching devices.

Tomás González García received the Electrical Engineering degree from the University of Seville, Sevilla, Spain.

In 1989, he joined Sevillana de Electricidad, which later became part of Endesa Distribución Eléctrica, the largest Spanish distribution utility. He has worked in the areas of T\&D network control center, T\&D network planning, and distribution network standardization. His primary areas

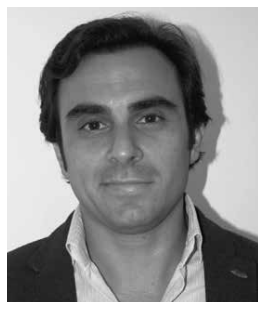
nents development, including power electronics applications. 